\title{
A review of analytical models to describe pull-out behavior- Fiber/matrix adhesion
}

\author{
Fatiha TEKLAL(a)*, Arezki DJEBBAR(a), Samir ALLAOUI(b), Gilles HIVET(b), Yoann Joliff(c)**, \\ Bachir KACIMI(a)
}

(a) Laboratory of Mechanics, Structures and Energetics (L.M.S.E) University of Mouloud MAMMERI, BP 17 RP 15000, Tizi Ouzou, Algeria.

\section{fatihagm07@yahoo.fr \\ Kacimiummto@yahoo.fr \\ Ar.djebbar@yahoo.fr}

(b) Laboratoire Prisme, Université d'Orléans, Polytech Orléans- Site de Vinci, 8, Rue Léonard de Vinci 45072 Orléans Cedex 2, France.

Samir.allaoui@univ-orleans.fr

Gilles.hivet@univ-orleans.fr

(c) Université de Toulon, Laboratoire MAPIEM, EA 4323, 83130 La Garde, France.

Yoann.joliff@univ-tIn.fr

* Corresponding author: fatihagm07@yahoo.fr (F. TEKLAL)

** Corresponding author: yoann.joliff@univ-tIn.fr (Y. JOLIFF).

\begin{abstract}
Micromechanical tests are reliable tools to study the failure mechanisms in composites reinforced with continuous fibers. This paper presents an overview of various analytical models developed to study the pullout (push-back) behavior of a fiber embedded in a matrix block to characterize the fiber/matrix interfacial adhesion. Two approaches can be distinguished: one based on a maximum stress criterion (shear lag) and the other based on fracture mechanics. This article gives an overview of the analytical models reported in the literature to measure the shear strength and critical fracture energy at the interface, the parameters influencing these properties, the geometry of the model, embedded length of the fiber, fiber diameter and loading conditions (opening width between the knife-edges for example), including components (fiber, matrix, interface), manufacturing route and the resulting defects.
\end{abstract}

Key Words: Interface; pull-out; interfacial shear strength; micro-indentation; damage.

\section{Contents}

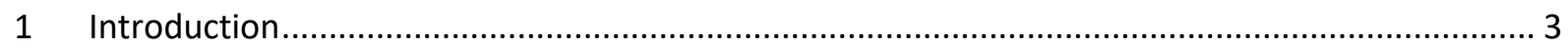

2 Theories of adhesion and types of bonding .......................................................................... 7

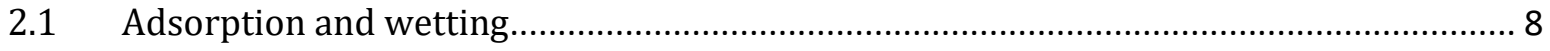

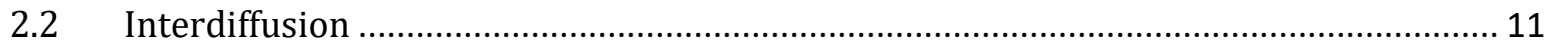




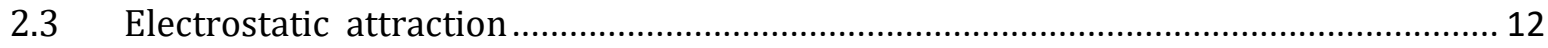

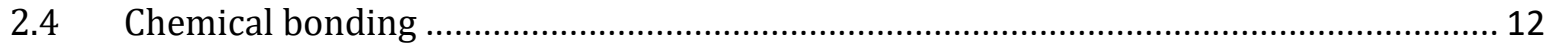

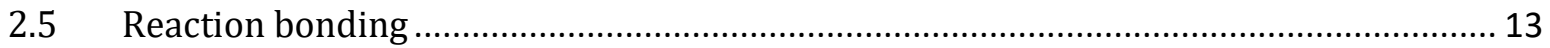

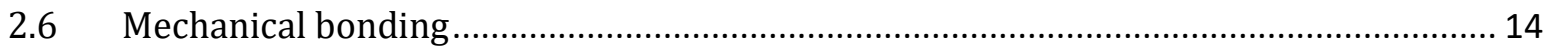

3 The influence of the interface/interphase on the macroscopic behavior of the material ........... 14

4 Rupture process in a composite: role of the interface ............................................................... 16

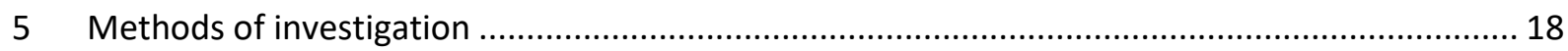

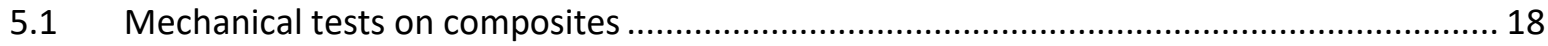

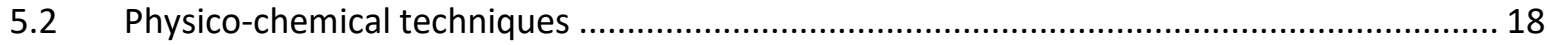

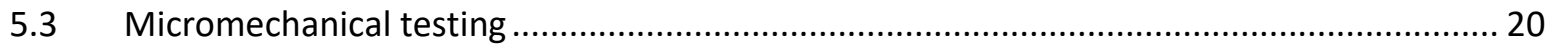

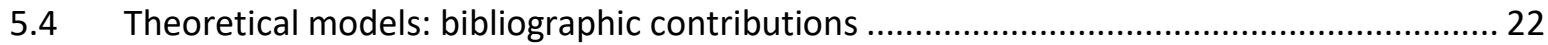

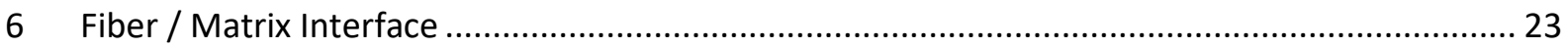

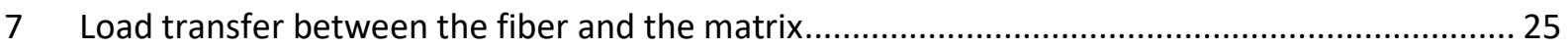

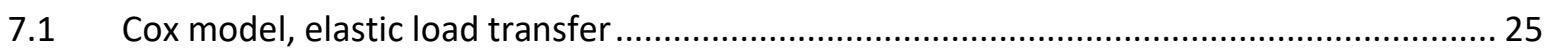

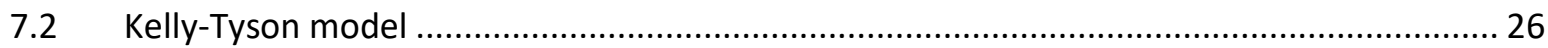

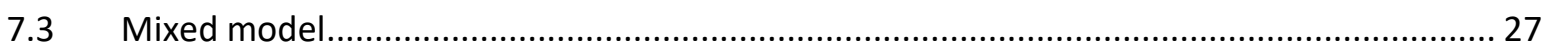

8 Principle and limitations of the debonding test (pull-out) ......................................................... 28

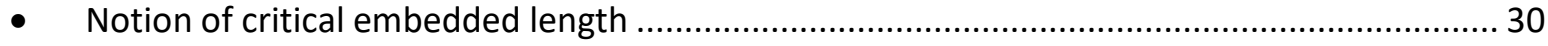

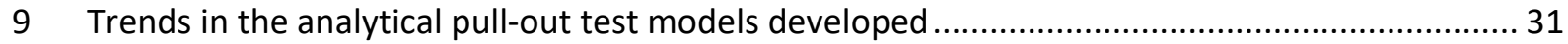

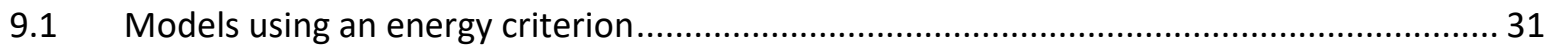

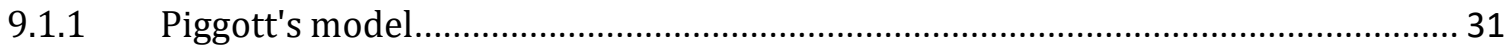

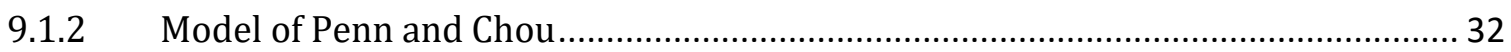

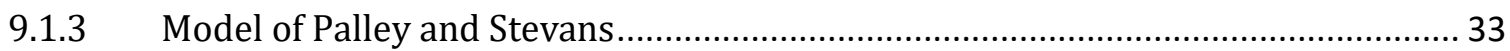

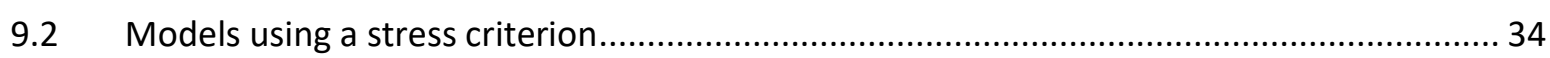

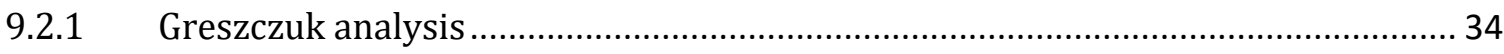

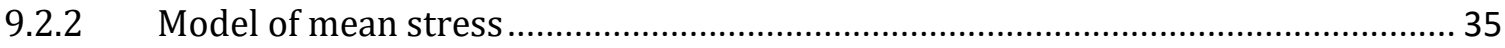

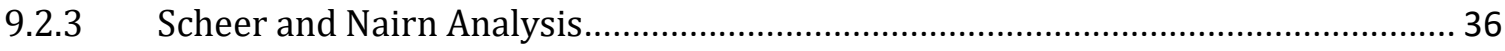

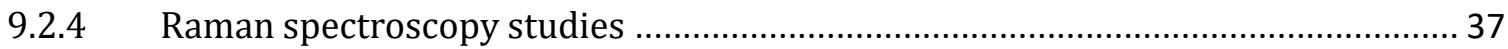

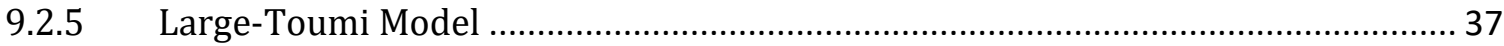

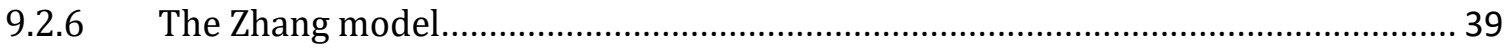

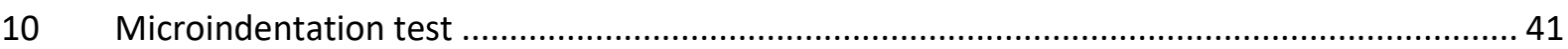

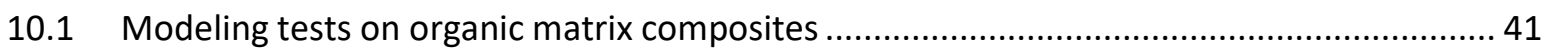

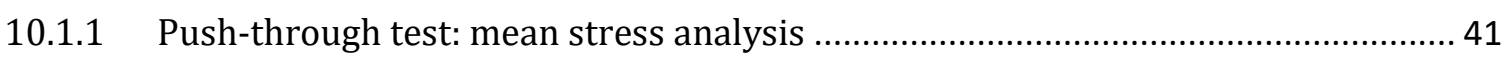

10.1.2 Classic configuration of the test: numerical studies ............................................. 42 
10.1.3 Large-Toumi Model

11 Discussion: validity of different models

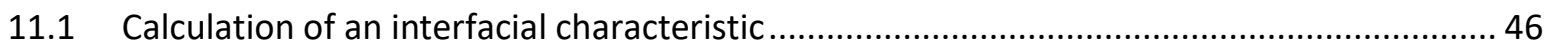

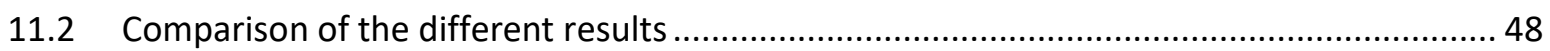

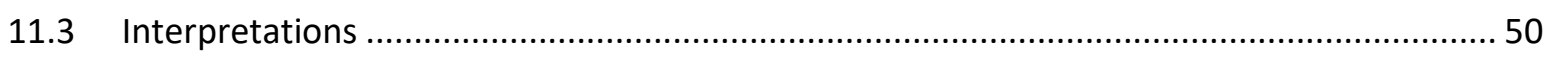

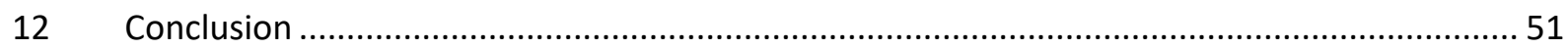

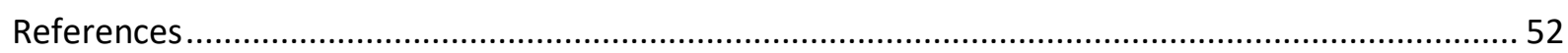

\section{Introduction}

Fiber composite technology is based on taking advantage of the high strength and high stiffness of fibers, which are combined with matrix materials of similar/dissimilar natures in various ways, creating inevitable interfaces. In fiber composites, both the fiber and the matrix retain their original physical and chemical identities, yet together they produce a combination of mechanical properties that cannot be achieved with either of the constituents acting alone, due to the presence of an interface between these two constituents [1]. The study of the mechanical behavior of composite materials often boils down to two basic constituents, the matrix and the reinforcement. While there is an abundant literature on composites, studies on the influence of the interface or the interphase are much sparser. Since the 1970s and in the last few years alone, fewer than $30 \%$ of published articles have dealt with interfaces while only $2 \%$ concern the interphase (Fig.1). The growing number of uses for fiber reinforced composites (FRCs) in many

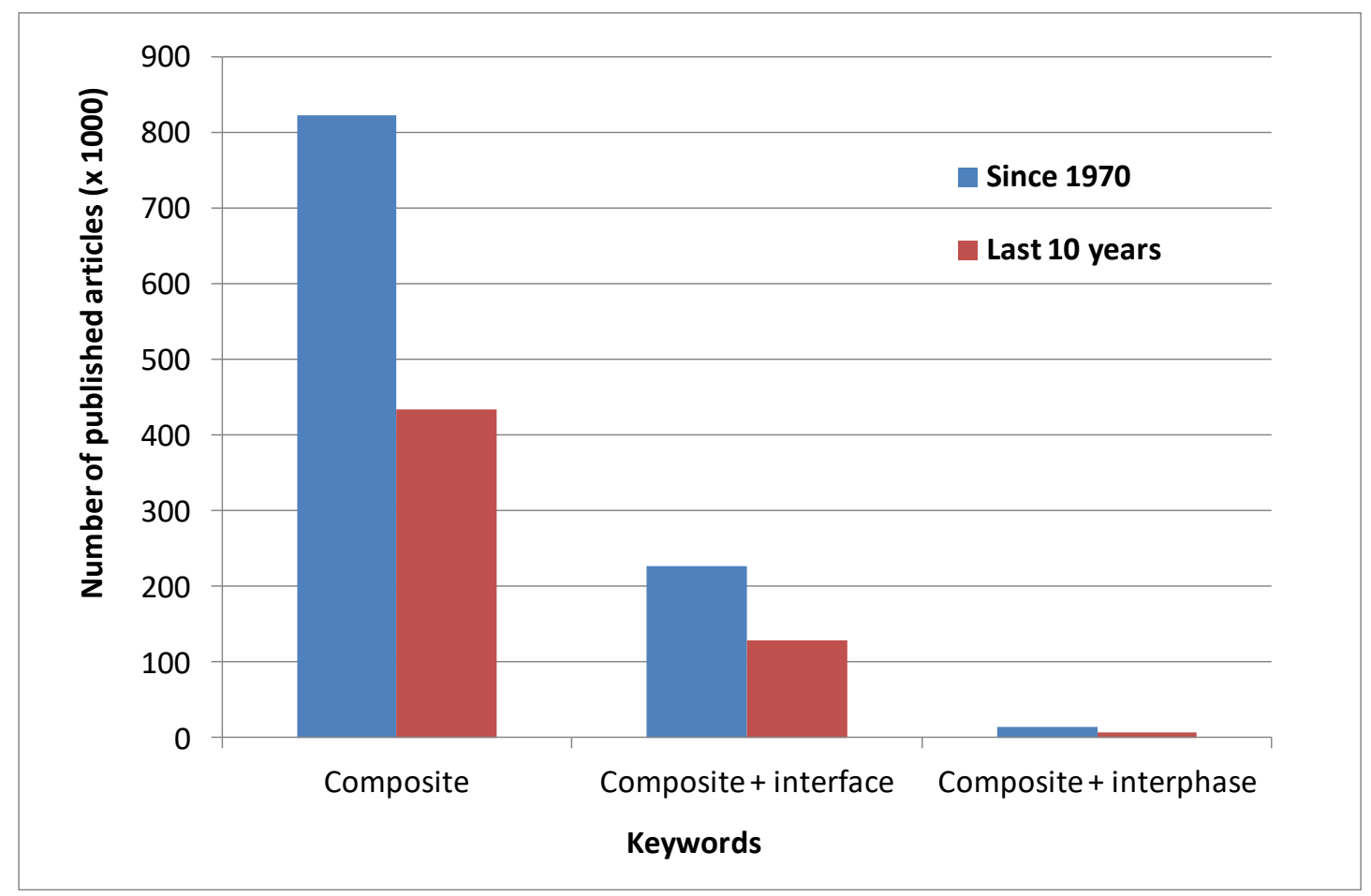

Fig.1. Number of publications on composites and interfaces / interphase since 1970. 
engineering applications has made the issue of interface (or more properly termed, interphase (Drzal et al., 1983) [2]) a major focus of interest in the design and manufacture of composite components. A classic definition of the interface in fiber composites is a surface formed by a common boundary of reinforcing fiber and matrix that is in contact with and maintains the bond in between for the transfer of loads. It has physical and mechanical properties that are unique from those of the fiber or the matrix. The notion of interface or interphase remains relatively vague, as the interfacial zone does not exist in itself but is created during the implementation of the composite. Therefore, it appears very difficult to assign mechanical properties to it.

In contrast, the interphase is the geometrical surface of the classic fiber-matrix contact as well as the region of finite volume extending therefrom, wherein the chemical, physical and mechanical properties vary either continuously or in a stepwise manner between those of the bulk fiber and matrix material [3]. In other words, the interphase exists from some point in the fiber through the actual interface into the matrix, embracing all the volume altered during the consolidation or fabrication process from the original fiber and matrix materials. Therefore, the earlier definition of Metcalfe (1974) [4] for interface can be used for interphase as well: "An interface is the region of significantly changed chemical composition that constitutes the bond between the matrix and reinforcement". Fig.2 schematically illustrates the concept of the interphase according to Drzal et al. (1983) [2]. Also shown in Fig.2 are the various processing conditions that are imposed on the interphase to allow chemical reactions to take place and volumetric changes and residual stresses to be generated. However, for analytical purposes in micromechanics the interface is still conveniently considered to be infinitely thin and the properties of the mating fiber and matrix are isotropic and homogeneous.

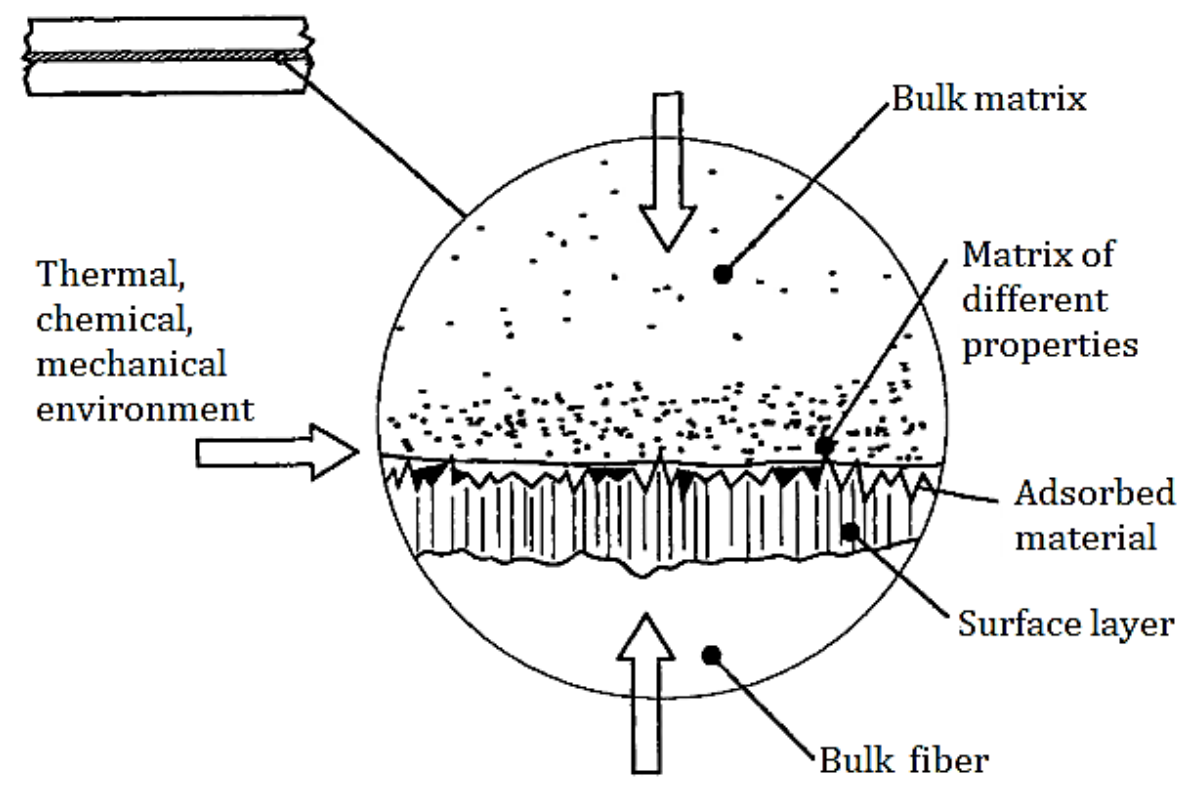

Fig.2. Schematic illustration of the components of the three-dimensional interphase between fiber and matrix [2]. 
The study and application of composite materials are a truly interdisciplinary endeavor that has been enriched by contributions from chemistry, physics, materials science, mechanics and manufacturing engineering. The understanding of the interface (or interphase) in composites is the central point of this interdisciplinary effort, the proof that interfaces are critical to composite properties. From the early development of composite materials of various nature, the optimization of the interface has been of major importance. Even more important, the ideas linking the properties of composites to the interface structure are still emerging. Given a combination of fiber and matrix, it is desirable that the testing method will provide a reproducible and reliable means of not only measuring the interface adhesion but also allowing the failure mode at the interface region to be studied. One important requirement of these tests, whether the microcomposite tests or the bulk composite tests, is that the mechanics model developed for data reduction must be consistent with the actual failure mechanisms. But more often than not, particular failure is assumed to have taken place without confirmation in experiments. This practice not only makes the interface properties obtained doubtful, but it also degrades the whole value of the test method. However, all of these tests can hardly be regarded as providing absolute values for these interface properties even after more than 30 years of development of these testing techniques, this may also explain why there is an extremely large data scatter in the test results for apparently the same materials tested in different laboratories. Efforts are being continued to improve the quality and accuracy of experimental data and to develop better mechanics models underpinning these testing methods. The issue of understanding the composition and properties of interfaces in fiber composite materials is still evolving despite the fact that there have been a great number of works devoted to research in this field. Part of the reason for this evolution is the interdisciplinary nature of the subject. These works have provided a centralized forum not only to discuss and identify the important problems of the subject, but also to disseminate important research results from various sources. They are thus leading the scattered research and development efforts in a sensible direction, as well as helping to make significant contributions toward the improvement of our fundamental understanding of interfaces in polymer, metal and ceramic matrices composites.

It is well known that the properties of an interface are governed largely by the chemical/morphological nature and physical/thermodynamic compatibility between the two constituents and most often limit the overall performance of the bulk composite [5-9]. There is now a considerable amount of evidential data regarding the influences of interfaces on fracture toughness in both transverse and interlaminar fractures, and strength and stiffness of fiber composites in various failure modes and loading configurations [10,11], although the relationship between documented material properties and the actual performances of composites is still in question. It follows therefore that a thorough knowledge of the microstructure-property relationship at the interface region is an essential key to the successful design and proper use of composite materials. Further, the interface properties are becoming gradually accepted as design and process variables to be tailored for particular end applications [12]. Although there is no simple quantitative relation known for interface optimization of a given combination of fiber and matrix, various chemicalphysical and thermodynamic-mechanical principles along with previous experience 
are invaluable sources of information to design the interface qualitatively. A number of potential solutions have been suggested to improve specific properties of the composites, particularly the interface bond quality for efficient stress transfer and the fracture resistance/damage tolerance of inherently brittle composites without sacrificing other important mechanical properties. This paper is concerned mainly with interfaces in advanced composites made from high performance fibers, such as glass, carbon, and matrix materials polymer. To control the interface properly and thereby to provide the composite with improved mechanical performance and structural integrity, it is essential to understand the mechanisms of adhesion which are specific to each fiber/matrix system, and the physico-chemical characterization of the interface with regard to the origin of adhesion.

The characterization of an interface is a challenging problem. To characterize the influence of interface on the load bearing capacity of composites, a number of experimental techniques, such as pull-out/ micro-droplet, compression test (Slice test), push-out (or indentation), microbond or fragmentation tests are commonly performed [13-22]. These tests have a variety of specimen geometries and scales involved. In these tests, the bond quality at the fiber-matrix interface is measured in terms of the interface fracture toughness, Gic, or the interface shear (bond) strength (IFSS), $\tau_{i}$, for the bonded interface; and the interface frictional strength (IFS), $\tau_{f r}$, which is a function of the coefficient of friction, $\mu$, and residual fiber clamping stress, $\mathrm{q}_{0}$, for the debonded interface. Therefore, these tests are considered to provide direct measurements of interface properties relative to the test methods based on bulk composite specimens. Microcomposite tests have been used successfully to compare composites containing fibers with different prior surface treatment and to distinguish the interface-related failure mechanisms. Theoretical analysis of interfacial debonding has received significant attention especially for the fiber pull-out test. The condition of interface debonding has been defined by two distinct approaches: the shear strength criterion and the fracture mechanics approach. In the shear strength criterion, when the interface shear stress (IFSS) reaches the interface shear bond strength, $\tau_{i}$, debonding occurs. In the fracture mechanics approach, extension of a debond crack requires the potential energy release rate of the composite constituents to reach a critical value, the interface fracture toughness, Gic. In these two debond criteria, both $\tau_{i}$ and Gic are assumed to be material constants, the characteristic interface properties to be determined in experiments.

One of the most important phenomena in FRCs for applications to load bearing primary structures is the stress transfer between the fiber and the matrix across the interphase/interface. When composites are subjected to various loading conditions, the efficiency of load transfer across the interface plays an important role in overall performance of the composites $[\mathbf{2 3}, \mathbf{2 4}]$. However, these zones (interface / interphase) play a leading role, as shown by Drzal 1986 [25] and Piggott 2004 [26], since the interface and / or interphase ensure the transmission of the forces between the relatively soft matrix and the stiffer reinforcement. Consequently, the contribution of the reinforcement on the mechanical properties of the composite is directly related to the quality of the interfacial zone [10]. Kim et al. $[\mathbf{2 7}, \mathbf{2 8}$ ] showed that a thorough understanding of the interfacial zone is considered as one of the criteria for composite design. From the stresstransfer mechanics viewpoint, theoretical analyses dealing with the stress state at the interface region are vital to understanding how and to what extent the interface 
properties influence the mechanical performance and fracture behavior of the composites. Since the early pioneering work by Cox (1952) and Rosen (1964) [29,30], a number of models have been developed to predict the response of composite materials in terms of thermo-mechanical properties and microfailure mechanisms under various loading conditions and different environmental situations. These range from simplified physical models such as the Kelly-Tyson model (1965) [31] to numerical solutions of stress and strain fields in the composite constituents based on rigorous finite element (FE) analyses. The fiber fragmentation test has a significant analogy with practical composites containing aligned short fibers when subjected to uniaxial tension along the fiber direction as it exhibits the fundamental damage modes that are present in the multiple fiber composites in service.

The central theme of this work is to propose a review of the different analytical models developed to study the pull-out (push back) behavior of a fiber embedded in a matrix block to characterize fiber / matrix interfacial adhesion. The available analytical models used to measure the shear strength and the critical fracture energy at the interface is described. The parameters influencing these properties, the geometry of the models, the embedding length of the fiber, the fiber diameter and the loading conditions (opening width between the knife-edges for example), including components (fiber, matrix, and interface), manufacturing route and the resulting defects are discussed in detail, all the models that are presented in this paper consider the material as a homogeneous structure, elastic, linear, that the radial effects are negligible (no radial dependence), that the strains and stresses imposed by the fiber under the application of the load F are fully accommodated within the interphase, of low thickness, the surrounding matrix is not disturbed.

\section{Theories of adhesion and types of bonding}

The physico-chemical aspect of composite interfaces is a difficult subject and our understanding of this feature is still far from complete. The nature or origin of the bonding between the fiber and matrix is discussed in terms of the theories of adhesion with associated mechanisms of bonding. The nature of bonding is not only dependent on the atomic arrangement, molecular conformation and chemical constitution of the fiber and matrix, but also on the morphological properties of the fiber and the diffusivity of elements in each constituent. It follows therefore that the interface is specific to each fiber-matrix system [10]. Proper characterization of composite interfaces, whether it is for chemical, physical or mechanical properties, is extremely difficult because most interfaces with which we are concerned are buried inside the material. Furthermore, the microscopic and often nanoscopic nature of interfaces in most useful advanced fiber composites requires the characterization and measurement techniques to be of ultrahigh magnification and resolution for sensible and accurate solutions. In addition, experiments have to be carried out in a well-controlled environment using sophisticated testing conditions (e.g. in a high vacuum chamber). There are many difficulties often encountered in the physico-chemical analyses of surfaces.

Adhesion in general can be attributed to mechanisms including, but not restricted to, adsorption and wetting, electrostatic attraction, chemical bonding, reaction bonding, and exchange reaction bonding [12], which are schematically shown in Fig. 3 and discussed in the following sections. In addition to the major mechanisms, hydrogen bonding, van der Waals forces and other low energy forces may also be involved. All these 
mechanisms take place at the interface region either in isolation, or, most likely, in combination to produce the final bond. Reviews on these major mechanisms can be found in many references including [23, 32-37] for polymer matrix composites; Metcalfe (1974) [4] for metal matrix composites (MMCs); and Naslain (1993) [38] for ceramic matrix composites (CMCs). More, mechanisms and mechanics modeling of interfaces in cementitious composites have received a lot of attention $[39,40]$.
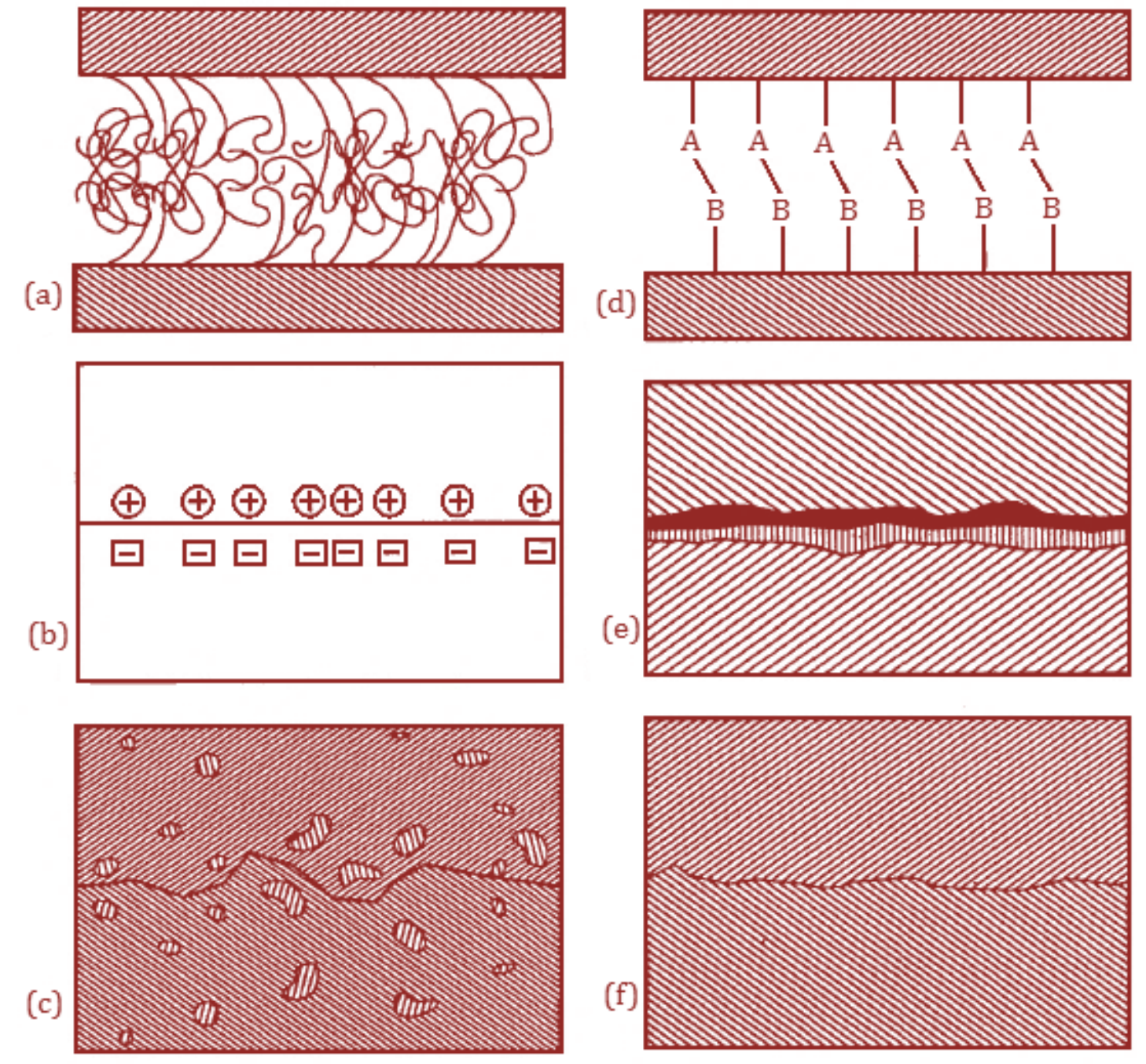

Fig. 3. Interface bonds formed (a) by molecular entanglement; (b) by electrostatic attraction; (c) by interdiffusion of elements; (d) by chemical reaction between groups A on one surface and groups B on the other surface; (e) by chemical reaction following forming of a new compound(s), particularly in MMCs; (f) by mechanical interlocking [23].

\subsection{Adsorption and wetting}

Good wetting of fibers by matrix material during the impregnation stages of fabrication is a prerequisite to proper consolidation of composites, particularly for composites based on polymer resins and molten metals. It is well understood that physical adsorption of gas molecules to solid surfaces is ascribed to the attraction arising from the quantum mechanical effect due to the valence electrons present in the constituents as a free gas. The physical attraction between electrically neutral bodies is best described by the 
wetting of solid surfaces by liquids. Bonding due to wetting involves very short-range interactions of electrons on an atomic scale which develop only when the atoms of the constituents approach within a few atomic diameters or are in contact with each other.

The determination of the thermodynamic characteristics of fiber surfaces is important as they play an important role in the adhesion process. Correct wetting of fibers by matrix resins is a necessary but not sufficient condition for good interface quality [41]. Improving wetting increases the reversible adhesion energy and reduces the number of defects in the interface region.

Many studies have examined the relationship between fiber/matrix interface strength, measured using micro-mechanics tests, and the reversible adhesion energy. This energy is measured by wetting studies $[\mathbf{2 1}, \mathbf{4 2 - 4 4 ]}$, or by inverse gas chromatography [45-50].

The work of adhesion WA, is a concept first introduced by Harkins [51]. In a simple system in which a liquid (L) adheres to a solid (S), the reversible work of adhesion is defined by (Eq.1):

$W_{A}=\gamma_{1}+\gamma_{2}-\gamma_{12}$

$\mathrm{W}_{\mathrm{A}}$ represents a physical bond resulting from highly localized intermolecular dispersion forces. It is equal to the sum of the surface free energies of the liquid, $\gamma_{1}$, and the solid, $\gamma_{2}$, less the interfacial free energy, $\gamma_{12}$. It follows that Eq.1 can be related to a model of a liquid drop on a solid shown in Fig.4. Resolution of forces in the horizontal direction at the point A where the three phases are in contact yields Young's equation.

$\gamma_{S V}=\gamma_{S L}+\gamma_{L V} \cos \theta$

Where $\gamma_{S V}, \gamma_{S L}$ and $\gamma_{L V}$ are the surface free energies of the solid-vapor, solid-liquid and liquid-vapor interfaces, respectively, and $\theta$ is the contact angle. Liquids that form contact angles greater and less than $90^{\circ}$ are respectively called 'non-wetting' and 'wetting'. If the liquid does not form a droplet, i.e. $\theta=0^{\circ}$ it is termed 'spreading' and the relationship given by Eq.2 becomes invalid. In this case, the equilibrium is expressed by an inequality

$\gamma_{S V}-\gamma_{S L}>\gamma_{L V}$

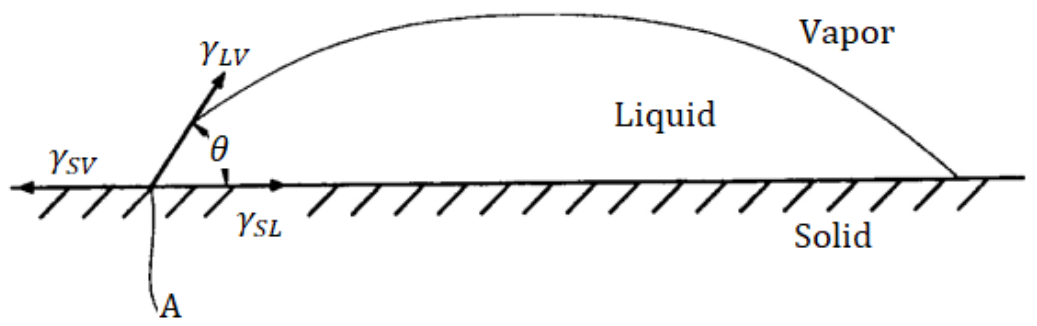

Fig.4. Contact angle, $\theta$, and surface energies, $\gamma_{L V}, \gamma_{S L}$ and $\gamma_{S V}$, for a liquid drop on a solid surface. 
The surface energy of a solid (i.e. reinforcement in composites), $\gamma_{S V}$, must be greater than that of a liquid (i.e. matrix resin), $\gamma_{L V}$, for proper wetting to take place. Thus, glass and carbon fibers can be readily wetted by thermoset resins like epoxy and polyester resins at room temperature unless the viscosity of the resin is too high [36], and by some thermoplastic resins (e.g. Nylon 6.6, PET, PMMA and PS). In contrast, it is difficult to wet polyethylene fibers (of surface energy approximately $31 \mathrm{~mJ} / \mathrm{m}^{2}$ ) with any of these resins unless the fibers are surface treated. For the same reason, carbon fibers are often coated with Ti-B [52] using a chemical vapor deposition process to allow wetting by an aluminum matrix. Combining Eqs. 1 and 2 yields the familiar Young-Dupre equation (Eq.4) :

$W_{A}=\gamma_{L V}(1+\cos \theta)$

The values of WA reflect directly the significance of energetics between the liquid and solid phases, i.e. the higher the work of adhesion the stronger the interactions. WA can be determined in experiments by measuring the surface energy of the liquid, $\gamma_{L V}$, and the contact angle, $\theta$.

Although the discussion of wettability presented above has focused on the thermodynamics between the fiber surface and the liquid resin, real composite systems consist of an extremely large number of small diameter fibers embedded in a matrix. Adding to the issue of proper wetting of fiber surfaces by the resin, a key to creating good adhesion at the fiber-matrix interface is infiltration of the resin into the fiber tow during the fabrication process.

The relationship between the reversible energy of adhesion and the shear strength of the fibre/matrix interface has been studied by several authors $[47,48,53,54]$ who show that an increase in the work of adhesion is observed to result in an increase in shear strength.

Nardin and Schultz [47] proposed a pressure of adhesion concept for composite materials. After examination of a large number of polymer/fibre combinations they suggested that the reversible energy of adhesion, measured by inverse gas chromatography, could be related to the interfacial shear stress measured by fragmentation tests, by the linear expression (Eq.5):

$\tau=\left(\frac{E_{m}}{E_{f}}\right)^{1 / 2} \frac{W_{A}}{\delta}$

with $E_{m}$ Young's modulus of the matrix, $E_{f}$ Young's modulus of the fibres, $W_{A}$ reversible adhesion energy, $\delta$ is a distance independent of the system studied and equal to about 0.5 $\mathrm{nm}$. It corresponds to the intermolecular distance, at equilibrium, between the centres of the molecules involved in interactions such as Van der Waals bonds.

In this approach the load transfer between fibre and matrix is considered to be perfectly linear elastic. 
Pisanova and Mäder [48] studied the liaisons between different matrix resins and glass fibres, treated and untreated. The fibre treatment with coupling agents resulted in an improvement of the fibre/matrix adhesion which correlated well with the reversible adhesion energy.

\subsection{Interdiffusion}

A bond between two surfaces may be formed by the interdiffusion of atoms or molecules across the interface. A fundamental feature of the interdiffusion mechanism is that there must exist a thermodynamic equilibrium between the two constituents. The bond strength in polymer matrix composites will depend on the amount of molecular entanglement, the number of molecules involved and the strength of the bonding between the molecules. Interdiffusion may be promoted by the presence of solvents and the amount of diffusion will depend on the molecular conformation, the constituents involved, and the ease of molecular motion. For example, bonding between glass fibers and polymer resins through silane coupling agents by a process other than chemical bonding can be explained by interdiffusion and the interpenetrating network (IPN) formation in the interface region [55-57], as illustrated in Fig. 5. A thin layer of epoxy matrix revealed on the fracture surface of the carbon fiber by using a scanning Auger microscope [58] is concrete evidence of interdiffusion.

The interface region thus formed has a substantial thickness, and its chemical, physical and mechanical properties are different from those of either the bulk fiber and the matrix (i.e., the interphase as opposed to the interface of zero thickness). The interphase is found to be significantly softer than the bulk matrix material in polymer matrix composites [59, 60]. For example, the average modulus of the interphase of a thickness of approximately $500 \mathrm{~nm}$ formed between a single carbon fiber and epoxy matrix is about one-quarter of that in the bulk matrix. However, the presence of a stiff fiber mitigates the effect of a soft interphase, increasing the effective modulus of the interphase beyond that of the bulk matrix in close vicinity of the fiber [59-62]. 


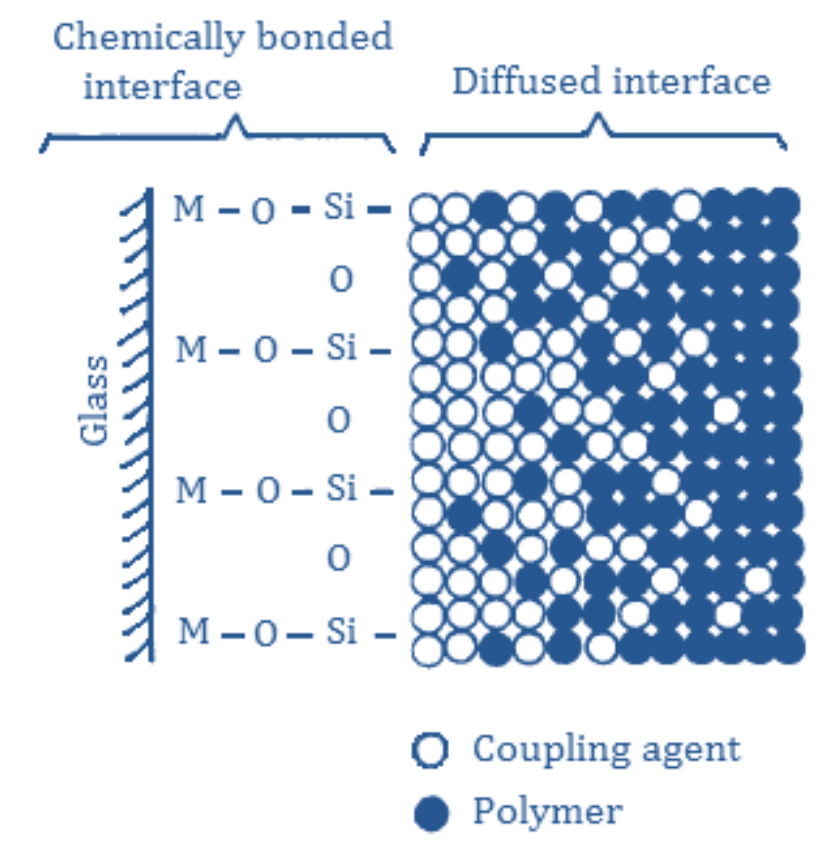

Fig. 5. A schematic model for interdiffusion and IPN in a silane-treated glass fiber-polymer matrix composite [23].

In MMCs (Metal Matrix Composites), interdiffusion also plays an important role in promoting reaction between elements of each constituent at the interface region. The special type of interdiffusion that takes place in conjunction with chemical reaction in MMCs is called an exchange reaction. However, interdif- fusion in MMCs may not be always beneficial because undesirable compounds are often formed, particularly when the oxide films present on the fibers are completely disrupted under extremely high temperature and pressure in a solid state process [4]. To prevent or at least reduce the interaction, it is necessary to apply an effective diffusion barrier in the form of a coating on the fiber, or alloying elements in the matrix. The selection of an appropriate diffusion barrier relies on a detailed knowledge of the nature of the interaction taking place at the interface region, which is specific to each fiber-matrix system.

\subsection{Electrostatic attraction}

A difference in electrostatic charge between constituents at the interface may contribute to the force of attraction bonding. The strength of the interface will depend on the charge density. Although this attraction is unlikely to make a major contribution to the final bond strength of the interface, it could be important when the fiber surface is treated with some coupling agent. This type of bonding will explain why silane finishes are especially effective for certain acidic or neutral reinforcements like glass, silica, and alumina, but are less effective with alkaline surfaces like magnesium, asbestos, and calcium carbonate [55].

\subsection{Chemical bonding}

Chemical bonding is the oldest and best known of all bonding theories. Physical adsorption mechanisms depend on van der Waal forces or the acid-based interaction, while chemical bonding mechanism is based on the primary bond at the interface. A chemical reaction at the interface is of particular interest in the study of polymer matrix 
composites because it offers a major explanation for the use of silane coupling agents on glass fibers embedded in thermoset and amorphous thermoplastic matrices. Surface oxidative treatments of carbon fibers have been known for many years to promote chemical bonding with many different polymer resins. Buxton and Baillie, 1995 [63] has shown that the adhesion is a two-part process: the first part is the removal of a weak layer of a graphitic-like structure from the fiber surface particularly at low levels of treatment; and the second part is chemical bonding at the acidic sites. However, much further work is still needed to verify this hypothesis.

In this mechanism of adhesion, a bond is formed between a chemical group on the fiber surface and another compatible chemical group in the matrix, the formation of which results from usual thermally activated chemical reactions. For example, a silane group in an aqueous solution of a silane coupling agent reacts with a hydroxyl group of the glass fiber surface, while a group like vinyl on the other end will react with the epoxide group in the matrix. The chemical compositions of the bulk fiber and of the surface for several widely used fiber systems. It is interesting to note that except for glass fibers, the chemical composition of the surface does not resemble that of the bulk fiber, and oxygen is common to all fiber surfaces.

\subsection{Reaction bonding}

Other than in polymer matrix composites, the chemical reaction between elements of constituents takes place in different ways. Reaction occurs to form a new compound(s) at the interface region in MMCs (metal matrix composites), particularly those manufactured by a molten metal infiltration process. Reaction involves transfer of atoms from one or both of the constituents to the reaction site near the interface and these transfer processes are diffusion controlled. Depending on the composite constituents, the atoms of the fiber surface diffuse through the reaction site, (for example, in the boron fiber-titanium matrix system, this causes a significant volume contraction due to void formation in the center of the fiber or at the fiber-compound interface [64], or the matrix atoms diffuse through the reaction product. Continued reaction to form a new compound at the interface region is generally harmful to the mechanical properties of composites.

Special cases of reaction bonding include the exchange reaction bond and the oxide bond. The exchange reaction bond occurs when a second element in the constituents begins to exchange lattice sites with the elements in the reaction product in thermodynamic equilibrium [65]. A good example of an exchange reaction is one that takes place between a titanium-aluminum alloy with boron fibers. The boride compound is initially formed at the interface region in an early stage of the process composed ofiboth elements. This is followed by an exchange reaction between the titanium in the matrix and the aluminum in the boride. The exchange reaction causes the composition of the matrix adjacent to the compound to suffer a loss of titanium, which is now embedded in the compound. This eventually slows down the overall reaction rate. 
The oxide bond occurs between the oxide films present in the matching surfaces of fiber and matrix. The reaction bond makes a major contribution to the final bond strength of the interface for some MMCs, depending on the fiber-matrix combination (which determines the diffusivity of elements from one constituent to another) and the processing conditions (particularly temperature and exposure time).

In general, in most CMCs (ceramic matrix composites), chemical reaction hardly occurs between fiber (or whisker) and matrix. However, an extremely thin amorphous film can be formed, originating from the oxide present on the fiber surface, due to the limited fiber/matrix reaction, e.g., between alumina whisker and zirconia matrix [66], or resulting from the decomposition of the metastable $\mathrm{SiC}$ fibers in $\mathrm{SiC}$ matrix [38]. The reaction compound thereby formed normally has a low fracture energy and is soft compared to the fiber or matrix. It acts as a compliant layer for the relaxation of residual thermal stresses and promotes longitudinal splitting along the fiber length.

\subsection{Mechanical bonding}

Mechanical bonds involve solely mechanical interlocking at the fiber surface. Mechanical anchoring promoted by surface oxidation treatments, which produce a large number of pits, corrugations and large surface area of the carbon fiber, is known to be a significant mechanism of bonding in carbon fiber-polymer matrix composites. The strength of this type of interface is unlikely to be very high in transverse tension unless there are a large number of re-entrant angles on the fiber surface, but the strength in longitudinal shear may be significant depending on the degree of roughness.

In addition to the simple geometrical aspects of mechanical bonding, there are many different types of internal stresses present in composite materials that arise from shrinkage of the matrix material and the differential thermal expansion between fiber and matrix upon cooling from the processing temperature. Among these stresses, the residual clamping stress acting normal to the fiber direction renders a synergistic benefit on top of the mechanical anchoring. These mechanisms provide major bonding at the interface of many CMCs (ceramic matrix composites) and play a decisive role in controlling their fracture resistance and R-curve behavior.

The next part of the review is dedicated to composites based on organic matrix reinforced by fibers. So, all the models presented thereafter refer to fiber and thermosetting resin.

\section{The influence of the interface/interphase on the macroscopic behavior of the material}

The results concerning the influence of the interface on the mechanical properties of a composite come either from mathematical studies (numerical or analytical) or experimental data. Mathematical models take into account the interface properties 
(modulus, thickness) and analyze the effects of their variation on macroscopical properties of the composite. Experimental works consist in testing composites with interfaces that are variable in nature and/or thickness. In both cases, this influence is strongly conditioned by the direction of the load compared to the reinforcement. A simple way to highlight this is to apply the law of mixtures for the two analytical models of Reuss and Voigt $[\mathbf{6 7}, \mathbf{6 8}]$ which correspond to morphology patterns of multiphase material in series and in parallel respectively. Fig.6 (a) shows an association in series (example: transverse tension) expressed by Eq.6, and Fig.6 (b) an association in parallel (example: longitudinal tension), Eq.7.

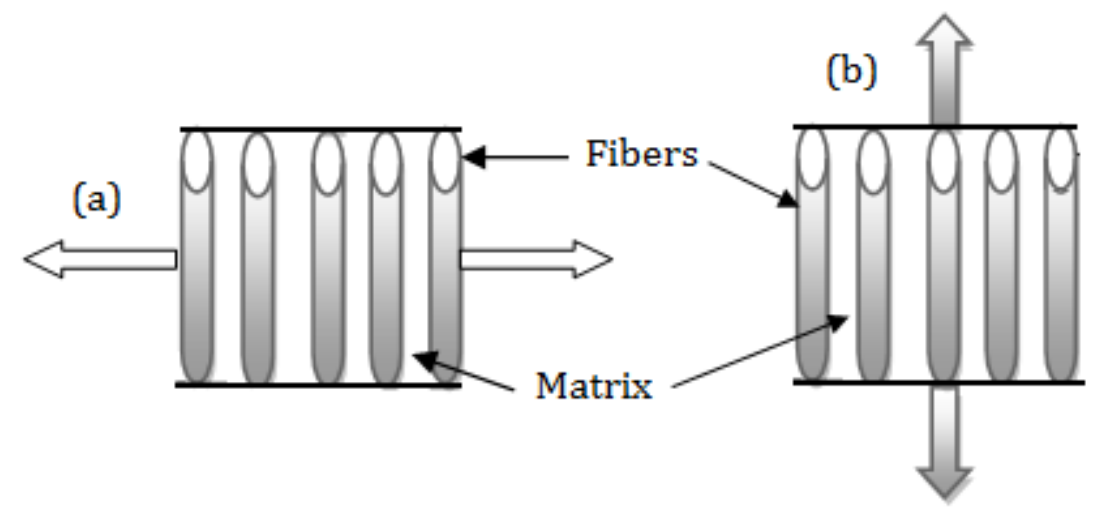

Fig.6. Models of association

$$
\begin{aligned}
& \frac{1}{E_{c}}=\frac{V_{f}}{E_{f}}+\frac{V_{m}}{E_{m}}+\frac{V_{i}}{E_{i}} \\
& E_{c}=E_{f} V_{f}+E_{m} V_{m}+E_{i} V_{i}
\end{aligned}
$$

Where $V_{f}, E_{f}, V_{m}, E_{m}$ and $E_{i}, V_{i}$, are respectively the volume fractions and moduli of the reinforcement, the matrix, and the interphase.

Association (a) can be regarded as the case of a transverse load of a UD composite material. The effective modulus of the composite, $E_{c}$, can be calculated by the Eq.6. In case (b), the load is applied in the direction of fibers and effective modulus $E_{c}$ is given by the Eq.7. In case (a), if the term $\mathrm{V}_{f} / E_{f}$ is negligible compared to $V_{m} / E_{m}$ (high reinforcement fiber modulus compared to that of the matrix), term $V_{i} / E_{i}$ in this case must be taken into account. It can become important in the case; for example, of an elastomer interphase whose modulus can be 100 times lower than that of the matrix (the volume fraction of the interphase $V_{i}$ may approach $10 \%$ of that of the matrix). In this case the interphase has a marked effect on the behavior of the composite. In general, this effect is pronounced for all loads that involve the matrix, such as transverse tension in which the fibers are not loaded [69, 70], shear tests [71], toughness tests [72, 73], or tensile tests on loaded polymers. Many studies emphasize the specific effect of the size of the interphase [74-77], which presents an optimum with respect to the properties of the composite. It has also been found experimentally that an interfacial module that is too weak directly affects the module of the composite [74]. As shown Wu et al. (2000) [78], the thickness of the interphase region ranges from 100 to $200 \mathrm{~nm}$ for carbon fiber-epoxy composites. However, the interphase thickness and properties depend on local changes in chemical and physical processes such as crystallization and crosslinking in the vicinity of the fiber. 
For instance, for S-glass epoxy composites, interphase thickness varies from 10 to 1000 $\mathrm{nm}$ [60]. The interphase is either compliant or brittle depending upon the composite system. For S-glass epoxy and graphite-epoxy composites, the interphase is much more compliant than the matrix [60]. On the other hand, the interphase is stiffer than the matrix material for some uncoated carbon-epoxy composites or for glass fiber/polyester composites [79]. Micrographic image analysis of the interphase region suggests that the interphase has a gradient in material properties such that it matches the properties of the fiber and the matrix at the boundaries [60]. The relative stiffness of the interphase region also depends on the thickness of the interphase layer. A thicker interlayer means a stiffer interphase whereas a thin interlayer exhibits a softer behavior [79].

Case (a), association in series, shows the impact of the interface on the fracture properties. Among the three elements (fiber, matrix, and interface), it is the weakest link (the one with the lowest strength) which will initiate the fracture. As Ivens et al. (1993) pointed out [80], below a certain threshold (related to the fracture strength of the matrix), the interface is the limiting parameter (the weak point) which controls the fracture behavior of the composite. In case (b), an association in parallel, the effect of the interface is less obvious: in equation (7), the $E_{f} V_{f}$ term dominates and the contribution of the interface is negligible, even compared to that of the matrix. Its effect on the modulus of the composite is then quasi-non-existent, as shown by experimental work [81, 82]. In order to understand this influence, it is necessary to analyze the fracture processes occurring in composites before the final failure and the role played by the interface in this process.

\section{Rupture process in a composite: role of the interface}

The interface is the element which conditions the degree of synergy of the fiber/matrix bonding [83], and which ensures the load transfer. Its role is crucial during the propagation of cracks in composites because in this case one of the components no longer bears its share of the applied load, which is transmitted to the rest of the material through the interface [84-86]. If we first consider the effect of fiber rupture, shown in Fig.7, the local normal constraint at the point of rupture is null, the shear stress at the fiber/matrix interface is maximum, and at a distance $\mathrm{x}=\delta_{\mathrm{f}}$ the fiber is fully reloaded whereas the shear stress $r$ falls to zero. 


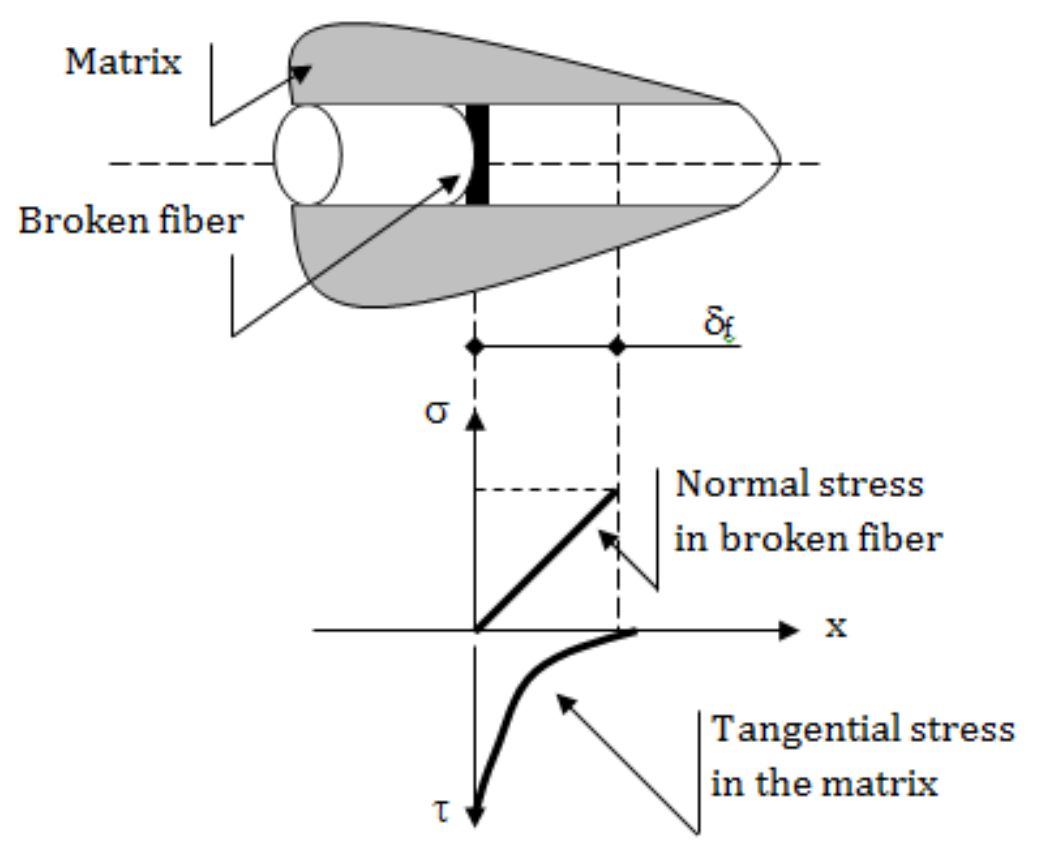

Fig.7. Mechanisms of load transfer by shearing of the matrix [87].

Let us now consider the rupture process following a crack initiated by a fiber break in a UD composite. In the case of a strong interface, a fiber break can induce the creation of a brittle rupture facies, and the break will in all likelihood be sudden. In the case of a weak interface, in contrast, a fiber break causes interfacial cracking (more or less extensive depending on the quality of the interface). If the interface is sufficiently resistant, this phenomenon can be enough to dissipate the elastic energy released by the breaking of the fiber and to distribute the constraints over a sufficiently large zone for the cracking to be locally stopped. If the interface is too weak, interfacial separation is so extensive that the broken fiber no longer contributes to the strength of the composite. This case is less favorable than the previous one because the overload experienced by the remainder of the composite is higher (but less localized) [7, 23, 77, 88-90]. Fig. 8 is a representation of the probable rupture processes following a fiber break in a UD composite according to the quality of the fiber /matrix interface. Case (a) presents a weak interface: interfacial debonding can occur. This failure mode is sought after in structures in service. Case (b) presents a material with a strong interface: as the crack cannot be projected at the level of the interface, the kinetics of the breakdown will spread to all the fibers, giving a brittle break [91].

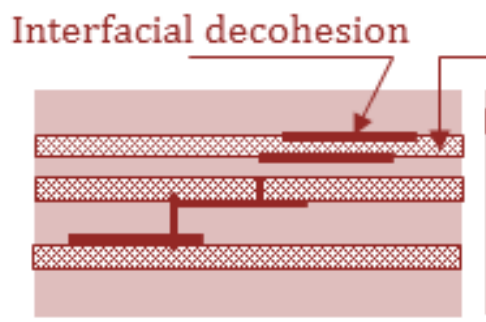

(a)

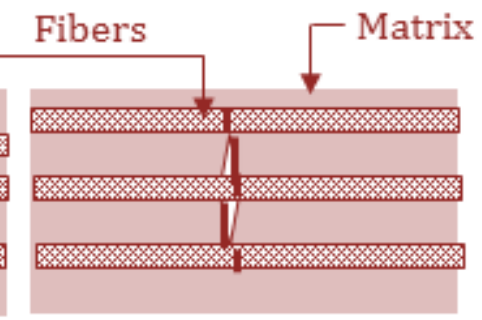

(b)

Fig.8. Damage in a UD composite [91]. 


\section{Methods of investigation}

A number of experimental and theoretical methods developed to assess the quality of the interface bond are summarized. The study of the interface / interphase involves the use of methods capable of delivering information on the links that connect it in the composite to the fiber and the matrix. This can be studied on several levels: either by approaches that can be described as indirect, consisting of macroscopic mechanical tests $[7,77,92-101]$ on industrial composites, or by more direct approaches, among which physicochemical tests [102-107] as well as "ad hoc" micromechanical tests [21, 41,7577, 92, 108-116]. As there can be no question of giving an exhaustive list of all the methods of analysis, this paper will just mention those that seem the most significant.

\subsection{Mechanical tests on composites}

Mechanical tests are often used as indicators of the quality of the interfaces in composites. They nevertheless constitute indirect methods because they take several parameters into account, among which the one related to the interface is not necessarily the most important. They can only lead to a qualitative assessment of materials of the same kind, in which the rupture process involves the interface in the same way [98-100]. Defining a parameter that is intrinsic to the interface requires very precise knowledge of the respective contributions of the fiber and the matrix (the effects of which generally dominate), but also of the effects of defects in the material. Take the case of shear tests, which give access to the interlaminar shear strength (ILSS) of the composite. Several authors have shown that this value is often considered representative and highly sensitive to the quality of the interfacial zone $[\mathbf{9 2 , 1 0 8 , 1 1 7 - 1 1 9 ] , ~ a n d ~ t h e ~ f i b e r ~ / ~ m a t r i x ~ i n t e r f a c e ~}$ plays a role in controlling the toughness to interlaminar fracture. This is true, but shear tests also characterize interfaces generated by the implementation of the material, particularly interply interfaces. A comparison of diverse materials in terms of their fiber / matrix interface is possible only for composites with defects that are equivalent and do not mask the influence of this type of interface: in this type of test, rupture is highly dependent on how crucial the defects are (as example: porosity, misalignment of fibers): if there is a critical defect of implementation in the material, its ILSS will be limited, even if it has a very good interfacial strength. The ILSS is mainly conditioned by the weak point of the material.

The mechanical tests that seem most suited to highlighting the interface effect are matrix tests, transverse tests, off-axis tensile tests, bending fatigue tests to characterize the fiber / matrix interface, the off-axis bending test to study intra-plies or inter-wicks, toughness tests and above all shear tests (Iosipescu, short beam shear test, cube test, interlaminar (ISD),...).

Bending tests along the fiber axis, due to the curvature and the stress state imposed on the sample, can also be used to apply greater force to the matrix and interfaces than for example longitudinal tensile tests. The case of compression tests is different because although they are sensitive to the influence of the interface $[\mathbf{1 1}, \mathbf{8 1}]$, the complexity of the phenomena involved makes them particularly difficult to interpret.

\subsection{Physico-chemical techniques}

Composite interfaces exist in a variety of forms of differing materials. The threedimensional nature of the interfacial zone led researchers to try to "see" the interface [120]. A convenient way to characterize composite interfaces embedded within the bulk 
material is to analyze the surfaces of the composite constituents before they are combined together, or the surfaces created by fracture. Surface layers represent only a small portion of the total volume of bulk material. The structure and composition of the local surface often differ from the bulk material, yet they can provide critical information in predicting the overall properties and performance. The basic unknown parameters in physicochemical surface analysis are the chemical composition, depth, purity and the distribution of specific constituents and their atomic/microscopic structures, which constitute the interfaces. Many factors such as process variables, contaminants, surface treatments and exposure to environmental conditions must be considered in the analysis.

When a solid surface is irradiated with a beam of photons, electrons or ions, species are generated in various combinations. An analytical method for surface characterization consists of using a particular type of probe beam and detecting a particular type of generated species. In spectroscopy, the intensity or efficiency of the phenomenon of species generation is studied as a function of the energy of the species generated at a constant probe beam energy, or vice versa. Most spectroscopic techniques are capable of analyzing surface composition, and some also allow an estimation of the chemical state of the atoms. However, it may be difficult to isolate the contributions of each surface layer of the material being probed to these properties. Since most surface analysis techniques probe only the top dozen atomic layers, it is important not to contaminate this region. For this reason and particularly to reduce gas adsorption, a vacuum always has to be used in conjunction with these techniques. The emergence of ultrahigh vacuum systems of less than $10^{-6} \mathrm{~Pa}$, due to rapid technological advances in recent years, has accelerated the development of sophisticated techniques utilizing electrons, atoms and ions. Amongst the currently available characterization techniques, the most useful ones for composite interfaces are: infrared (IR) and Fourier transform infrared (FTIR) spectroscopy, laser Raman spectroscopy, X-ray photoelectron spectroscopy (XPS), Auger electron spectroscopy (AES), secondary ion mass spectroscopy (SIMS), ion scattering spectroscopy (ISS), solid state nuclear magnetic resonance (NMR) spectroscopy, wideangle X-ray scattering (WAXS), small-angle X-ray scattering (SAXS) and the measurement of the contact angle. The use of spectroscopic methods to characterize the chemical composition of the interface has been discussed in some articles $[23,102,121,122]$. These methods enable a chemical analysis of superficial layers (a few nanometers thick) to be carried out. They are applicable to the analysis of sizing on naked fibers, or even of debonded fibers, to identify (and quantify) the functional groups or to trace the concentration profiles of a given species. Each technique has its own complexity, definite applications and limitations $[23, \mathbf{1 2 3}]$ for the in situ analysis of real composites. Often the information sought cannot be provided by a single technique. This has resulted in the design of equipment that utilizes two or more techniques and obtains different sets of data from the same surface of the sample (e.g. ISS/SIMS two-in-one and XPS/AES/SIMS three-in-one equipment). Adamson (1982) [37], Lee (1989) [124], Castle and Watts (1988) [125] and Ishida (1994) [126] have presented excellent reviews of most of these techniques, with Ishida (1994) being particulalry informative for characterization of composite materials.

In addition to surface analytical techniques, microscopy [98-100], such as scanning electron microscopy (SEM) and transmission electron microscopy (TEM) can help determine the interphase thickness when it is clearly differentiated from the matrix. They allow observing the contact between phases at the atomic scale [127] and visualize porosity or potential phase separations. Highly detailed studies on the internal structure and surface of carbon fiber have been conducted with TEM. However, SEM which has 
lower resolution has led to very fruitful applications in fractographic analysis (fracture surface analysis) to determine failure modes of composites subjected to mechanical stress [71, 128]. Scanning tunneling microscopy (STM) and atomic force microscopy (AFM), also provide invaluable information regarding the surface morphology, physico-chemical interaction at the fiber-matrix interface region, surface depth profile and concentration of elements.

In fact, the interlayer between the fiber and the matrix is inhomogeneous, with a smooth transition of mechanical properties. At this scale, it becomes extremely difficult to conduct measurements, although the properties of interphases can be determined through molecular dynamics simulations. However, researchers have demonstrated the use of SIEM (Speckle Interferometry with Electron Microscopy) to measure the elastic properties of interphases [129]. The application of atomic force microscopy (AFM) to the study of the interphase is also a promising field of investigation. For example, Mai et al. (1998) [130] in force modulation mode showed that the variation in the fiber properties with respect to the matrix differed depending on whether the fiber is sized or not. It is thus possible to distinguish a linear gradient in the case of a sized fiber, whereas constant interphase properties are observed for untreated fibers. Joliff et al. [131, 132] characterized the interphase of a UD composite (glass/epoxy), first in terms of molecular mobility by micro-thermal analysis and then in terms of mechanical properties by force measurements with AFM. The measurements showed an increase in elastic modulus and in glass transition temperature around each fiber. Optical microscopy revealed considerable heterogeneity of fiber distribution inside the matrix with many contacts between fibers. A realistic microstructure including the interphase size (defined by $\mu \mathrm{TA}$ ) and fiber distribution was therefore used to model the composite accurately.

\subsection{Micromechanical testing}

Micromechanical tests, unlike all the previous tests, are tests that were specially designed to determine the characteristics of fiber / matrix interfaces, in particular their strength or toughness, and to establish the fundamental features of load transfer and interfacial break. Most of these tests are performed on model composites (monofilament), i.e. on samples whose geometry is generally specific to each test, and which contain only one fiber surrounded by resin. It should be pointed out, however, that these tests are generally difficult to perform and limited to a small number of specialized research laboratories. The main tests include micro-indentation, fragmentation, debonding (better known as pull-out), of which a derived form is the 'micro-droplet' test, and compression [13, 119] (Fig.9).

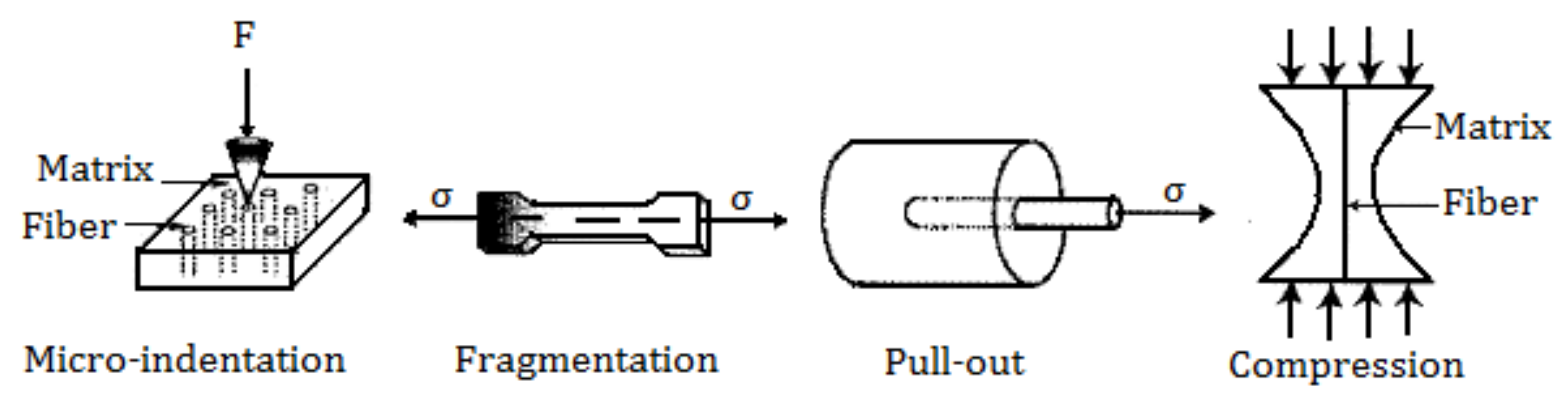

Fig.9. Examples of micromechanical tests used to characterize the fiber/matrix interface. 
The micro-indentation test, proposed by Mandell et al. [18], measures the debonding force in situ on real composites. This method at present comprises a fully automated measuring and data acquisition process [133]. It requires the polishing of composite samples with fibers perpendicular to the surface and consists in pressing the extremity of a fiber by means of an indenture until fiber debonding. This test can be applied to real composites, which avoids the often difficult manufacturing of a model composite and also guarantees the representativeness of the tested interface; in model composites (monofilament), the interface obtained can differ from that of real composites because of the conditions of implementation and the absence of surrounding fibers. The advantages of the indentation technique are that:

- it can be applied by using a polished face of a standard UD composite,

- it does not depend on the fiber break properties because the fiber is tested in compression.

Two types of samples can be used, either thick or thin samples. Thick samples are generally easy to produce, but the fiber is compressed during the test, which requires a strong force compared with the necessary sliding strength. Moreover, it is difficult to determine the length of the separated part of the fiber and as a result, calculating the interfacial pressures requires additional hypotheses. With thin samples, in contrast, it is easy to determine the parameters of the interface. However, the preparation of specimens containing fibers of small diameter remains the most difficult step. With thin samples, the test is named "push-up" or "push-down" [134].

The most widely used micromechanical test is the fragmentation test [135-137] developed by Kelly and Tyson [31] and applied by Fraser et al. [138, 139] to composites with an organic matrix. The method consists in subjecting a specimen to a monofilament tensile test along the fiber axis. Continuous application of the force leads to breakage of the fiber in several places. The fragmentation process continues throughout the test until a certain critical fragment length is reached, $\mathrm{Lc}$, that no longer allows the transfer of load by shear to generate tension constraints equal to the fiber strength. This technique is relatively simple to implement but has the disadvantage that it can only be used with strongly deformable matrices, which is rarely the case of commercial resins [140]. In the case of glass / epoxy systems, matrix cracking problems and the lack of interfacial debonding have for example been observed [141], including in cases of pre-deformation of the fiber, which precludes any calculation of the load transfer capacity defined by Kelly and Tyson. This test is effective for determining the shear strength of the fiber / matrix interface especially when the interface is strong.

The pull-out method is the simplest test. It is the oldest test, but also the one that has been developed and improved the most in recent years. The test consists in extracting a fiber from a block [142], a disk or a droplet of resin [143]. This technique presents several advantages, among which the possibility of taking into account friction phenomena following debonding and of determining the corresponding rupture energies or both phases (debonding and friction). Conversely, the downside is not only the great complexity of analyzing the results but especially the experimental difficulties of manufacturing, handling and loading the samples. The failure rate reaches over $75 \%$ according to Piggott [142].

Lastly, the compression method was developed by Mooney and Mc Garry [144] based on microcomposites to measure the bond strength of glass fibers with 
transparent polymer matrices, then Broutman [145]. This method consists in applying a compressive load to the parallelepipedic specimen or dumbbell to determine the compressive stress $\sigma_{c}$ at which the onset of debonding is discerned. This test compresses both the fibers and the matrix by interposing a metal plate usually made of aluminum between the composite surface and the elements of the compression machine. The sample's geometry or the difference in the Poisson ratio between fiber and matrix and in their stiffness generates shear stress or tension at the interface. Interfacial debonding is detected either in the necking region [146] or at the ends of the fiber and propagates on a critical length $L_{c}$ at a constant speed which then increases abruptly and initiates during loading. If the fibers are stiffer than the matrix, the deformation of the matrix is greater during the displacement of the transom. The fibers protrude from the matrix and leave footprints on the metallic plate which is assumed to be perfectly plastic [147]. The depth of these footprints corresponds to the maximum displacement of the fibers during the loading of the composite, and their residual displacement is measured directly on the composite.

The single fiber compression test has not been as popular as other microcomposite tests because of the problems associated with specimen preparation and visual detection of the onset of interfacial debonding. To be able to obtain accurate reproducible results, the fibers have to be accurately aligned. With time, this test method became obsolete, but it has provided a sound basis for further development of other testing techniques using similar single fiber microcomposite geometry.

\subsection{Theoretical models: bibliographic contributions}

Experimental evaluation of interfacial properties in fiber reinforced composites using fiber pull-out tests has been investigated by several researches [148-153]. However, analytical/numerical modeling of fiber pull-out (push-back) tests has gained popularity subsequent to experimental testing due to cost and time saving advantages. Several theoretical models have been developed to predict the load-displacement behavior of fiber pull-out test and the inherent interfacial properties [154-158]. Generally, these solutions are obtained by adopting a few simplistic assumptions. One of the commonly employed assumptions is the state of plane-strain [29] in the assembly in order to relate radial and shear stresses in the equilibrium equations. For example, [154, 159-162] published a series of papers on different aspects of fiber pull-out/push-out problems, adopting plane-strain conditions. However, the plane-strain assumption is not a good approximation for perfectly bonded interfaces where the load transfer length is very small (only a few fiber radii) (Hsueh, 1991). Another such simplification is to ignore the radial dependence of axial stresses, either in the fiber or matrix, or in both [29, 159-161], which is justifiable only when embedded fibers are sufficiently long. Owing to the mathematically involved nature of this boundary value problem, a few investigators have chosen to impose boundary conditions in an approximate sense. For instance, Hsueh (1990, 1991) [154, 159-161] developed an analytical solution based on shear-lag theory. In this model, shear stress in the matrix region was assumed to be inversely proportional to the radial distance. Consequently, a stress free boundary condition was satisfied only in a limited sense which is appropriate only for problems where the outer radius of the matrix is considerably large compared to the fiber radius. Nairn (1997) [163] showed that the shear-lag analysis is best suited for composites with high fiber to matrix stiffness 
ratio. Moreover, a shear-lag analysis predicts inaccurate results for composites with low fiber volume fractions. However, the total energy prediction through shear-lag analysis is reasonably accurate and therefore shear-lag theory has been utilized to study fracture mechanics of embedded fibers [164].

A simple model to predict the ultimate tensile strength of fiber-reinforced composites when the failure is governed by fiber debonding has proposed by Stang and Shah [155]. Gao et al. [156] have studied the fiber/matrix debonding problem using a simple shear lag model, which includes friction at a debonded interface and Poisson contraction of the fiber. The authors have observed interfacial friction to have a significant effect on the debonding behavior. Further, the load-displacement relationship has been modeled in terms of interface toughness and frictional parameters of the interface. Hsueh [154] analyzed the nonlinear dependence of stresses required to debond the fiber/matrix interface and for fiber pull-out as a function of embedded fiber length for a fiberreinforced composite. The roles of residual clamping stresses at the interface, and Poisson contraction of the fiber, have been taken into consideration. Kerans and Parthasarathy [158] have developed fiber pull-out and pushout models to predict the loaddisplacement behavior in terms of the fiber/matrix interface parameters. The authors have found residual axial strain in the fiber to have a significant effect on fiber debonding and also included fiber surface topography in their model. The authors have suggested a methodology to extract interface parameters from experimental data.

To develop tractable models, many researchers have modeled the interphase region as a homogeneous material [165-169]. However, a few studies considered the inhomogeneous nature of interphase adopting a stair-case variation of material properties across the thickness of the interphase layer [170, 171]. Alternatively, a few investigators proposed an effective interphase model (EIM) and uniform replacement model (URM) to replace the fiber and the surrounding interphase by an effective homogeneous fiber in order to convert a three-phase composite into a two-phase composite [172]. For mathematical convenience and to better describe the variation of properties within the interphase region, several researchers treated the interphase as an inhomogeneous material by smoothly varying the material properties as a function of radius. Usually in such models, the material properties are graded by adopting an empirical law [173-178]. Since, it is rather difficult to arrive at an explicit closed form 3D solution for such problems; many researchers have adopted numerical methods, particularly FE analysis $[176, \mathbf{1 7 9}, \mathbf{1 8 0}$. Most of the analytical studies that exist in the literature do not account for the anisotropy of fibers. Nevertheless, Wu et al. (2000) [78] presented a generic solution that is valid for both isotropic and transversely isotropic materials for a two-phase fiber-reinforced composite.

\section{Fiber / Matrix Interface}

The mechanical performance and durability of composite materials are mainly governed by three factors: the strength and stiffness of the fibers; the strength and chemical stability of the matrix; the nature of the bond between the fibers and the matrix. While there is an abundant literature $[\mathbf{1 0 8 , 1 8 1 - 1 8 3 ]}$ on general data and calculation methods according to the type of fiber and resin, the structure of the ply stack and rate of reinforcement, few studies have investigated the influence of the fiber/matrix interface on the behavior of the composite or characterized it. The absence of quantitative data means that the result of the so-called safety coefficients (or even ignorance coefficients) 
has to be weighted. These coefficients are often very high, with the economic consequences which that engenders. Several studies have been conducted to observe the influence of the interface depending on the method of characterization, so as to specify the sensitivity of each technique to changes in the interfacial zone and clarify the role of the latter on the fracture behavior of composites by comparing the results of the mechanical properties of the micromechanical tests and the macroscopic tests.

For example, Keusch et al. $[92, \mathbf{1 0 8}]$ used different tests (micromechanical and macromechanical) on UD composites (glass / epoxy) in order to compare the surface treatment of glass fibers. The composites used differed in the interface only, as it is of vital importance that all other parameters be kept constant for differences in behavior to be attributed to interfacial phenomena alone. The fiber / matrix bonding was characterized by determining the interfacial shear strength by a debonding (pull-out) test, the interlaminar shear strength by a compression shear test and short bending, and the transverse tensile strength of UD laminates. The results showed that the type of sizing has an influence on these properties, that the surface treatment of glass fiber has a pronounced effect, and that the use of an amino-silane as coupling agent improved all the properties measured.

Mäder et al. [53] studied the relations between surface, interphase and the final properties of composites with diverse surface treatments on various composites (glass/epoxy and carbon/epoxy). The characteristics of the carbon fiber surface and the surface of the treated glass were variously determined by contact angle measurements, using a capillary penetration technique and zeta potential measures. Micromechanical tests were applied to the model composites to establish the interphase properties (interfacial shear strength) with pull-out tests, fiber fragmentation and the mechanical properties of composites with the transverse tensile strength and interlaminar shear.

Herrera-Franco et al. [118] compared, for an epoxy matrix and carbon fibers with different surface treatments, the micromechanical properties (using fragmentation tests, microdroplet debonding, and micro-indentation) to macroscopic properties obtained from tensile tests on $\pm 45^{\circ}$ specimens, Iosipescu shear tests and short beam shear tests. Among the different methods used on a single fiber to determine the interfacial shear strength, the fragmentation technique is more sensitive to changes in the fiber / matrix bonding that are due to the surface treatment effect or finishing, if the composite properties need to be predicted. Experimental results also suggest that it is possible to establish a correlation between the interfacial shear strength and the acoustic response of a laminate when subjected to localized heating. Samples with weaker interphases give stronger AE (Acoustic Emission) signals than those with a strong interfacial bond. A global thermal analysis is necessary to fully characterize this behavior of fiber-reinforced composites. In the various tests available on laminates, the Iosipescu shear test seems to be the most appropriate for determining the interfacial shear strength. Given that the interlaminar shear strength determined by the SBS (short beam shear) test method follows the same trends as the interfacial shear strength, it can be said that this technique is suitable for use as a screening tool to assess the strength of the fiber-matrix bond in a laminate. Even if micromechanical tests produce an interfacial shear strength value that is very similar to the composite values, the use of single-fiber measures should be avoided until further research is completed to predict composite properties.

Kessler et al. [184] showed that for glass/epoxy material with various surface treatments, the quality of the interface has a strong influence on the distribution of the damage during the impact. The matrix and the interface determine crack initiation by 
loading in flexure, tension and shear and the subsequent development of delamination. To optimize material performance, it is important to establish how the microscopic properties (wetting, fiber / matrix bonding) are correlated with the behavior of the composite [184].

The results from all these studies show that when the shear strength of the fiber/matrix interface is improved there is a corresponding improvement in the macroscopic composite properties. However, the improvement in macroscopic properties is rarely directly proportional to the improvement in microscopic properties. This underlines the complexity of this type of study, as parameters such as residual stresses and the development of interphase zones are difficult to control, but also shows that improved performance is attainable in this material $[119, \mathbf{1 8 5}]$.

The analysis of different studies shows that the optimal interface is not the one with the highest characteristics. Furthermore, each fiber/matrix system considered has its own values of optimal interfacial properties, which are related to the properties of the fiber and the matrix. Lastly, for a given system, there is not a unique optimal interface; the study of every property of the composite (for example ILSS, fatigue behavior, fracture property) can lead to the definition of a different optimal interface each time.

\section{Load transfer between the fiber and the matrix}

The interface is where an important mechanism takes place, as the transfer of load between fiber and matrix within a composite material [110]. This transfer of load is fully dependent on the mechanical response of the contact zone between the fiber and the matrix, i.e. the interface or interphase. When composites are subjected to various loading conditions, the efficiency of the load transfer across the interface plays an important role in the overall performance of the composite [23]. It is this transmission of load that allows the composite to fulfil its mechanical function. Load transfer processes can be described with simplified micromechanical models considering, for example, an RVE (Representative Volume Element) consisting of a fiber embedded in a matrix cylinder to which a tensile stress is applied. The profile of the tensile stress in the fiber and that of the shear at the interface can be theoretically determined from the elastic equilibrium equations. From these data, it is possible to evaluate the stress-strain curve of the composite.

Depending on the assumed behavior of the interface, various responses can be simulated. In this paper, two pioneering models are presented, those of Cox (1952) [29] and of Kelly-Tyson (1964) [84]. In the Cox model, the link between fiber and matrix is assumed to be perfect and the mechanical behavior of these constituents is elastic. On the contrary, the Kelly-Tyson model was developed initially for materials with a metallic matrix in which the mechanisms of plasticity are activated in the vicinity of the fiber ends. Another model applicable to composites with polymer matrices that combines the approaches of Cox and Kelly-Tyson is the mixed model [186], which adopts the Cox hypothesis in the central part of the fiber, i.e. that the fiber is subject to an elastic load until debonding of the interface, and in the part where debonding occurs, it adopts Kelly's assumption, i.e. constant shear.

\subsection{Cox model, elastic load transfer}

We consider an RVE consisting of a fiber radius fragment embedded in a matrix cylinder having a radius $\mathrm{R}$ set by the fiber volume fraction, $V_{f}$, and the hypotheses made on the fiber arrangement. This RVE is subjected at its extremities to a tensile strain $\varepsilon_{l}$. 
Only the axial components of the stresses generated in the fiber and the matrix are considered. It is, therefore, a one-dimensional approach in which the axial stress in a given section of the fiber is also assumed to be uniform. In this model, the fiber and the matrix are assumed to be perfectly elastic and the fiber/matrix bond perfect. This model gives the stresses in the fiber and at the interface by Eq.8 and Eq.9 (profiles of the stresses are shown in Fig.10).

$\sigma_{f}=E_{f} \varepsilon_{l}[1-\cosh (n x / r) / \cosh (n s)]$

$\tau_{i}=\frac{1}{2} n E_{f} \varepsilon_{1} \sinh (n x / r) / \cosh (n s)$

where $E_{f}$ is the Young modulus of the fiber, $G_{m}$ shear modulus of the matrix, $\varepsilon_{1}$ is the applied strain, $a, R$, are respectively the radius of the fiber and the matrix, $L$ is the fibre length, $x$ is the variation of the length of the fiber, $r$ variation of rate of the matrix , $s=L / a$ is the aspect ratio of the fiber, $n$ is a constant calculated from Eq.10.

$n^{2}=\frac{2 G_{m}}{E_{f} \ln (R / a)}$

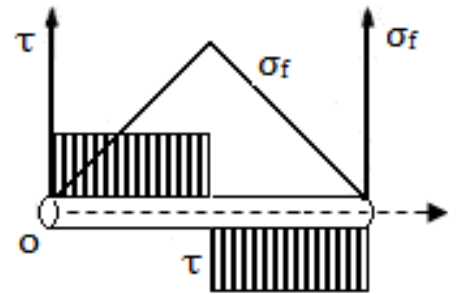

Kelly/Tyson

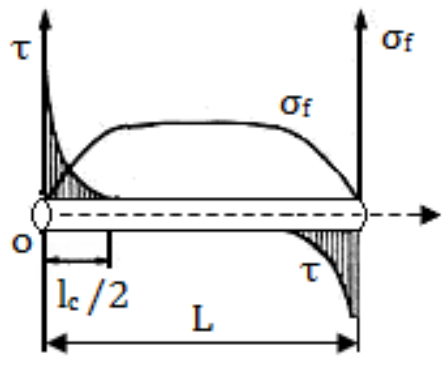

$\operatorname{Cox}$

Fig.10. Profiles of the tensile stress in the fiber and shear at the interface from KellyTyson and Cox models.

It can be seen that the development of shear stresses at the ends of the fiber fragment results in a progressive tensile loading of the fiber. Forces are therefore transferred from the matrix to the fiber.

\subsection{Kelly-Tyson model}

The Kelly-Tyson model was initially developed for materials with a metallic matrix in which the mechanisms of plasticity are activated in the vicinity of the fiber ends. The Cox model shows that the transfer of load leads to the development of interfacial shear stresses, the amplitude of which is maximum at the fiber ends. In practice, these concentrations of stress are limited by the plasticity threshold of the matrix or the sliding of the interface. Moreover, the elastic approach is no longer valid once the tensile stress in the matrix exceeds its elastic limit. These phenomena were initially demonstrated by Kelly et al. in the case of copper matrix composites reinforced by tungsten and molybdenum fibers. The very low yield strength of the matrix then leads, under tensile load, to the early and progressive development of a plastic deformation zone from the ends of the fiber. 
To describe these processes, Kelly et al. [84] considered that the interfacial stress was constant at the fiber ends in the plastic zone. The elastic equilibrium of the fiber in this portion of the fiber is written by Eq.11:

$$
\sigma_{f}=\frac{2 \tau_{i}}{a}(L-x)
$$

Where $\sigma_{f}$ is the nominal tensile stress of the fiber, $\tau_{i}$ shear stress at the interface, $a$, is the radius of the fiber, $L$ is the fiber length; $x$ is the variation of the length of the fiber.

This relation also applies when the physical mechanism involved at the fiber ends corresponds to friction with constant stress. In this sense, the Kelly model can also be used for elastic matrix composites in which the reinforcement is achieved by sliding at the interface. The strain in the fiber cannot exceed the deformation of the composite, meaning that the stress $\sigma_{f}$ increases linearly Eq.11 from the end of the fiber, until the value $E_{f} \varepsilon_{1}$ if the fiber is long enough. The latter condition corresponds to the following criterion (Eq.12):

$$
L_{i} \geq \frac{a E_{f} \varepsilon_{l}}{2 \tau_{i}}
$$

Where $L_{i}$ is the so-called inefficient fiber length corresponding to the portion in which the tensile stress has not yet reached its maximum value: $\sigma_{f \max }=E_{f} \mathcal{E} 1$.

It is important to note that this model takes into account only the load transfer occurring in the plastic zone at the ends of the fiber. The effects of elastic load transfer in the central portion of the fiber are neglected $\tau_{i}=0$. This approach is valid only if the plasticity threshold of the matrix (or the sliding threshold of the interface) is very low. In this case, plastic deformation (or slippage) occurs at the beginning of the loading, without an elastic load phase. The analysis usually adopted is that of Kelly and Tyson [84] which considers that the tensile stress in the fiber $\tau(\mathrm{x})$ increases linearly from the ends of the fragment (Fig.10).

\subsection{Mixed model}

In the Kelly model, elastic load transfer effects are totally neglected, which amounts to considering that the plastic deformation of the matrix, or the sliding of the interface, occurs at low strains. In reality, these processes often occur after a preliminary elastic loading phase that needs to be taken into account.

In the case of composites with a polymer matrix, the sliding of the interface occurs for a limit value of the interfacial shear stress $\tau_{d}$, which corresponds physically to fiber/matrix debonding. In the debonded fiber zone, sliding processes depend on the value of the fiber / matrix friction coefficient and the radial stress applied to the fiber.

In such a situation, the corresponding value of interfacial shear $\tau_{g}$ is often less than the value of the debonding stress $\tau_{d}$.

To account for these processes, we can consider an RVE in which:

- The central portion of the fiber is subjected to an elastic load; the value of interfacial shear is limited by the debonding stress $\tau_{d}$. In this zone, exactly the same equations of elastic equilibrium as those introduced in the Cox model can be written.

- When $\tau_{i}>\tau_{d}$, sliding is considered to be at a constant stress $\tau_{g}$. The load transfer in this zone is accomplished according to the hypotheses of the Kelly model. By solving the equilibrium equations with the appropriate boundary conditions, the stress-strain relationship can be calculated as follows by Eq.13. 


$$
\sigma_{l}=\left[V_{f} E_{f}+V_{m} E_{m}\right] \varepsilon_{l}-\frac{V_{f}}{S}\left[\frac{\left(E_{f} \varepsilon_{l}\right)^{2}-\left(2 \tau_{d} / n\right)^{2}}{4 \tau_{g}}+\frac{2 \tau_{d}}{n^{2}}\right]
$$

Where $V_{f}, E_{f}$ and $V_{m}, E_{m}$, are respectively the volume fractions and moduli of the reinforcement and the matrix, $\varepsilon_{l}$ is the applied strain, $s=L / a$ is the aspect ratio of the fiber, $n$ is a constant.

For low values of $\sigma$, the second term of the second member of Eq.13 induces nonlinearity in the stress-strain relationship.

\section{Principle and limitations of the debonding test (pull-out)}

The debonding test (or pull-out test) is a micromechanical test used to characterize interfacial fiber / matrix bonding. It is considered to be the most advanced technique. It consists in conducting a tensile test on a monofilament partially embedded in resin and measuring the force required to extract the fiber from its matrix sheath. The debonding test was originally developed by Shiriajeva and Andreevskaya (1962) [187], improved by Favre and Perrin (1972) [188], Piggott et al. (1985) [142], Hampe 1988 and Hampe et al. 1989 [189, 190]. There are several different pull-out configurations (Fig.11): the fiber may be embedded either in a microdroplet of resin or in a resin button or still, more typically, in a block of resin. In all cases, the resin is bonded to the lower part of the traction device.

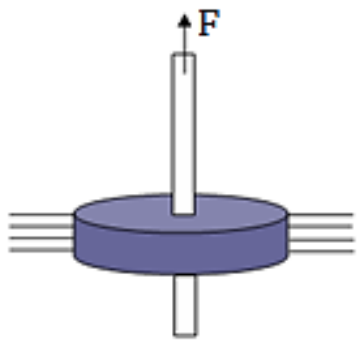

(a)

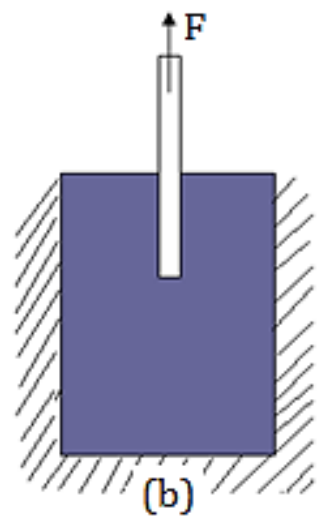

(b)

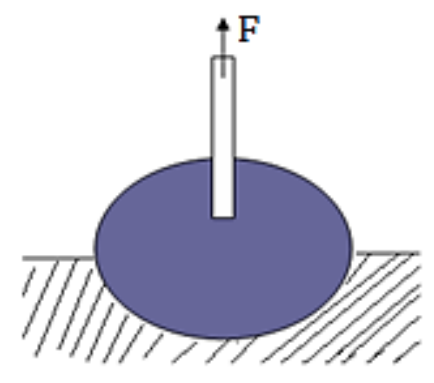

(c)

Fig.11. Different pull-out configurations: (a) Favre (b) Piggott (c) Hampe.

Fig.12 presents a typical curve obtained during the debonding test. It generally contains three typical zones [191]. The first part, $0 \leq F \leq F_{d}$, is linear and corresponds to an elastic solicitation of the whole: fiber, matrix, and interface. The force reaches its critical value at the point $F_{d}$ at which the slope of the curve decreases and crack initiation occurs, related to the breakdown phenomenon at the interface. For the part, $F_{d} \leq F \leq F_{\max }$, the fiber begins to pull out of the matrix by crack propagation, which explains the decrease in the slope to the point $F_{\max }$. From this point on, all the part embedded in the matrix is extruded and complete debonding takes place. The only forces recorded from this moment on are friction forces between the fiber and the matrix. The interface quality is evaluated using 
the interfacial strength (IFSS). This is calculated from the maximum debonding load, $F_{\max }$, and the sample geometry.

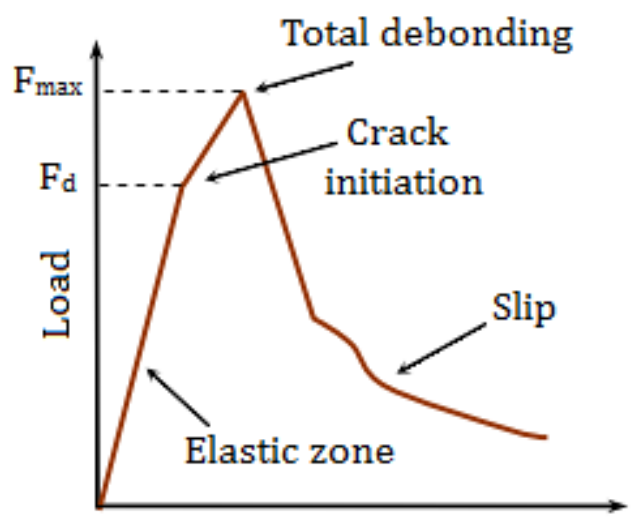

Displacement

Fig.12. Typical debonding curve: tensile [110].

The debonding load " $F_{d}$ " is an important parameter of the test. The length of the embedded fiber is denoted L. In the case of systems with high interfacial adhesion, this length must be small enough for the strength necessary for debonding to remain lower than the tensile failure strength of the fiber [97]. The competition existing between these two phenomena can be demonstrated by a simple analysis. We can thus define the notion of critical embedding length; high adhesion systems require very low critical lengths $(<100 \mu \mathrm{m})$ that are difficult to achieve in pull-out. For low embedding lengths, some studies have shown that in pull-out (in the case of configurations (a) and (c) only Fig.11), the force required to break the adhesion of the end of the fiber to the matrix was greater than the force necessary for debonding, making the test unusable. These disadvantages have led to the development of a variant of this test: the droplet test, which in addition to the easy implementation of samples, makes it possible to test systems with stronger adhesion (obtaining shorter embedded lengths).

The microdroplet test differs from that of debonding by the particular configuration of samples: here, the fiber is embedded in a micro-droplet of resin deposited on the monofilament before curing. With this technique, very low embedding lengths of $30 \mu \mathrm{m}$ can be achieved, which is rarely possible in pull-out. The only limiting factor of the test is, in the case of a thermosetting resin, the initial viscosity of the resin which, if it is too high, prevents the deposition of small droplets. Lastly, the micro-droplet test, unlike pull-out, enables the relatively fast production of a large number of samples (as the implementation of the samples does not require specific mounting) [97]. Fig. 13 shows the shape of the tensile curves obtained in the microdroplet test on glass/epoxy systems [185]. As in pull-out, these curves enable determination of the debonding load $F_{d}$. The main problem is then to relate this experimental quantity to a specific parameter in the interface: this is the subject of diverse modelings. 

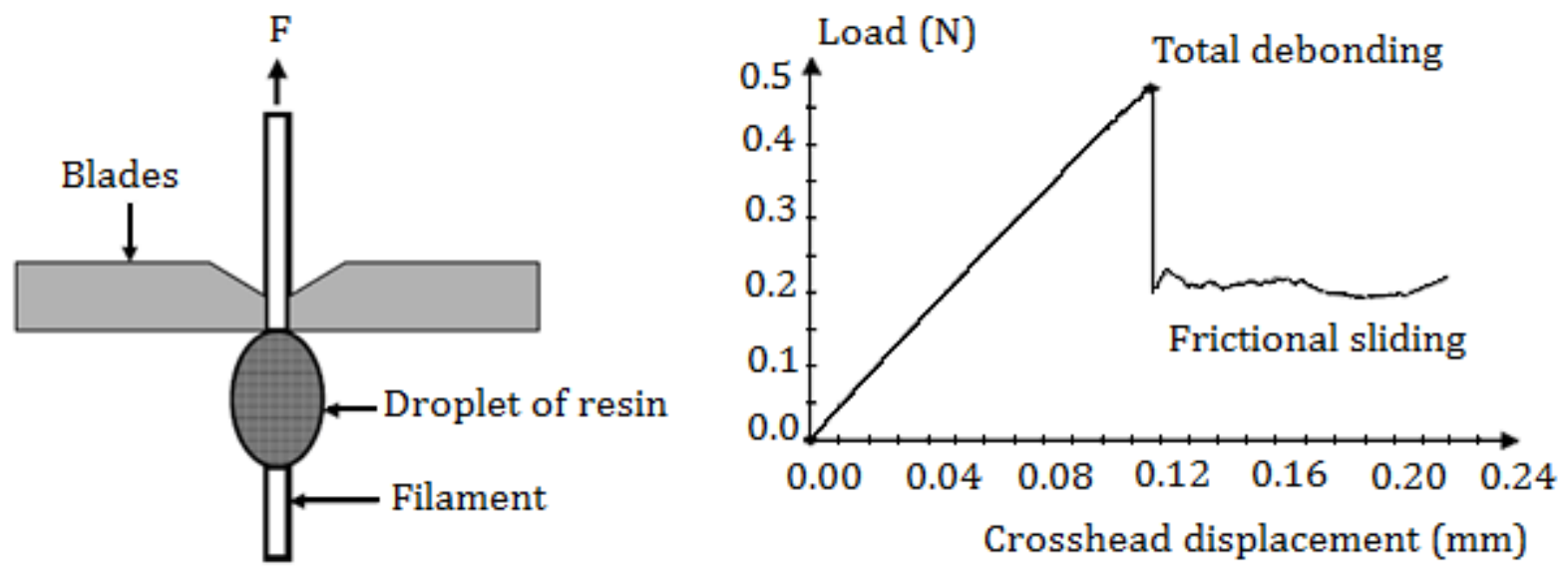

Fig.13. Schematic diagram of microdroplet test, typical debonding curve: tensile [185].

- Notion of critical embedded length

Assumption: the interfacial shear strength at the fiber/matrix interface is homogeneous along the interface.

The equilibrium force on a fiber subjected to tension gives (Eq.14):

$\pi r^{2} \sigma=2 \pi r L \tau=F$

Where $r$ is the fiber radius, $L$ is the embedded length, $F$ is the tensile force applied to the fiber, $\sigma$ the tensile stress in the fiber, and $\tau$ is the shear stress at the fiber / matrix interface.

For interfacial debonding $\tau_{i}$ to occur, the force $F$ must be lower than the tensile failure strength of the fiber $F_{c}$ such that $\tau_{i}$ gives (Eq.15):

$\tau_{i}=\frac{F}{\delta_{f}}=\frac{F}{2 \pi r L}$

For interfacial debonding it is necessary that $F=F_{d}$ (Eq.16) $\left(F_{d}\right.$ debonding force)

$\tau_{d}=\sigma_{d}=\frac{F_{d}}{2 \pi r L}$

Debonding without fiber failure occurs if (Eq.17):

$F_{f}^{R} \geq F_{d}$ (Tensile strength of the fiber)

This critical embedding length $L_{\mathrm{c}}$ is calculated by equations (Eq.18) and (Eq.19):

$F_{d}=\sigma_{d} 2 \pi r L_{c}$

$F_{R}^{f}=\sigma_{R}^{f} \pi r^{2}$

Inserting equations (Eq.16) and (Eq.17) into (Eq.15) gives (Eq.20):

$L_{c} \leq \frac{\sigma_{R}^{f}}{2 \sigma_{d}} r$

With $L_{c}$ the critical length.

For embedding values lower than $L_{c}$ the pull out test can be performed. 
For example for glass fiber $\mathrm{E}: 2 r=8 \mu \mathrm{m}, \sigma_{r}=3500 \mathrm{MPa}$ and $\tau_{i}$ can be estimated as at least $50 \mathrm{MPa}$, hence $L_{c}=140 \mu \mathrm{m}$.

\section{Trends in the analytical pull-out test models developed}

Few studies have been conducted so far on the micro-droplet test, which is a recent variant of the pull-out test. The numerous theories, however [192-194], used in pull-out tests cannot be applied directly to the study of this test, since a simple comparison of test configurations (Fig. 11 and 13) shows that the boundary conditions imposed on the matrix and the fiber end are different. In general, in pull-out tests, the resin can be deformed more easily than in the micro-droplet test, especially in shear (as its stiffness is lower). Therefore, interpreting the microdroplet test requires specific modeling. As for micromechanical testing, one can distinguish two main approaches [97, 191,195]:

- A fracture mechanics approach, in which an energy balance at the moment of interfacial failure is established (energy criterion);

- A shear-lag type approach in which a balance of the stresses within the fiber/ micro-droplet system is established (maximum stress criterion).

Finite element analyses can be included in the latter type of approach.

\subsection{Models using an energy criterion}

The interest of this type of model was underlined in particular by Piggott. After having initially used a stress criterion in his early work, he chooses an energy criterion to interpret tests in which brittle fracture occurs, which is the case of glass or carbon/epoxy systems in particular, since sudden failure phenomena appear to be governed by an energy criterion resulting from the fracture mechanics, while the progressive failure process depends on a stress criterion [193]. The energy model developed by Piggott is well adapted to a classic pull-out configuration.

\subsubsection{Piggott's model}

The geometry used is that of pull-out [196], in which a fiber of radius $r$ has one end embedded on a length $L$ in a resin cylinder with a radius $R$ (Fig.14).

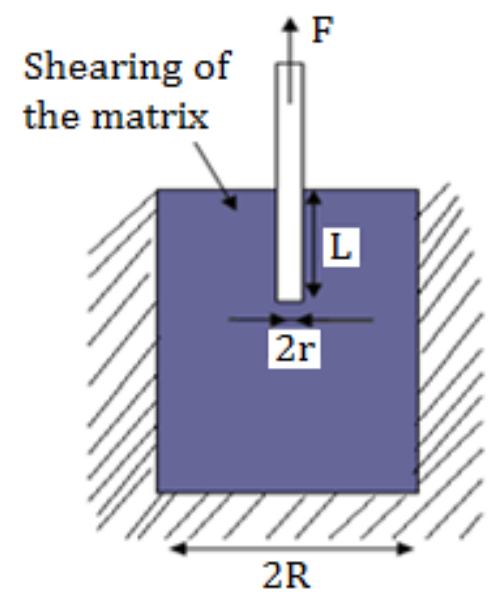

Fig.14. Test geometry used by Piggott. 
Under the action of the tensile force, $F$, to which the fiber is subjected, the matrix is sheared. The fiber is abruptly debonded for a force $F_{c}$ (Eq.21).

$$
F_{c}=2 \pi r \sqrt{\left(E_{f} G_{i} r\right)} \sqrt{\left(\frac{n L t h(n L / r)}{r}\right)}
$$

With: $n^{2}=\frac{2 G_{m}}{E_{f} \ln \left(\frac{R}{r}\right)}, E_{f}$ : the Young's modulus of the fiber, $G_{m}$ : the shear modulus of the matrix, $G_{i}$ : the fracture energy of the interface and th: the hyperbolic tangent function .

It interesting to note that Piggott used this expression to criticize the results obtained with the microdroplet test [152] on a Kevlar/epoxy system, for which droplet lengths from 40 to $400 \mu \mathrm{m}$ were obtained.

\subsubsection{Model of Penn and Chou}

The geometry described by Penn and Chou [197] (Fig.15) is closer to that of the microdroplet test.

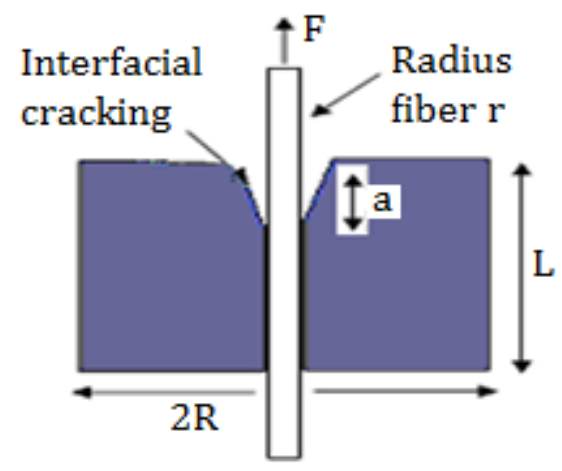

Fig.15. Model of Penn and Chou.

However, the presence of the blades that more or less embed the upper border of the matrix does not appear to be taken into account. The authors consider an initial interfacial crack size of length a. The energy equilibrium indicates that part of the stored elastic energy is released to allow breaking of the interface. This gives the expression of the debonding force $F_{c}$ (Eq.22):

$$
F_{c}=\frac{2 \pi r \sqrt{\left(r E_{f} G_{i}\right)}}{\sqrt{\left(1+\frac{1}{\operatorname{ch}\left(\operatorname{ch}\left(n\left(\frac{L-a}{r}\right)\right)\right)}\right)}}
$$

with $n^{2}=\frac{2 G_{m}}{E_{f} \ln \left(\frac{R}{r}\right)}$ and ch: the hyperbolic cosinus function. 
In the case where the crack length is negligible compared with the embedding length, $a<<$ $L$, this expression can be simplified to give Eq.23. This is particularly the case of samples for which Scanning Electron Microscopy observations have never revealed cracks.

$$
F_{c}=\frac{2 \pi r \sqrt{\left(r E_{f} G_{i}\right)}}{\sqrt{\left(1+\frac{1}{\operatorname{ch}\left(\operatorname{ch}\left(\frac{n L}{r}\right)\right)}\right)}}
$$

This expression brings in the same parameters as that of Piggott, in particular as regards the parameter $\mathrm{n}$, which is closely related to the shearing of the matrix sheath with a thickness $R-r$. When the embedding length " $L$ " is sufficient, Eq.23 has a simplified form $F_{c}=2 \pi r \sqrt{\left(r E_{f} G_{i}\right)}$ which cannot be used when the coated fiber lengths are too low.

\subsubsection{Model of Palley and Stevans}

The in-depth study of Palley and Stevans [198] considers a highly realistic test configuration (Fig.16). The droplet is represented by a cylinder of length $L$ and diameter $D$. The model can take into account the possible spacing, $h$, of the two blades relative to the fiber. This spacing then causes, during the test, shearing of a matrix cylinder with a thickness $h$ around the fiber; the matrix located below the blade is, in turn, compressed during the test. After the onset of interfacial cracking, friction between the separated fiber and the matrix is taken into account.

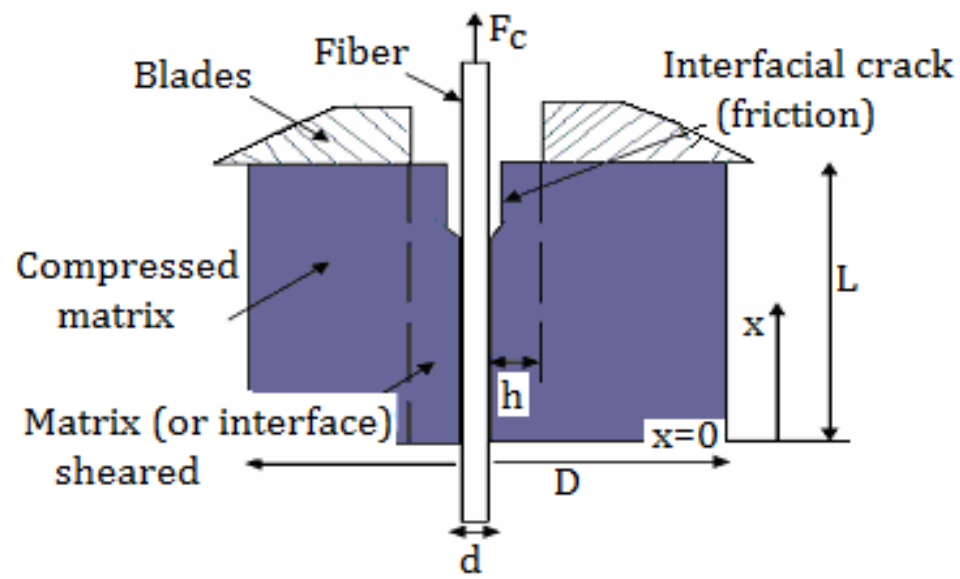

Fig.16. Definition of the geometry used by Palley and Stevans.

Palley and Stevans assume linear elasticity and consider the initiation and propagation of a cylindrical crack at the interface. Their energy balance equation leads to a rather complex expression of the debonding force, $F_{c}$, as a function in particular of the position of the crack front. This enables them to study the evolution of the strength during crack propagation. 
The equation, which is complex but not restrictive, gives the debonding force and allows for numerical studies of sensitivity to various parameters such as the coefficient of interfacial friction and the thickness $h$ of the sheared matrix. The latter parameter is considered to have only a minor influence on the result, and can therefore be neglected experimentally. This means that poor control of the positioning of blades should not, within limits at least, significantly impact the debonding force obtained, i.e. should not scatter the results.

The expression giving the debonding force $F_{c}$ is then simplified by assuming first that the contribution of the shearing of the matrix cylinder is negligible, and second that the friction at the interface is very low. This leads to Eq.24:

$$
F_{c}=2 \pi r \frac{\sqrt{\left(r E_{f} G_{i}\right)}}{\sqrt{\left(1+\frac{E_{f}}{E_{m}\left(\frac{D^{2}}{d^{2}}-1\right)}\right)}}
$$

\subsection{Models using a stress criterion}

This group of models aims at estimating the profile of the stresses at the interface according to the applied load. Usually, it is postulated that debonding occurs when the maximum interfacial stress reaches the interfacial strength. This approach is simpler than the energy approach and often gives results that are closer to experimental reality.

\subsubsection{Greszczuk analysis}

Greszczuk's analysis, which is probably the oldest, has inspired many authors $[192,199,200]$ and is unquestionably the theory of reference for the interpretation of pull-out tests. The test geometry studied by Greszczuk is similar to that considered by Piggott (Fig.14), except that it introduces an interphase of thickness $b_{i}$ and Coulomb modulus $G_{i}$, forming a sheath along the entire length of the fiber.

The assumptions made by Greszczuk when the model is axisymmetric, elastic, and linear, are: radial effects are negligible (no radial dependence); the strains and stresses imposed by the fiber on application of the load $F$ are completely accommodated within the interphase that is assumed to be thin; the surrounding matrix is not disturbed. He obtains the expression of the stress profile along the interface. The shear stress is not constant along a fiber. The following formulation (Eq.24) estimates the value of the stress at a point of the fiber which is at a distance $l$ with respect to an origin 0 (Fig.17). 


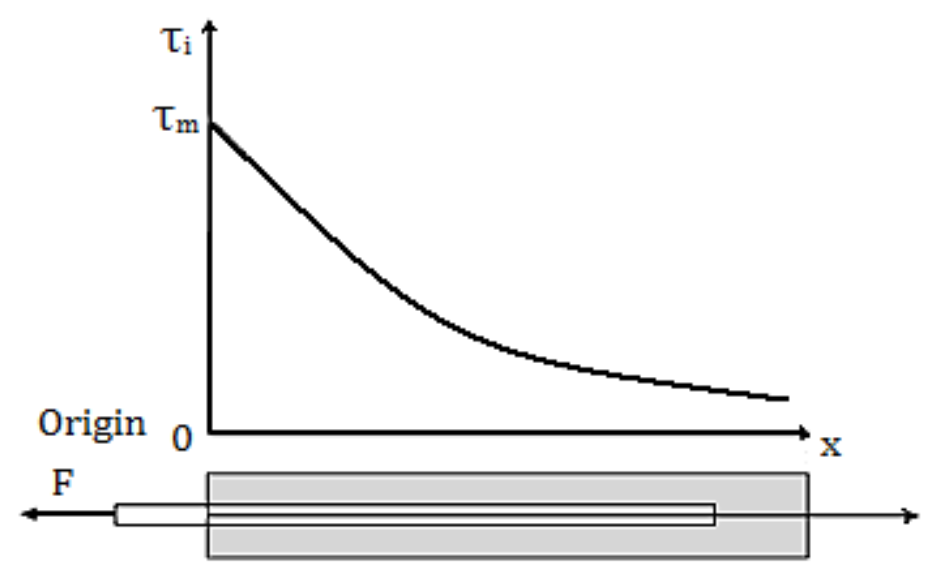

Fig.17. Shape of the interfacial shear stress curve as a function of distance from an origin (the pull-out method).

The fiber is embedded in the matrix at a depth $L$ relative to the same origin; the shear stress is maximum at the point of emergence of the fiber and is:

$\tau_{i}=\tau_{m} \frac{\alpha L}{\operatorname{th}(\alpha L)}$

With $\quad \tau_{m}=\frac{F_{d}}{2 \pi r L} \quad$ and $\quad \alpha^{2}=\frac{2 G_{i}}{b_{i} r E_{f}}$

This expression involves parameters that are specific to the interface, which limits the application of this model (in this form) since these quantities are generally unknown. To circumvent this difficulty, it is often assumed that $G_{i}=G_{m}$ and $b_{i}=r \ln (R / r)$ where $R$ is the radius of the matrix surrounding the fiber, which leads to a new expression of $\alpha$ :

$\alpha^{2}=\frac{2 G_{m}}{r^{2} E_{f} \ln (R / r)}$

This expression is the most classical variant but other formulations can be found in the literature (the general formula giving $\tau_{i}$ remains unchanged). The problem of this type of model is to formulate precise hypotheses leading to the evolution of $\alpha$.

Greszczuk's hypothesis, which posits that the deformations are fully accommodated by the interphase, is valid only if the deformation capacity of the interphase is much greater than that of the matrix (assumed to be rigid); in the opposite case, the calculation is incorrect and should take the contribution of the surrounding matrix into account.

\subsubsection{Model of mean stress}

The simplest hypothesis that can be formulated about the interfacial shear stress is, of course, that it remains constant throughout the fiber / matrix interface. This hypothesis is the one made by the mean stress model. The equilibrium of forces on the fiber gives (Eq.27): 
$F=2 \pi r L \tau_{i}$

Where $L$ is the embedded length, $r$ is the fiber radius and $\tau_{i}$ is the interfacial shear strength. This formula gives an estimate of the mean shear stress; it is widely used for the microdroplet [201] and pull-out [188] tests and even in micro-indentation tests. Its simplicity allows rapid exploitation of the results. It is currently the most commonly used model for the interpretation of microdroplet test results.

\subsubsection{Scheer and Nairn Analysis}

Scheer and Nairn [201] consider the same type of geometry as Palley and Stevans, albeit with slightly different boundary conditions (Fig.18).

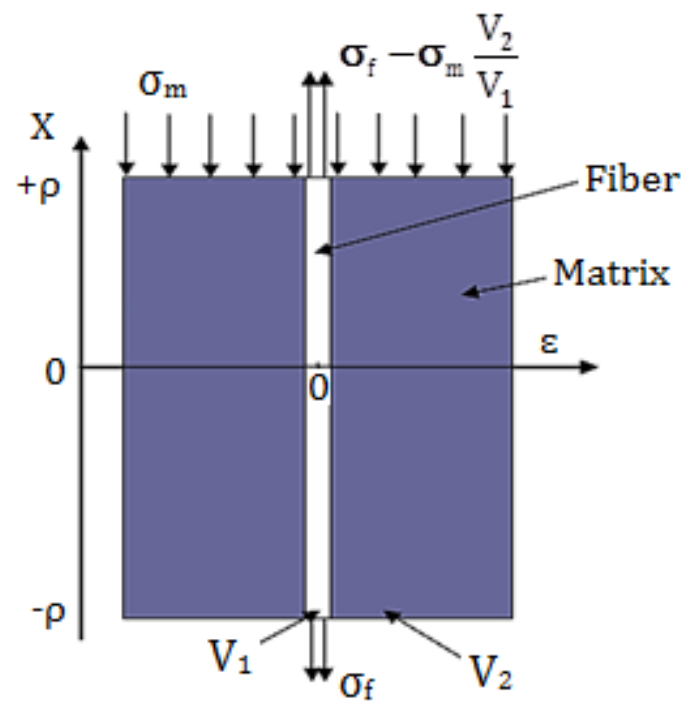

Fig.18. Geometry used by Scheer and Nairn.

The model is axisymmetric, elastic and linear; axial stresses in the fiber and the matrix are assumed to depend only on $\mathrm{x}$ (no radial dependence). Using a variational method, the most admissible stress field for the problem is sought. The general expressions obtained for the diverse internal stresses are complex and will not be described here, nor even exploited.

Scheer and Nairn plotted the stress profiles along the interface for the case of a microdroplet of epoxy resin on a carbon fiber. The embedded length chosen is ten times the fiber radius, which is a realistic experimental case. The major result which stands out from this study is the complex character of the stress state at the interface, which is as likely to break under the influence of the radial tensile stress as of the shear stress. Other authors [203] reach similar conclusions by modeling the pull-out test by finite elements. The interpretation of debonding in terms of failure then becomes much more difficult and it would perhaps be preferable to consider a mixed failure criterion. The microdroplet test may not provide the interfacial shear strength but rather the strength of the interface to a complex tensile / shear stress state. 


\subsubsection{Raman spectroscopy studies}

Alongside the diverse mathematical models of micromechanical tests, an experimental technique to evaluate the deformations undergone during these tests has been developed over the last few years, namely infrared spectroscopy; at vibrational frequencies characteristic of the atomic groups of the material tested (Raman peaks). These frequencies are a function of the strength and length of interatomic bonds, and hence of the lattice strain. Raman spectroscopy gives a direct measurement of strains at a microscopic level (resolution of a few microns).

This technique has already been successfully coupled with micromechanical fragmentation tests [204] and pull out tests [205, 206], allowing a direct visualization of the profile of global deformation applied to the specimen. We can go back to the profile of the interfacial shear stress, $\tau_{i}$, by the classical expression of the equilibrium of forces on a fiber section (Fig.19) and by assuming the elasticity of the fiber, hence (Eq.28):

$\tau_{i}=E_{f} \frac{r d \varepsilon}{2 d x}$

Where $\varepsilon$ is the axial strain in the fiber and $E f$ the Young's modulus.

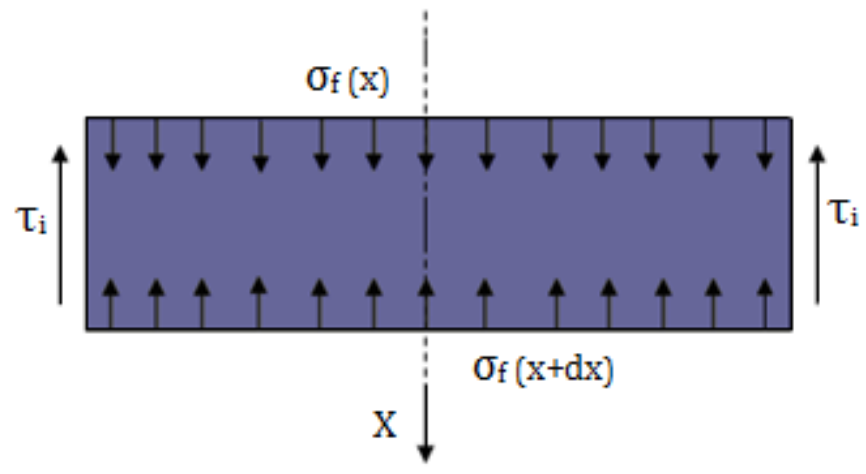

Fig.19. Equilibrium forces on a section of fiber

This technique to measure the deformations in situ has the advantage of limiting the number of hypotheses made to estimate the interfacial shear. Admittedly, any technique has its limitations and Raman spectroscopy can only be used to study the fibers situated on the surface of a composite, for a transparent matrix and for fibers having a sufficiently intense Raman signal. It can therefore be successfully applied to model composites such as those tested in pull-out and fragmentation tests. An application in micro-indentation tests is much more difficult to perform. This type of study still remains to be done on carbon/epoxy composites experimented in micro-droplet tests, where the presence of jaws can be an additional difficulty.

\subsubsection{Large-Toumi Model}

Large-Toumi [97] has developed an approach based on a stress criterion for a geometrical configuration that closely resembles the real test configuration (the micro- 
droplet test, Fig.11). The model is on the same lines as that of Greszczuk (the same set of equations), but the geometry and the boundary conditions are adapted to the case of the droplet test. In this approach, the real test geometry can be modeled as indicated in Fig.20. The droplet is represented by a cylinder of length $L$, where $L$ is not the embedding length, but the length of the droplet debonded from the fiber during the test (i.e., regardless of the residual meniscus). This value is obtained by a systematic visual inspection after each test. Given the elliptical shape of droplets and the relative position of the jaws, the diameter of the matrix cylinder in Fig.14 is equal to the diameter of the droplet. This axisymmetric geometry is close to that considered by Palley and Stevans.

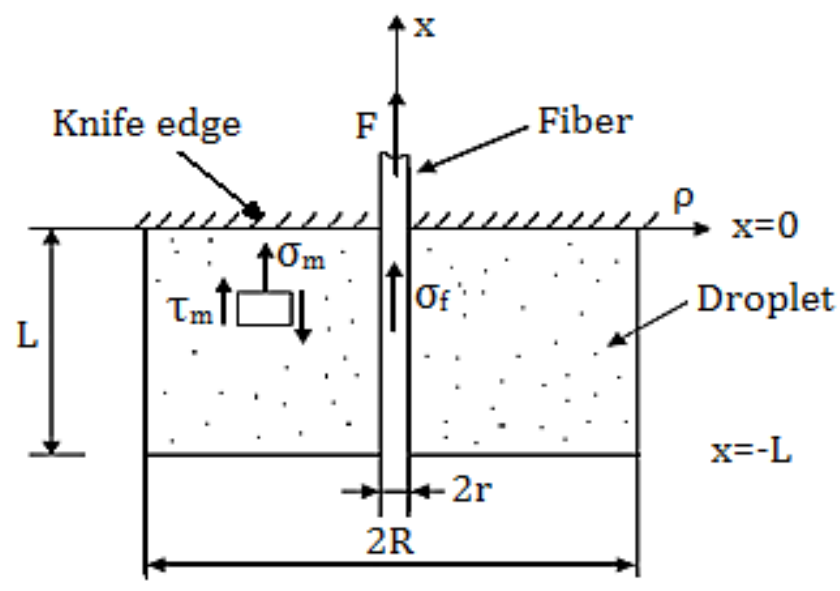

Fig. 20. Modeling the micro-droplet (B. Large-Toumi).

The indices " $m$ " and " $f$ " refer respectively to the matrix and the fiber, $\tau_{i}$ indicates the interfacial shear stress, that is $r=\rho$. It is assumed that the system is elastic and linear, with symmetry of revolution (no torsion). It is assumed that the axial stress in the matrix $\sigma_{m}$ and in the fiber $\sigma_{f}$, do not depend on $\rho$ and that radial effects are negligible. These effects include inflation of the matrix and contraction of the fiber due to the effects of the Poisson ratio; these two hypotheses are classical in analytical calculus (Greszczuk 1969, Piggott 1980).

Taking the boundary conditions into account, the expression of the stresses $\sigma_{f}$ and $\sigma_{m}$ can be formulated as follows (Eq.29 and 30):

$$
\begin{gathered}
\sigma_{f}=\frac{F[\operatorname{ch}(\alpha(x+L))-1]}{\pi r^{2}[\operatorname{ch}(\alpha L)-1]} \\
\sigma_{m}=\frac{-F[\operatorname{ch}(\alpha(x+L))-1]}{\pi\left(R^{2}-r^{2}\right)[\operatorname{ch}(\alpha L)-1]}
\end{gathered}
$$

When the applied force $\mathrm{F}$ reaches the debonding strength $F_{d}$, the maximum of the stress is the interfacial shear strength $\tau_{i}$ (Eq.31), therefore: 
$\tau_{i}(x)=\frac{-\alpha F}{2 \pi r(\operatorname{ch}(\alpha L)-1)} \operatorname{sh}[\alpha(x+L)]$

With as before: $\alpha^{2}=\frac{4 G_{m}\left[\frac{r^{2}}{R^{2}}\left(\frac{E_{f}}{E_{m}}-1\right)+1\right]}{r^{2} E_{f}\left[2 \operatorname{Ln}\left(\frac{R}{r}\right)-\left(1-\frac{r^{2}}{R^{2}}\right)\right]}$

and sh: the hyperbolic sinus function

When $R$ is greater than $r$, which is generally the case in pullout tests, the term $\alpha^{2}$ can be simplified to Eq.33 where we find the coefficient $\alpha$ initially introduced by Greszczuk (1969)

$$
\alpha^{2}=\frac{2 G_{m}}{r^{2} E_{f} \operatorname{Ln}\left(\frac{R}{r}\right)}
$$

The expression $\tau_{i}$ obtained by the Large-Toumi model remains different from that obtained by Greszczuk $\tau_{i}=\frac{F_{d}}{2 \pi r L} \frac{\alpha L}{t h(\alpha L)}$, because of the particular boundary conditions of the droplet test.

\subsubsection{The Zhang model}

Zhang et al. [191] developed an analytical model to study the pull-out behavior of a continuous fiber-reinforced cementitious composite. This model is based on the analysis of the stress and displacement of the yarn combining continuity conditions. Zhang et al. studied the failure mechanism of continuous yarn reinforced cementitious composites (yarn embedded in a cement block). In this work, the failure mechanism was analyzed by dividing the pull-out curve into three phases: perfect bonding phase, debonding phase, and pure friction phase. When the uniaxial tensile force $F$ applied on the free end of the yarn reaches a critical value $F_{c}$, debonding of the yarn begins to take place. This is the beginning of the second phase. The length of the debonding part increases as the applied force increases. When this length reaches the embedded length, the applied force reaches its maximum value $F_{\max }$. This is the third phase which is pure friction between the yarn and the matrix. The level of applied force decreases greatly. These three phases are shown in Fig. 21. 


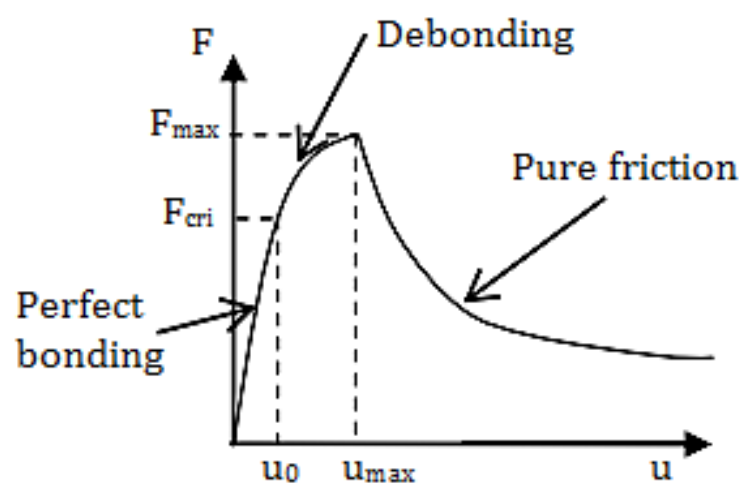

Fig.21. Pull-out curve [191].

The following assumptions are made in this model:

- The matrix is considered as a rigid non-deformable body and only the displacement of the yarn in the matrix is studied;

- The multi-filament yarn is considered as a single fiber so there is no shear between filaments. Only the bond between multi-filament yarn and cementitious matrix is studied;

- The materials of the yarn and the matrix are respectively homogeneous, isotropic and linearly elastic;

- The shear stress $\tau$ at the interface between yarn and matrix increases proportionally to the displacement $\mathrm{u}$ of the yarn $\tau=k_{1} u$ during the perfect bonding phase. It reaches its maximal value $\tau_{\max }$ at the onset of the debonding phase and then it decreases proportionally to the displacement $\mathrm{u}$ of the yarn $\tau=k_{2} u$ during the debonding phase. In the end, during the pure friction phase, it becomes constant $\tau_{0}$ along all length of the yarn. Fig.22 shows the shear stress versus displacement. $k_{1}$ and $k_{2}$ are the bond moduli corresponding respectively to the perfect bonding phase and the debonding phase. $\tau_{\max }$ and $\tau_{0}$ are bond parameters obtained from experimentation.

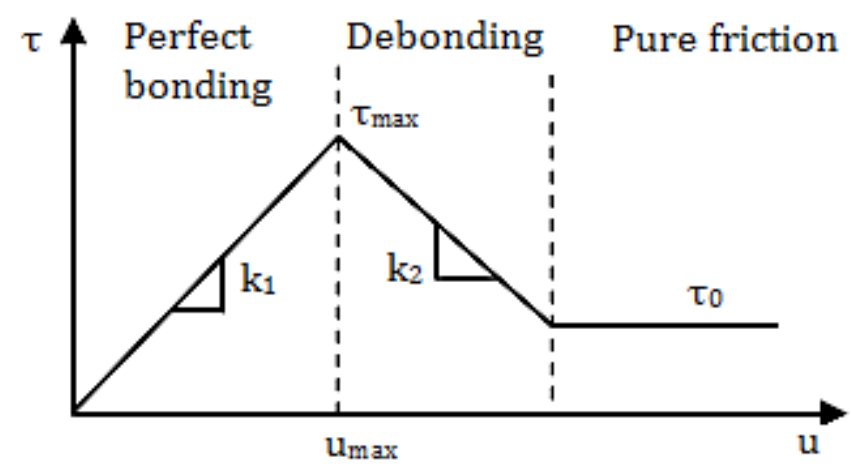

Fig.22. Shear stress versus displacement [191].

The establishment of the relationship between the pull-out displacement $u$ of a yarn and the pull-out force $F$ is based on the analysis of the stress $\tau$ and displacement $u$ of the yarn at the interface between yarn and matrix by considering different continuity conditions for each phase. A comparison of the analytical and experimental results showed that the 
experimental results are in good agreement with those obtained according to the analytical model developed.

\section{Microindentation test}

The micro-indentation test is the closest to reality as it uses a finished product that integrates the manufacturing parameters of the material. This test is widely used to determine the two mechanical properties of the fiber-matrix interface, the friction coefficient and the residual radial stress according to Ye and Kaw [207], as it enables the debonding force to be measured in situ on real composites (mainly unidirectional). The success of the tests is also closely linked to the quality of polishing of the samples tested; unsuitable polishing can prevent the correct identification of fibers and cause their preliminary embrittlement. Based on the measure of the debonding stress $\sigma_{d}$, the interfacial shear strength $\tau_{i}$, which is a rather complex function of $\sigma_{d}$, the elastic characteristics $G_{m}$ of the matrix and $E_{f}$ of the fiber, the diameter $d$ of the fiber and the interfiber distance can then be deduced [98-100].

\subsection{Modeling tests on organic matrix composites}

In general, most of the models representing the behavior of organic matrix composites during micro-indentation tests take into account not only the difference in the elastic properties of the fibers and the matrix but also the interfiber distance. Obviously, as the interface is chemically bonded, the first goal is to characterize this adhesion, associated with the debonding force found experimentally. As in pull out tests, two approaches can be taken, one considering an energy failure criterion and the other one a maximum stress criterion. In micro-indentation tests, the latter criterion is the most widely used; even if certain authors [208] note that the interfacial toughness is doubtless the parameter that is intrinsic to debonding (this type of analysis would allow a better description of the dependence of the debonding force on the radius of the indented fiber). Due to the complexity of the stress states engendered (in particular because of the contact between the indenter and the fiber), many studies $[209,210]$ use numerical methods, particularly finite element approaches. The push-through test, however, provides a very simple analysis.

\subsubsection{Push-through test: mean stress analysis}

The push-through test is to micro-indentation what the droplet test is to pull-out. The thinness of the samples used, coupled with the boundary conditions imposed on the fiber, mean that the interface can be stressed over its entire length, leading to complete debonding [211]. As in the droplet test, the test can be reasonably interpreted (in terms of the scatter of the results) by considering that the interfacial shear stress, $\tau$, is constant (Eq.34), i.e.:

$$
\tau=\frac{F_{d}}{2 \pi r L}
$$

Where $F_{d}$ is the debonding force, $r$ the radius of the fiber and $L$ is the sample thickness. While this approach is extremely simple, it nonetheless requires very particular samples (between 80 and $1300 \mu \mathrm{m}$ thickness for a glass/epoxy), which are very difficult to cut and 
polish. The push-through test is, therefore, an interesting alternative that allows a simple analysis of the results, but that raises considerable experimental problems.

\subsubsection{Classic configuration of the test: numerical studies}

Numerical methods are very powerful and enable a large number of experimental parameters to be taken into account, such as those related to fiber loading. They are considered to give very good approximations of the fields of stress and strain within the composites tested. A detailed numerical study is that conducted by Mandell et al. [210] using the finite element method. This study has the enormous advantage of having been conducted and presented so that its results can be applied to highly diverse geometries and materials.

\subsubsection{Finite element approach}

The geometry used by Mandell 1986 [210] is represented in Fig. 23. The indented fiber of diameter $D_{f}$ is surrounded by a thick matrix cylinder $T_{m}$, itself surrounded by a sheath of material possessing the average properties of the composite. The contact area between the punch and the fiber is characterized by its diameter $D_{\sigma}$, which is a fraction of the fiber diameter.

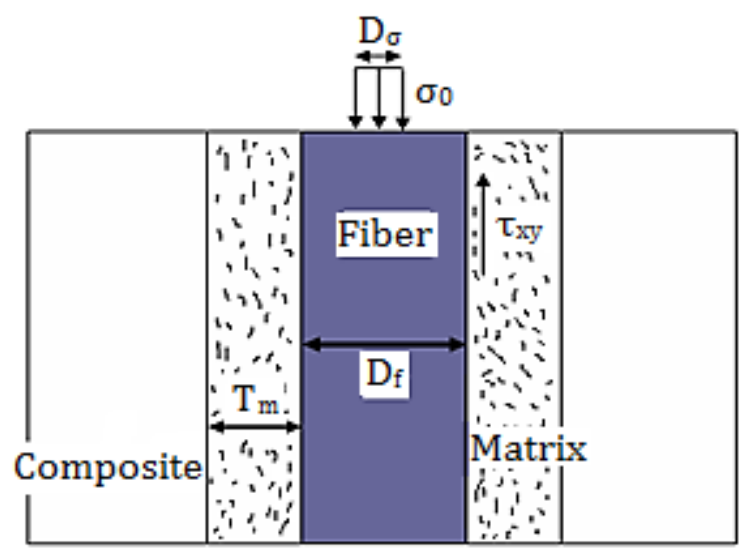

Fig.23. Geometry considered by Mandell 1986.

The authors conducted several sensitivity studies. Concerning the influence of the type of loading, they observed the influence of the diameter $D_{\sigma}$ of the contact zone on the value of the ratio of the interfacial shear stress, $\tau_{x y}$ and on the medium stress applied to the fiber (Eq.35).

$\sigma_{m}=\frac{4 F}{\pi D_{f}^{2}}=\sigma_{0} \frac{D_{\sigma}^{2}}{D_{f}^{2}}$

Where $F$ if the applied load, and $\sigma_{0}$, the stress at the summit of the fiber.

The authors assessed this effect in the case of a glass/epoxy material, and showed that while the location of the maximum shear stress along the interface depends on the extent 
of the contact zone; its value is practically unchanged. This means that the real contact area can be neglected and that only the medium stress $\sigma_{m}$ (Eq.35) needs to be taken into account.

\subsubsection{Boundary elements approach}

Chen and Young 1991 [212] used the same geometry and the same approach as the previous study; only the numerical method varied, as they proposed an integral method using not finite elements but boundary elements. This technique allows a better evaluation of interfacial stress fields, since the finite element method gives only an approximate solution (finite element stress values are calculated in fact not in the interface but on the mesh elements bordering it).

To conclude this part, it should be mentioned that numerical methods, although very efficient, require heavy investment, since they require the acquisition (or development) of a suitable calculation code, and perfect knowledge of the code in order to interpret the results critically (and detect, in particular, inadequacies in the code itself). Unfortunately, such studies are often reported in the literature as "black boxes": they deliver a lot of information, but the conditions in which the information was obtained are not made explicit (boundary conditions, geometric information, values of the constants used, etc.). Their validity is therefore difficult to assess.

\subsubsection{Large-Toumi Model}

In this model Large-Toumi et al. developed an analytical approach that is simpler to implement that in the numerical method, and which allows a more direct interpretation of the physical phenomena believed to take place during the tests $[\mathbf{9 7}, \mathbf{2 1 3}]$. The model was based on the work of Piggott, 1980 (in turn influenced by previous work by Greszczuk, 1969), which already took into account the effect of inter-fiber distance but in a configuration of global tension of the composite specimen. Piggott's model was modified by introducing loading conditions and boundary conditions representative of the test conditions. They considered a perfect hexagonal arrangement of fibers and introduced the notion of an equivalent radius, $R_{e q}$, to reduce the initial geometry to an equivalent one (Fig.24) (The introduced geometry is an axisymmetric model formed of concentric cylinders). 


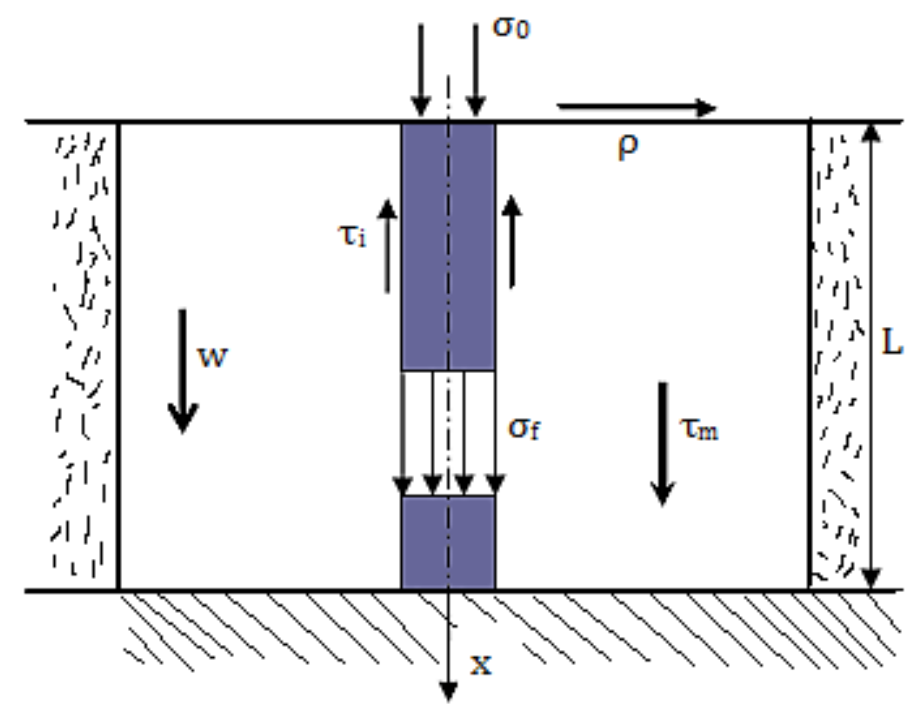

Fig.24. Equivalent geometry (section)

The equivalent radius is defined by: $\pi R_{e q}{ }^{2}-\pi r^{2}=A$

Where $r$ is the fiber radius and $A$ is the matrix area contained in the circle of radius $R$.

It is assumed that the longitudinal displacement is zero at the "equivalent" fiber/matrix interface (at a distance $R_{e q}$ ) since tests showed that the bordering fibers did not move and that the interfaces were not damaged. Using Piggott's approach, this leads to the differential equation (Eq.36):

$\frac{d^{2} \sigma_{f}}{d x^{2}}=\frac{n^{2}}{r^{2}} \sigma_{f}$

Where

$$
n^{2}=\frac{2 G_{m}}{E_{f} \operatorname{Ln}\left(\frac{R_{e q}}{r}\right)}
$$

$\sigma_{f}$ is the fiber longitudinal stress, $E_{f}$ the fiber Young's modulus and $G_{m}$ the matrix shear modulus. The solution is done from Eq.37.

$$
\sigma_{f}=\operatorname{Bsh}(n x / r)+\operatorname{Dch}(n x / r)
$$

With sh and ch refer respectively to the sinus and cosinus hyperbolic function.

To write the boundary conditions, it is assumed first that $\sigma_{f}$ is homogeneous on a section of fiber (even on the upper surface) and second that $L>>R$, where $L$ is the thickness of the sample. We obtain at $x=0, \sigma_{f}=\sigma_{0}=-F / \pi r^{2}$ and at $x=L, \sigma_{f}=0$. Thus (Eq.38):

$$
\sigma_{f}=-\sigma_{0}\left[\operatorname{ch}\left(\frac{n x}{r}\right)-\operatorname{coth}\left(\frac{n L}{r}\right) \operatorname{sh}\left(\frac{n x}{r}\right)\right]
$$


If $\tau_{i}$ is the interfacial shear stress, then the equilibrium force on a fiber section leads to

Eq.39.

$\tau_{i}=-\frac{r}{2} \frac{d \sigma}{d x}$

This gives (Eq.40).

$\tau_{i}=\frac{n \sigma_{0}}{2}\left[\operatorname{sh}\left(\frac{n x}{r}\right)-\operatorname{coth}\left(\frac{n L}{r}\right) \operatorname{ch}\left(\frac{n x}{r}\right)\right]$

$\tau_{i}$ is maximum at $x=0$ and $\tau_{\text {imax }}=\frac{n \sigma_{0}}{2} \operatorname{coth}\left(\frac{n L}{r}\right)$ and as $L / r \rightarrow \infty: \tau_{\text {imax }}=\frac{n \sigma_{0}}{2}$ (indeed, experimentally $L=1 \mathrm{~cm}$ and $R=10 \mu \mathrm{m})$.

Then, for $F=F_{d}, \tau_{\text {imax }}=\tau_{i}$, where $\tau_{i}$ is the interfacial shear strength (Eq.41); thus:

$$
\tau_{i}=\frac{F_{d}}{2 \pi r^{2}} \sqrt{\frac{2 G_{m}}{E_{f} \operatorname{Ln}\left(\frac{R_{e q}}{r}\right)}}
$$

\section{Determination of $\mathbf{R}_{\mathrm{eq}}$ :}

The real neighborhood of a fiber is different from the idealized case: the nearest fibers are positioned at various distances and generally, they do not have the same diameter. The tests performed induce only a partial debonding of each indented fiber; this means that the model presented above can be applied. The equivalent radius, $R_{e q}$, is then defined (Eq.42):

$\frac{\theta R_{e q}^{2}}{2}=\frac{\theta r^{2}}{2}+A_{m} \quad$ or by $\quad \frac{\theta R_{e q}^{2}}{2}=\frac{\theta R^{2}}{2}-A_{f}$

$A_{m}$ (resp. $A f$ ) is the area of matrix (resp. of fiber) included in the sector of angle $\theta$ and radius $R$ (Fig.25). $A_{f}$ is approximated by (Eq.43):

$$
A_{f}=\frac{(\pi-\theta) c^{2}}{2}+c R\left(1-\cos \left(\frac{\theta}{2}\right)\right)
$$

So :

$$
R_{e q}^{2}=R^{2}+c^{2}-\frac{2 c R}{\theta}\left(1-\cos \left(\frac{\theta}{2}\right)\right) \quad \text { where } \theta=2 \operatorname{Arcsin}\left(\frac{c}{R}\right)
$$




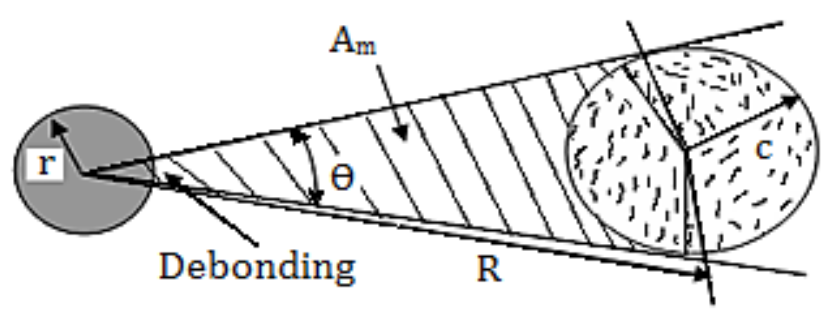

Fig.25. Local determination of the equivalent radius

\section{Discussion: validity of different models}

Frist of all, analytical models described in this review consider the matrix as a homogeneous structure with a well-defined interface. It is well known that a significant heterogeneous area can be presented at the vicinity of the fibers.

This assumption can be explained by the difficulty to characterize and analyze the vicinity of the fiber and the interphase area. Indeed, the experimental method micro/nanoscale limit the investigation of its areas at the initial state and during ageing. Due to a complex interaction between with chemical and physical phenomena, the mechanical behavior of the interphase can be highly modified (as example, local plasticity, local viscoelasticity....).

Moreover, the aim of the analytical representation is to proposed an approached solution of the real solution. In this case, the homogenous representation of the matrix can be proposed especially at the initial state. As example, Riano et al. [214] have shown that an error around $15 \%$ about the Young's modulus is calculated when the interphase is not taken into account in the numerical model. Similar results have been presented in the literature with the kinetic water diffusion [132] and stress at break [215-217].

\subsection{Calculation of an interfacial characteristic}

The results calculated with the various analytical models presented previously, which give the characteristic parameters of the interface, $G_{i}$ the interfacial failure energy, and $\tau_{i}$, the interfacial shear strength, are given in Table 1 for four materials were chosen to highlight the role of fiber / matrix interface. The materials have the same reinforcement fiber, T300-6K from Toray, and the same epoxy matrix, DGEBA/DDM, LY1808RF/HT972 from Ciba-Geigy, with a formulation very close to the system LY556/HT972).

The composite plates were made by stacking unidirectional layers (14 plies) and autoclave curing. Both cycles of curing are: A long said cycle containing a post-curing supposed to lead to a total crosslinking of network and an industrial cycle, said short, Says court, without post-curing, not that must produce that an incomplete crosslinking (slight sub-crosslinking). The sizings used for the manufacture of these materials are Toray Commercial sizings 4 and 5, with the sizing 5, which is the standard sizing T300 fibers, is an sizing compatible epoxy and polyester while the sizing 4 is only epoxy Compatible.

These four systems used in the analysis of different analytical models as well as the nomenclature used for designers are: 
S: Standard- denotes the reference material, T300-6K-50B fiber (oxidized fiber, sizing 5) long cycle of curing;

SR: Under crosslinked- indicate the material in which the matrix has a density of weaker crosslinking, T300-6K-50B fiber (oxidized fiber, sizing 5) short curing cycle;

ENS: sizing- indicate the material for which the sizing has been modified, T300-6K-40D fiber (oxidized fiber, sizing 4) long cycle of curing;

NO: Oxidized No-indicate the material for which the fiber has not undergone a treatment of oxidation, T300-6K-59A fiber (unoxidized fiber, sizing 5) long cycle of curing.

Table 1: Evaluation $G_{i}$ and $\tau_{i}$ by various models

\begin{tabular}{c|c|c|c|c|c|}
\hline Material & $\begin{array}{c}G_{i} \text { (Piggott) } \\
\mathbf{J} / \mathbf{m}^{2}\end{array}$ & $\begin{array}{c}G_{i} \text { (Penn) } \\
\mathbf{J} / \mathbf{m}^{2}\end{array}$ & $\begin{array}{c}G_{i} \text { (Palley) } \\
\mathbf{J} / \mathbf{m}^{2}\end{array}$ & $\begin{array}{c}\boldsymbol{\tau}_{\boldsymbol{i}} \text { (Medium) } \\
\mathbf{M P a}\end{array}$ & $\begin{array}{c}\boldsymbol{\tau}_{\boldsymbol{i}} \text { (B.L .T) } \\
\mathbf{M P a}\end{array}$ \\
\hline $\begin{array}{c}\text { S (Reference } \\
\text { system) }\end{array}$ & $\begin{array}{c}15 \pm 5 \\
(36 \%)\end{array}$ & $\begin{array}{c}21 \pm 10 \\
(47 \%)\end{array}$ & $\begin{array}{c}54 \pm 14 \\
(27 \%)\end{array}$ & $\begin{array}{c}72 \pm 8 \\
(12 \%)\end{array}$ & $\begin{array}{c}230 \pm 25 \\
(11 \%)\end{array}$ \\
\hline $\begin{array}{c}\text { SR (no } \\
\text { oxidation) }\end{array}$ & $15 \pm 4$ & $22 \pm 9$ & $51 \pm 12$ & $70 \pm 7$ & $215 \pm 21$ \\
\hline $\begin{array}{c}\text { ENS } \\
\text { (different }\end{array}$ & $15 \%)$ & $(39 \%)$ & $(24 \%)$ & $(10 \%)$ & $(10 \%)$ \\
\hline sizing) & $(58 \%)$ & $(74 \%)$ & $(28 \%)$ & $(13 \%)$ & $(13 \%)$ \\
\hline $\begin{array}{c}\text { No (sub- } \\
\text { crosslinking) }\end{array}$ & $11 \pm 5$ & $15 \pm 9$ & $38 \pm 16$ & $60 \pm 11$ & $190 \pm 39$ \\
\hline
\end{tabular}

It appears from the study of this table that:

- The NO material has, in all cases, a significant dispersion due to experimental scatter related to the material structure (in all likelihood, poorer homogeneity of the surface properties of unoxidized fibers);

- The energy models of Piggott and Penn lead to highly scattered results;

- The two models that evaluate the interfacial strength $\tau_{i}$, lead to reasonable scatter, which may indicate a good description of the experimental results;

- In general, the orders of magnitude of the different values of $\tau_{i}$ (or $G_{i}$ ) obtained by the different models are not comparable; this partly explains the wide range of values that can be found in the literature concerning the same types of materials, in addition to problems associated with experimental techniques and the precise definition of the materials studied.

The study of the results shows that the models of Piggott and Penn do not reflect the real dependence of $F_{d}$ (debonding force) on the droplet diameter. This is understandable, 
given the test configurations chosen by the authors, which are relatively remote from the conditions imposed by the other models.

The models of Palley, mean stress and Large-Toumi take this dependence into account for the various materials. These three models are thus better adapted to the description of the tests, but in the range of the droplet diameters tested. However, this analysis does not really distinguish which of the three approaches is the most adequate.

\subsection{Comparison of the different results}

The interfacial failure energy values obtained by the model of Palley are the same order of magnitude as the results reported in the literature on carbon fiber composites (for example, $G_{i}=40 \mathrm{~J} / \mathrm{m}^{2}$, the value obtained by Piggott (1986) in pull out tests, the configuration the best adapted to Piggott's model), suggesting that the interfaces of the materials studied by Large-Toumi have a high failure energy for a carbon/epoxy composite (glass/epoxy having interfacial energies between 50 and $150 \mathrm{~J} / \mathrm{m}^{2}$ ). These values remain well below that measured on pure resin.

The gap between the interfacial strength estimated by the Large-Toumi and mean stress models assumes a constant stress profile along the interface, which is not absolutely unrealistic, (cf. the Raman spectroscopy studies or the finite element studies in pull out tests). The Large-Toumi model calculates the maximum of the shear stress, which is necessarily greater than $\tau_{i}$ (average) since:

$$
\begin{aligned}
& \frac{1}{L} \int_{-L}^{0} \tau_{i}(\text { B.L.T. })(x) d x=\frac{1}{L} \int_{-L}^{0} \frac{-F \alpha}{2 \pi r[\operatorname{ch}(\alpha L)-1]} \operatorname{sh}[\alpha(x+L)] d x=\frac{-F[\operatorname{ch}(\alpha(x+L))]_{-L}^{0}}{2 \pi r L[\operatorname{ch}(\alpha L)-1]} \\
& \frac{1}{L} \int_{-L}^{0} \tau_{i}(\text { B.L.T. })(x) d x=\frac{-F}{2 \pi r L}=\tau_{i}(\text { average })
\end{aligned}
$$

The mean stress model simply evaluates the average value of the interfacial stress at the time of debonding, whereas the Large-Toumi model proposes an a priori evaluation that is more realistic of the interfacial strength.

Table 2 summarizes the results obtained in pull out tests or in droplet tests on carbon / epoxy composites. The classification is based on the type of modeling used since we saw that this had a significant impact on the magnitude of the results. It is difficult to make a global comparison of these results, however, because from one study to another not only the test configurations but also the materials and models used change. 
Table 2: Synthesis of results obtained in droplet and pull out tests of carbon fiber / epoxy resin composites based on the type of modeling used.

\begin{tabular}{|c|c|c|c|c|c|}
\hline Type of analysis & authors & $\begin{array}{c}\text { Test } \\
\text { Configuration }\end{array}$ & $\begin{array}{l}\text { Material (fiber } \\
\text { / resin) (1) }\end{array}$ & $\begin{array}{l}\text { Fiber } \\
\text { Type }_{(2)}\end{array}$ & $\begin{array}{c}\tau_{i} \\
(\mathrm{MPa})\end{array}$ \\
\hline \multirow{4}{*}{$\begin{array}{c}\text { Average stress } \\
\tau_{i}=F_{d} / 2 \pi r L\end{array}$} & $\begin{array}{l}\text { Favre, } \\
\text { Perrin } \\
(1972)\end{array}$ & Pull-out & $\begin{array}{l}\text { Courtauld } \\
\text { HTS/epoxy } \\
\text { HM/epoxy }\end{array}$ & $\begin{array}{l}\text { HTS } \\
\text { HM }\end{array}$ & $\begin{array}{l}57 \\
5,5\end{array}$ \\
\hline & $\begin{array}{l}\text { Piggott } \\
\text { (1985) }\end{array}$ & Pull-out & $\begin{array}{l}\text { Herculès } \\
\text { AS1/epoxy }\end{array}$ & $\mathrm{HM}$ & 56 \\
\hline & $\begin{array}{l}\text { Herrera- } \\
\text { Franco, } \\
\text { Drzal } \\
(1992)\end{array}$ & Droplet & $\begin{array}{c}\text { Herculès } \\
\text { AU4/828 } \\
\text { AS4/828 }\end{array}$ & $\begin{array}{c}\text { HT } \\
\text { N.O. } \\
\text { O. }\end{array}$ & $\begin{array}{l}23 \\
50\end{array}$ \\
\hline & $\begin{array}{l}\text { Large- } \\
\text { Toumi }\end{array}$ & Droplet & $\begin{array}{c}\text { Toray } \\
\text { T330-59/epoxy } \\
\text { T330-50/epoxy }\end{array}$ & $\begin{array}{c}\text { HT } \\
\text { N.O. } \\
\text { O. }\end{array}$ & $\begin{array}{l}60 \\
72\end{array}$ \\
\hline \multirow{3}{*}{$\begin{array}{c}\text { Greszczuk (3) } \\
\begin{aligned} \tau_{i}= & \tau^{\prime} \alpha L / t h(\alpha L) \\
& \text { With } \\
\tau^{\prime}= & F_{d} /(2 \pi r L)\end{aligned}\end{array}$} & $\begin{array}{c}\text { Barbier et } \\
\text { al. } \\
(1989)\end{array}$ & Pull-out & $\begin{array}{l}\text { Courtauld } \\
\text { XAU/5208 } \\
\text { XAS/5208 }\end{array}$ & $\begin{array}{l}\text { HTS } \\
\text { N.O. } \\
\text { O. }\end{array}$ & $\begin{array}{l}88,5 \\
125\end{array}$ \\
\hline & $\begin{array}{l}\text { Désarmot, } \\
\text { Sanchez } \\
\text { (1984) }\end{array}$ & Pull-out & $\begin{array}{l}\text { Courtauld } \\
\text { HT/LY556 } \\
\text { Toray } \\
\text { T300/LY556 }\end{array}$ & $\begin{array}{l}\text { HT } \\
\text { N.O. } \\
\text { O. } \\
\text { HT N.E. } \\
\text { N.O. } \\
\text { O. }\end{array}$ & $\begin{array}{l}20 \\
70 \\
50 \\
60\end{array}$ \\
\hline & $\begin{array}{l}\text { Guigon, } \\
\text { Klinklin } \\
\text { (1993) }\end{array}$ & Pull-out & $\begin{array}{c}\text { Toray } \\
\text { T300 /5208 }\end{array}$ & $\begin{array}{c}\text { HT N.E. } \\
\text { N.O. } \\
\text { O }\end{array}$ & $\begin{array}{l}133 \\
150\end{array}$ \\
\hline Large-Toumi & $\begin{array}{l}\text { Large- } \\
\text { Toumi }\end{array}$ & Droplet & $\begin{array}{c}\text { Toray } \\
\text { T330-59/epoxy } \\
\text { T330-50/epoxy }\end{array}$ & $\begin{array}{c}\text { HT } \\
\text { N.O. } \\
\text { O. }\end{array}$ & $\begin{array}{l}190 \\
230\end{array}$ \\
\hline \multicolumn{6}{|c|}{$\begin{array}{l}\text { (1) The resins used are epoxy resins, designated by their commercial name when known. LY556 and } \\
\text { MY750 come from Ciba, } 828 \text { from Shell and } 5208 \text { from Narmco. } \\
\text { (2) The fibers are generally oxidized and sized unless otherwise stated; N.O.: unoxidized; N.E: unsized; } \\
\text { HT and HTS: high strength fibers; HM: high modulus fiber; } \\
\text { (3) The expression of parameter } \alpha \text { varies among the authors, but it still depends on the Young's modulus } \\
\text { of the fiber, the matrix shear modulus, the fiber radius and the matrix radius. }\end{array}$} \\
\hline
\end{tabular}

If we look at all the results for a given method of calculation, the T300 (Toray) fiber / epoxy resin system has a high interfacial strength, as already noted by Favre and Perrin (1972), who were unable to test this system because its adhesion was too strong (leading to tensile failure of the filament). This system has a higher strength than that obtained with HTS fibers from Courtauld (XAU XAS). The same classification can be seen in the pullout tests of Désarmot and Sanchez (or Guigon and Barbier, who both used the same modeling). Désarmot and Sanchez tested unsized T300 fibers (T300 90A), which have lower adhesion properties than the fibers used in the study by Large-Toumi; the strengths obtained with unsized fibers (60MPa) are comparable to those of the Courtauld fibers (70 $\mathrm{MPa})$. 
The values obtained in the study by Désarmot and Sanchez contrast with those of Guigon on the one hand and Barbier on the other. The use of a different resin cannot explain such a discrepancy (a two- or three-fold difference, sets of values), which is probably due to the modeling used. The values obtained by Guigon on unsized T300 fiber can be considered as a lower bound compared to the material characteristics studied by LargeToumi, which is not contradicted by the latter's results.

Note: In all which precedes, the authors did not evoke the phenomenon of plasticization some resin or interface, possible phenomenon seen the constraint levels undergone, this for two reasons, Firstly, the epoxy resin used is of brittle type, which makes this phenomenon very limited; secondly, the examination of the fracture facies in MEB indicates the existence of frank fractures in the level of the droplet, For which we do not distinguish a track of resin residual on the fiber: the facies are reflect of ruptures localized with the interface, without trace of plasticization.

Let us notice all the same that the hypotheses of linear elasticity formulated in most of the calculations (analytical and numerical) are likely limitative, even in the case of an epoxy resin; indeed, although his behavior can be considered elastic, it has marked nonlinearity, in particular for deformations close to the fracture strain.

\subsection{Interpretations}

Whatever the model chosen, the classification of the materials S, SR, ENS and NO in terms of fracture energy or interfacial strength remains identical and can be summarized by:

$$
N O \leq S R \leq S<E N S
$$

This classification is also highlighted in Fig.26, which also shows the scatter. The three models used thus propose the same relative assessment for the different materials; from this point of view, the average stress analysis is quite acceptable, and enables the various fiber resin systems to be compared. It should, however, be borne in mind that the $\tau_{i}$ parameter (average) delivered in such an approach is not the interfacial strength of the tested system, but only the average value of the shear stress at the time of failure; this value nevertheless enables a comparative analysis of materials. 

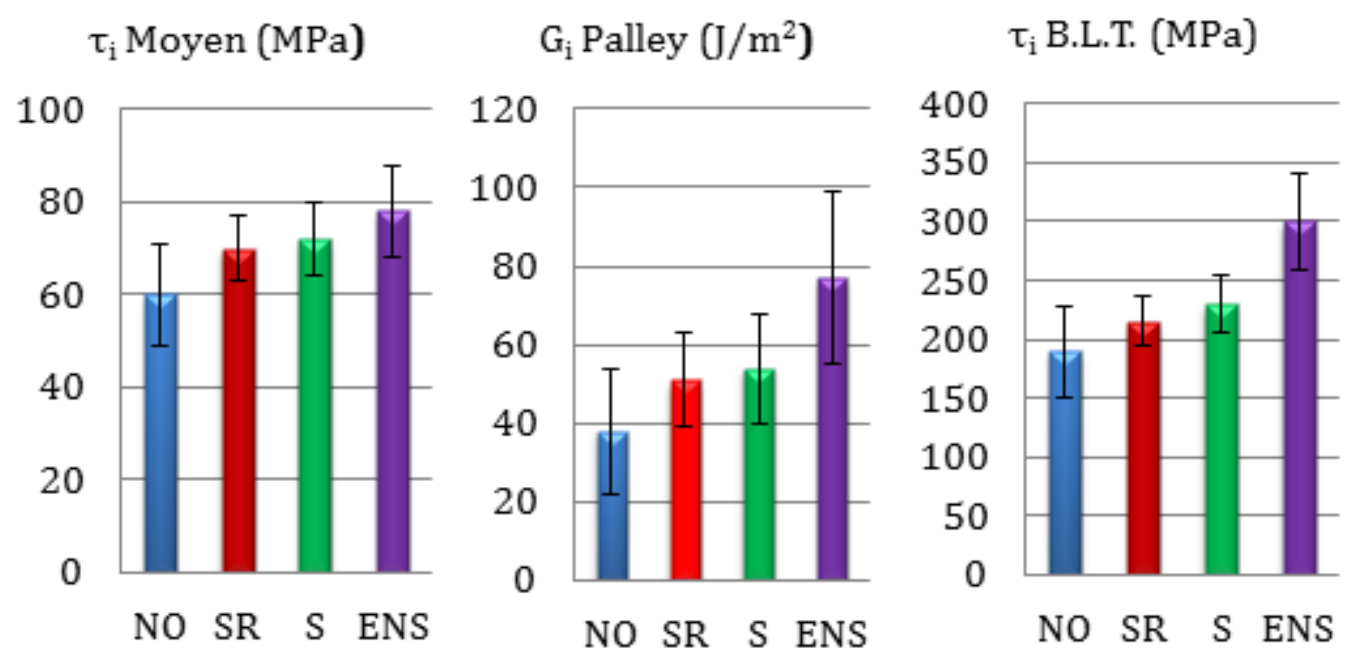

Fig.26. Value and dispersion of interfacial characteristics calculated by the models of mean stress, Palley and B.L.T.

The studies realized in the test of droplet proved that this test is a discriminating test, adapted to the characterization of the interface in carbon / epoxy systems. From a point of view material, these test there shown that:

- The industrial curing cycle used for the SR material leads to an interfacial resistance equivalent to that of a completely crosslinked material (material S);

- The epoxy-specific sizing (4) insures higher interfacial shear strength than the standard sizing (5);

- The oxidation treatment of the fibers increases the interfacial resistance and decreases the dispersions of the results (homogenization of the properties of the fibers by probable decrease in the number of surface defects).

The analysis of the different results obtained in the different studies showed that the optimal interface is not the one with the highest characteristics. Moreover, each system fiber/matrix considered has its own values of optimal interfacial properties, this one being related to the properties of the fiber and the matrix, at last, for a given system, there is not a single optimal interface; the study of each property of the composite (for example, ILSS, fatigue strength, property at rupture) can lead to the definition of an optimal interface each time.

\section{Conclusion}

An overview of some of the analytical models available to characterize the fiber/matrix interfacial area is proposed in this paper. Various analytical forms have been presented, but these forms differ from the boundary conditions applied and the presence of various factors that are not included in the analysis. We have seen that the complete modeling (i.e. taking into account radial effects and/or residual stresses as example) of this test is, from a mechanical point of view, a complex and as yet unresolved problem. Nevertheless, it appears that a simple approach that only evaluates an average shear stress at the interface 
proves acceptable and representative of the quality of the fiber/matrix bond. We obtain thereby a good relative assessment of the interfacial properties. The pull-out (droplet) test, associated with this kind of modeling, then becomes a fairly easy to use and effective tool.

Of course, the problem of an absolute determination of the interfacial characteristics remains unsolved. Concerning the precise evaluation of the stress state during the test, Raman spectroscopy studies provide a wealth of information. The results of these tests may be considered as a reference, in particular for readjusting procedures addressed by the finite element method. Meanwhile, numerical studies (finite element or other approaches) should make it possible to investigate the influence of "loading parameters" (e.g., position and shapes of blades). These studies generally give access to very valuable information on the constraints and in particular on radial constraints, which Raman spectroscopy cannot do.

The real mastery of the pull-out (droplet) test thus necessarily involves a thorough mechanical analysis, combined with a good knowledge of the behavior of the tested material (plasticity, etc.). This is not specific to this test but highly characteristic of all micromechanical techniques, all of which tend to use simple assumptions. We now know that the stress state is a complex mixture of tensile and shear stress. In this case, what failure criterion should we choose? It appears necessary to introduce a more elaborate criterion than the criterion of a maximum stress fracture. The choice of an adapted criterion of break requires a study in oneself, both the possibilities are numerous and the fundamental problem. If a coupled criterion is considered, it can be noted that the apparent resistance in shear, evaluated by simpler models, can, depending on the state of the radial stresses, be remote enough away from its real value, in pull-out. A coupled criterion does not introduce any more one but at least two unknowns, who could be determined only by mastering at the same time the longitudinal and radial stresses, the latter depend on residual stresses of curing existing in the composite sample.

It is clear that any interpretation of the pull-out (droplet) test and of micromechanical tests in terms of absolute interfacial characteristics must take into account the effect of radial stresses. This doubtless limits the possibilities of analytical resolution and favors the use of numerical methods. Alongside this mathematical aspect, two crucial problems will then have to be addressed:

- Determination of the failure criterion;

- Knowledge of residual stresses in model composites and in real composites.

\section{References}

[1] Wu, Q., Li, M., Gu, Y., Li, Y., Zhang, Z., 2014. Nano-analysis on the structure and chemical composition of the interphase region in carbon fiber composite. Compos. Part A Appl. Sci. Manuf. $56,143-149$.

[2] Drzal, L.T., Rich, M.J. and Lloyd, P.F. (1983). Adhesion of graphite fibers to epoxy matrices, part I. The role of fiber surface treatment. J. Adhesion 16, 1-30.

[3] Sottos, N.R., McCullough, R.L., Scott, W.R., 1992. The influence of interphase regions on local thermal displacements in composites. Compos. Sci. Technol. 44 (4), 319-332. 
[4] Metcalfe, A.G. (1974). Interfaces in metal matrix composites. Composite Materials Series Volume I. (A.G. Metcalfe ed.), Academic Press, New York, pp. 65-123.

[5] Atkins, A.G., 1975. Intermittent bonding for high toughness/high strength composites. J. Mater. Sci. 10 (5), 819-832.

[6] Hughes, J., 1991. The carbon fibre/epoxy interface-a review. Compos. Sci.Technol. 41 (1), 1345.

[7] Naslain, R.R., 1998. The design of the fibre-matrix interfacial zone in ceramic matrix composites. Compos. Part A Appl. Sci. Manuf. 29 (9), 1145-1155.

[8] Gao, S.L., Mäder, E., 2002. Characterisation of interphase nanoscale property variations in glass fibre reinforced polypropylene and epoxy resin composites. Compos. Part A Appl. Sci. Manuf. 33 (4), 559-576.

[9] Liu, L., Song, Y., Fu, H., Jiang, Z., Zhang, X., Wu, L., et al., 2008. The effect of interphase modification on carbon fiber/polyarylacetylene resin composites. Appl. Surf. Sci. 254 (17), 53425347.

[10] J.K. Kim \& Y.W. Mai, High Strength, High Fracture Toughness Fibre Composites with Interface Control A Review, Composites Science and Technology 1991; 41: 333-378.

[11] Drzal L.T., Madhukar $M$ «Fibre-matrix adhesion and its relationship to composite mechanical properties» Journal of Materials Science 1993; 28: 569-610.

[12] Kim, J.K. and Mai, Y.W. (1993). Interfaces in composites. In Structure and Properties of Fiber Composites, Materials Science and Technology, Series Vol. 13 (T.W. Chou ed.) Ch. 6, VCH Publication, Weinheim, Germany, pp. 239-289.

[13] M. R. Piggott « Why interface testing by single-fibre methods can be misleading» Composites Science and Technology 1997; 51: 965-974.

[14] Favre J P, Merienne M C. «Characterization of fibre/ resin bonding in composites using a pullout test » International Journal of Adhesion and Adhesives, 1981; 1: 311-316.

[15] Penn L S, Lee S M. «Interpretation of the force trace for Kevlar/epoxy single filament pull-out tests» [J]. Fibre Science and Technology, 1982; 17(2): 91-97.

[16] Gaur U, Miller B. «Microbond method for determination of the shear strength of a fiber/resin interface: evaluation of experimental parameters» [J]. Composites Science and Technology, 1989; 34(1): 35-51.

[17] Day R J, Cauich Rodriges J V. « Investigation of the micromechanics of the microbond test» [J]. Composites Science and Technology, 1998; 58(6): 907-914.

[18] Mandell, J. F. Chen, J. H. and McGarry, F. J., «A Microdebonding Test for in Situ Assessment of Fibre/Matrix Bond Strength in Composite Materials» International Journal of Adhesion and Adhesives 1980; vol. 1, No. 1, pp. 40-44.

[19] Ho H, Drzal L T. «Evaluation of interfacial mechanical properties of fiber reinforced composites using the microindentation method »[J]. Composites Part A: Applied Science Manufacturing, 1996; 27(10): 961-971.

[20] Herrera-Franco P J, Rao V, Drazal L T, et al. «Bond strength measurement in composites analysis of experimental techniques » [J]. Compos Engineering, 1992; 2(1): 31-45.

[21] Wagner H D, Gallis H E, Wiesel E. «Study of the interface in Kevlar 49-epoxy composites by means of microbond and fragmentation tests: effects of materials and testing variables» [J]. Journal of Materials Science, 1993; 28(8): 2238-2244.

[22] Zhandarov, S. F. and Pisanova, E. V., «The Local Bond Strength and Its Determination by Fragmentation and Pull-out Tests» Composites Science and Technology 1997; 57: 957-964.

[23] Kim, J.K., Mai, Y.W., 1998. Engineered Interfaces in Fiber Reinforced Composites. Elsevier Science. 
[24] Jiang Xiaoyu, Kong Xiangan, Micro-mechanical characteristics of fiber/matrix interface in composite materials, Composites Science and Technology 59(1999) 635-642.

[25] Drzal L. T. the Interphase in Epoxy Composites , Advances in Polymer Science, Editor: K. Dušek 1986; vol.75: pp 1-32.

[26] M.R. Piggott, The Effect of the Interface/interphase on Fiber Composite Properties, polymer Composites, October 1987, Volume 8, Issue 5, pages 291-297, (Version of Record online: 30 AUG 2004).

[27] J. K. Kim, L. Zhou, Y.W. Mai / Stress transfer in the fiber fragmentation test- Part I An improved analysis based on a shear strength criterion/ Journal of Materials Science 1993; 28: 6233-6245.

[28] J. K. Kim, Y.W. Mai, Stress transfer in the fiber fragmentation test- Part II Multiple fiber composites, Journal of Materials Science 1995; 30: 3024-3032.

[29] Cox, H.L., J. « The elasticity and strength of paper and other fibrous materials» British Journal of Applied Physics. March 1952; Vol. 3, Issue 3: p. 72.

[30] Rosen, B.W. (1964). Tensile failure of fibrous composites. AIAA J. 2, 1985-1991.

[31] Kelly A., Tyson W.R., «Tensile properties of fiber-reinforced metals: copper/tungsten and copper/molybdenum», Journal of Mechanical Physics and Solids 1965; 13: pp 329-350.

[32] Scolar, D.A. (1974). In Interfaces in Polymer Matrix Composites, Composite Materials, Vol. 6 (E.P. Plueddemann ed.), Academic Press, New York, pp. 217-284.

[33] Wake, W.C. (1978). Theories of adhesion and uses of adhesives: A review. Polymer 19, 291308.

[34] Kinloch, A.J. (1980). Review - The science of adhesion, part 1, surface and interfacial aspects. J. Mater. Sci. 15, 2141-2166.

[35] Kinloch, A.J. (1982). Review - The science of adhesion, part 2, mechanics and mechanisms of failure. J. Mater. Sei. 17, 617-651.

[36] Hull, D. (1981). An Introduction to Composite Materials, Cambridge University Press, Cambridge, pp. 36-58.

[37] Adamson, A.W. (1982). In Physical Chemistry of Surfaces, 4th Edition, John Wiley and Sons, New York, pp. 294-318, 332-268.

[38] Naslain, R. (1993). Fiber-matrix interphase and interfaces in ceramic matrix composites processes by CVI. Composite Interfaces 1, 253-286.

[39] Maso, J.C. (1993). Interfaces in Cementitious Composites, E \&FN Spon, London \&New York.

[40] Cotterell, B. and Mai, Y.W. (1996). Fracture Mechanics of Cementitious Materials, Blackie Academic and Professional, London, UK.

[41] Ramanathan, T., Bismarck, A., Schultz, E. and Subramanian, K. «Investigation of the Influence of Acidic and Basic Surface Groups on Carbon Fibres on the Interfacial Shear Strength in an Epoxy Matrix by Means of Single-Fibre Pull-Out Test», Composite Science and Technology 2001; 61: 599-605.

[42] Drzal, L. T., Sugiura, N. and Hook, D., 'The Role of Chemical Bonding and Surface Topography in Adhesion between Carbon Fibers and Epoxy Matrices', Composite Interfaces 4, 1997, 337-354.

[43] Jacobasch, H. J., Grundke, K., Uhlmann, P., Simon, F. and Mäder, E., 'Comparison of SurfaceChemical Methods for Characterizing Fiber-Epoxy Resin Composites', Composite Interfaces 3, 1996, 293-320.

[44] Liu, F. P., Wolcott, M. P., Gardner, D. J. and Rials, T. G., 'Characterization of the Interface between Cellulosic Fibers and a Thermoplastic Matrix', Composite Interfaces 2, 1994, 419-432.

[45] Nardin , M., Asloun, E. M. and Schultz, J., 'Physico-Chemical Interactions between Carbon Fibers and PEEK', in Controlled Interfaces in Composite Materials, H. Ishida (ed.), Elsevier, New York, 1990, pp. 285-293. 
[46] Nardin, M. and Schultz, J., 'Relationship between Fibre-Matrix Adhesion and the Interfacial Shear Strength in Polymer-Based Composites', Composite Interfaces 1, 1993, 172-192. [47] Nardin, M. and Schultz J., 'Relations between Work of Adhesion and Equilibrium Interatomic Distance at the Interface', Langmuir 12, 1996, 4238-4242.

[48] Pisanova, E., and Mader, E., 'Acid-Base Interactions and Covalent Bonding at a Fiber-Matrix Interface: Contribution to the Work of Adhesion and Measured Adhesion Strength', Journal of Adhesion Science Technol. 14(3), 2000, 415-436.

[49] Shen, W. and Parker, I. H., 'Surface Composition and Surface Energetics of Various Eucalypt Pulps', Cellulose 6, 1999, 41-55.

[50] Rield, B. and Kamdem, P. O., 'Estimation of the Dispersive Component of Surface Energy of Polymer-Grafted Lignocellulosic Fibers with Inverse Gas Chromatography', Journal of Adhesion Science Technol. 6(9), 1992, 1053-1067.

[51] Harkins, W. D., 'Surface Energy and the Orientation of Molecules in Surfaces as Revealed by Surface Energy Relations', Z. Phys. Chem. 139, 1928, 647-691.

[52] Amateau, M.F. (1976). Progress in the development of graphite-Al composites using liquid infiltration technology. J. Composite Mater. 10, 289-296.

[53] Mäder, E., Grundke, K., Jacobash, H. J. and Wachinger, G., «Surface, Interphase and Composite Property Relations in Fibre-Reinforced Polymers», Composites 1994; 25(7): 739-744.

[54] Bismarck, A., Richter, D., Wuertz, C. and Springer, J., 'Basic and Acidic Surface Oxides on Carbon Fiber and Their Influence on the Expected Adhesion to Polyamide', Colloids Surfaces A $159,1999,341-350$.

[55] Plueddemann, E.P. (1974). In huetfaces in Polymer Matrix Composites, Composite Materials Vol. 6. (E.P. Plueddemann ed.), Academic Press. New York.

[56] Ishida, H., Koenig, J.L. (1978). Fourier transformed infrared spectroscopic study of the silane coupling agent/porous silica interface. J. Colloid. Interface Sci. 64, 555-564.

[57] Plueddemann, E.P., Stark, G.L. (1980). In Proc. 35th Annual Tech. Conf Reinf. Plast./Composite. SPI. Section 20-B.

[58] Cazeneuve, C., Castle, J.E. and Watts, J.F. (1990). The structure of the interface in carbon fiber composites by scanning Auger microscopy. J. Mater. Sci. 25, 1902-1908.

[59] Williams, J.G., Donnellan, M.E., James, M.R. and Morris, W.L. (1990). Properties of the interphase in organic matrix composites. Mater. Sci. Eng. A126, 305-312.

[60] Tsai, H.C., Arocho, A.M. and Gause, L.W. (1990). Prediction of fiber-matrix interphase properties and their influence on interface stress, displacement and fracture toughness of composite materials. Mater.Sci. Eng. A126, 295-304.

[61] Garton, A. and Daly, J.H. (1985). Characterization of the aramid-epoxy and carbon-epoxy interphases. Polym. Composites 6, 195-200.

[62] Thomason, J.L. (1990). Investigation of composite interphase using dynamic mechanical analysis: artifacts and reality. Polym. Composites 11, 105-113.

[63] Buxton, A and Baillie, C.A. (1995). Predicting the behavior of the carbon-fiber/epoxy interface under different service conditions. Composite InteJfaces 3, 411-423.

[64] Blackburn, L.D., Herzog, J.A., Meyerer, W.J., Snide, J.A., Stuhrke, W.F. and Brisbane, A.W. (1966). MAMS internal study on metal matrix composites, MAM-TM-66-3.

[65] Rudy, E. (1969). A compendium of phase diagram, AFML-TR-65-2, Part V.

[66] Becher, P.F. and Tiegs, T.N. (1987). Toughening behavior involving multiple mechanisms: whisker reinforcement and zirconia toughening. J. Am. Ceram. Soc. 70, 651-654.

[67] A. Reuss Berechnung der Fliessgrenze von mischkristallen auf Grund der plastizitätsbedingung für Einkristalle Z. Angew. Math. u. Mech., 1929; 9: pp. 49-58.

[68] W. Voigt Lehrbuch der Kristallphysik Teubner, Berlin (1910). 
[69] Adams D.F. «A micromechanical analysis of the influence of the interface on the performance of polymer-matrix composites » Procedings of the Americaion Society for Composites, Ist technical conference, 1986, pp.207-226.

[70] De Kok J.M.M., Venderbosch R.W., De Jong E.E., Meijer H.E.H. « Modelling of the interphase in transversely loaded carbon fibre reinforced composites ». Proceding of IPCM3, 13-15 september 1993, Cambridge (UK).

[71] Denison P., Jones F.R., Brown A., Humphrey P., Watts J .F « A micromechanical study of the interface bond in carbon fibre composites » Proceedings of ICCM-6, vol.5, pp5.423, 20- 24 july 1987, london (UK).

[72] Mai Y.W. "Controlled interfacial bonding on the strength and fracture toughness of Kevlar and carbon fibre composites » Journal of Materials Science Letters 1983; 2: 723-725.

[73] Barbier B., Vilatte M., Desarmot G. « Greffage électrochimique de fonction aminées en surface de fibres de carbone : effet sur la ténacité d'un composite carbone/époxy » ECCM3, Bordeau, 2023 mars 1989.

[74] Puzanszky B., "Influence of interface interaction on the ultimate tensile properties of polymer composite » Composites may 1990; volume 21 number 3: pp.225-262.

[75] Singh, J.P., Singh, D., and Sutaria, M., S.K., Ceramic composites: role of fiber and interface., Composites Part A., 1999; Vol. 30: p. 445-450.

[76] Hinoki, T., et al., Effect of fiber coating on interfacial shear strength of $\mathrm{SiC} / \mathrm{SiC}$ by nanoindentation technique. J. of Nuclear Mat., 1998; Vol. 258-263: p.1567-1571.

[77] Bertrand, S., Pailler, R., and Lamon, J., SiC/SiC minicomposites with nanoscale multilayered fibre coatings. Composites Science and Technology, 2001; Vol. 61: p. 363-367.

[78] Wu, Z.J., Ye, J.Q., Cabrera, J.G. 3D analysis of stress transfer in the micromechanics of fiber reinforced composites by using an eigen-function expansion method. J. Mech. Phys. Solids 2000; 48 (5): 1037-1063.

[79] Cech, V., Palesch, E., Lukes, J. The glass fiber-polymer matrix interface/interphase characterized by nanoscale imaging techniques. Compos. Sci. Technol. 2013; 83: 22-26.

[80] Ivens J., Wevers M., Verpoest I., " the effect of carbon/epoxy interface on damager accumulation during fatigue » ICCM 9, ed A.Miravete, Woodhead Pub. Lim., Vol.2, pp724-731, Madrid, 12-16 July 1993.

[81] Norita T., Matsui J., Matsuda H.S. « Effet of surface treatment of carbon fiber on mechanical propperties of CFRP » Composite interfaces, H. Ishida and J.L. Koenig, Editor, Elsevier Science Publishing Co., Inc., 1986, pp.123-132.

[82] Swain R .E., Reifsnider K.L., Jayaraman K., El-Zein .M. « Interface/interphase concepts in composite material system » Proceeding of the Américain Sociey for composite, 4 th technical conference, oct. 3-5, 1989, Blackbursg, Virginia, Technomic publishing co., Inc., pp.377-386.

[83] Theocaris P.S., " the concep ande properties of mesophase in composites» Composite interfaces, H. Ishida and J.L. Koenig, Editors, Elsevier Science Puplishing Co., 1986, pp. 329-349.

[84] Kelly. A, Tyson W.R « Fiber strengthened materials, in high strength material» V.F, Zackay Ed, J. Wiley \&Sons, London (1964).

[85] Lacroixa, C., Leguillona, D., and Martin, E. The influence of an interphase on the detection of a matrix crack in a ceramic-matrix composite, Composites Science and Technology, 2002; Vol. 62: p. 519-523.

[86] Jean-wei Hao, Yan Zhao, Yun-feng Luo, Yan Wang, Da Chen, « Experiments and finite element simulation of interfacail properties for monofilament composites » New Carbon Materials, June 2014; 29(3): 176-185. Pblished by Elsevier.

[87] Particle and Continuum Aspects of Mesomechanics Edited by G.C. Sih, M. Nait-Abdelaziz and T. Vu-Khanh, ISTE Ltd, 2007. 
[88] D. Hull , T. W. Clyne , An Introduction to Composite Materials (Cambridge Solid State Science Series) 2nd Edition, 1996.

[89] Blassiau S, Thionnet A, Bunsell AR. Micromechanisms of load transfer in a unidirectional carbon fibre-reinforced epoxy composite due to fibre failures. Part 2: influence of viscoelastic and plastic matrices on the mechanisms of load transfer. Compos Struct 2006; 74(3):319-31.

[90] Chou HY, Bunsell AR, Mair G, Thionnet A. Effect of the loading rate on ultimate strength of composites. Application: pressure vessel slow burst test. Compos. Struct. 2013; 104:144-53.

[91] Jean-Marie BERTHLOT « Matériaux composites, Comportement mécanique et analyse des structures » 4eme édition, Ed TEC\&DOC, Lavoisier, 2005.

[92] S. Keusch, H. Queck and K. Gliesche «Influence of glass fibre/epoxy resin interface on static mechanical properties of unidirectional composites and on fatigue performance of cross ply composites» Composites Part A 29A (1998) 701-705.

[93] S. S. Sonti and E. J. Barbero, «Determination of shear properties for RP pultruded composites » Journal of reinforced plastics and composites April 1995; vol. 14: 390-401.

[94] Iosipescu, N., «New Accurate Procedure for Single Shear Testing of Metals», Journal of Materials 1967; 2(3): 537-566.

[95] Roudet F., Desplanques Y., Degallaix S. / Fatigue of glass/epoxy composite in three-pointbending with predominant shearing/ International Journal of Fatigue 2002; 24: 327-337.

[96] Pierron, F. and Vautrin, A., «Measurement of the In-Plane Shear Strengths of Unidirectional Composites with the Iosipescu Test », Composites Science and Technology 1997; 57(12): 16531660.

[97] Béatrice LARGE -TOUMI Etude du comportement en fatigue de composite carbone époxyde : rôle de l'interface Thèse de doctorat école centrale de LYON (1994).

[98] AVESTON \& KELLY «Theory of multiple fracture of fibrous composites. » J. Mat. Sci., 1973; vol. 8: p. 352-62.

[99] THOULESS M.D. \& EVANS A.G. « Effet of pull-out on the mechanical properties of ceramic matrix composites. » Acta Metall., 1988; vol. 36, n 3: p. 517-22.

[100] MARSHALL D. B. \& EVANS A. G. «Failure mechanisms in ceramic-fiber/ceramic matrix composites. » J. Am. Ceram. Soc., 1985; vol. 68, n 5: p. 225-31.

[101] I. Verpoest, F. Jones/ Interfacial Phenomena in Composite Materials '91, ButterworthHeinemann Ltd, 1991, Linacre House, Jordan Hill, Oxford 0X2 8DP.

[102] Vancso, GJ; Hillborg, H; Schonherr, H. «Chemical composition of polymer surfaces imaged by atomic force microscopy and complementary approaches». Polymer analysis, polymer theory. 2005; 182: 55-129.

[103] J.L. THOMASON, D.W.DWIGHT. «XPS Analysis of the Coverage and Composition of the Coatings on Glass Fiber». Adhes. Sci. Thechnol. 2000; 14(5): 745-764.

[104] J.L. Thomson, D.W. Dwight. «The use of XPS for Characterization of the Glass Fiber Coatings». Composites: Part A. 1999; 30: 1401-1413.

[105] Y.Lu, J.F.Cai, G.Xue. «Molecular design of a soft interphase and its role in the reinforcing and toughening of aluminum powder-filled polyurethane». Journal of Adhesion Science and Technology 2001; 15(1):71-82.

[106] Jinmei He, Yudong Huang, Li Liu, et al. «Controlled interface between carbon fiber and epoxy by molecular self-assembly method». Materials chemistry and physics 2006; 99(2-3):

388-393.

[107] J.M.He, Y.D.Huang, L.H.Meng, H.L.Cao, H.B.Gu. «Effects of chain lengths, molecular orientation and functional groups of thiols adsorbed onto CF surface on interfacial properties of CF/epoxy composites». Journal of applied polymer science 2009; 112: 3380-3387. 
[108] S. Keusch, R. Haessler, "Influence of surface treatment of glass fibres on the dynamic mechanical properties of epoxy resin composites» Composites: Part A 1999; 30: 997-1002.

[109] Broutman, L.J.; Sahu, S. «The effect of interfacial bonding on the toughness of glass filled polymers». Material Science and Engineering 1971; 8(2): 98-107.

[110] Zhandarov S., Edith Mäder, "Characterization of fiber/matrix interface strength: applicability of different tests, approaches and parameters Serge» Composites Science and Technology 2005; 65: 149-160.

[111] Antoine Le Duigou, Peter Davies, Christophe Baley « Durability of interface of interface in flax fibre/epoxy micro-composites» Composites: Part A 2013; 48: 121-128.

[112] G.N. Frantziskonis, P.Theodore, E. M., Karpur, S. Krishnamurthy, P.D. Jero, fiber/matrix interface-information from experiments via simulation, Composite Structures 1994; 29: 231-247. [113] Y. Swolfs, I. Verpoest, L. Gorbatikh, A review of input data and modelling assumptions in longitudinal strength models for unidirectional fibre-reinforced composites, Composite Structures 2016; 150: 153-172.

[114] CURTIN W. A. (1991). Fiber fragmentation in a single-filament composite. Appl. Phys.Lett., 1991; vol. 58, n 11: p. 1155-57.

[115] HSUEH C.H. (1993). Analyses of slice compression tests for aligned ceramic matrix composites. Acta Metall. Mater., 1993; vol.41, n 12: p. 3585-93.

[116] Mei Zu and al, The effective interfacial shear strength of carbon nanotube fibers in an epoxy matrix characterized by a microdroplet test, Carbon 2012; 50: $1271-1279$.

[117] Hoecker, F., Friedrich, K., Blumberg, H. and Karger-Kocsis, J., « Effects of Fiber/Matrix Adhesion on Off-Axis Mechanical Reponse in Carbon-Fiber/Epoxy-Resin Composites», Composites Science and Technology 1995; 54: 317-327.

[118] Herrera-Franco, P., Wu, W. L., Madhukar, M. and Drazl, L. T., "Contemporary Methods for Measurement of Fiber-Matrix Interfacial Shear Strength», 46th Annual Conference, Composite Institute, The Society of the Plastics Industry, Inc., February 18-21, 1991, Session 14B/1-6.

[119] Christophe Baley, Peter Davies, Yves Grohens and Grégoire Dolto, "Application of Interlaminar Tests to Marine Composites. A Literature Review » Applied Composite Materials 2004; 11: 99-126.

[120] Favre J.-P., «Caractéristiques physiques et hygrométriques des composites, Etude de l'interface», 8ème Ecole d'hiver: Matériaux et structures composites - Méthodes de calcul et caractérisation (Tome 2), Université de Bordeaux 1- CODEMAC, Cauterets (27 jan- 2 fév 1990).

[121] Castle J.E., Watts J.F., «Surface analytical techniques for studying interfacial phenomena in composite materials», Proceedings of Interfacial Phenomena in Composite Materials (IPCM'89), Ed. F.R. Jones, Butterworth Publ., Sheffield UK (Sept. 1989) pp 3-6.

[122] Thomason J.L., "Characterisation of fibre surfaces and the interphase in ibrereinforced polymer composites», Proceegings of Interfacial Phenomena in Composite Materials (IPCM'89), Ed. F. R. Jones, Butterworth Publ., Sheffield UK (sept. 1989) pp 171-180.

[123] Li Liu a et al « Review Interfacial characterization, control and modification of carbon fiber reinforced polymer composites » Composites Science and Technology (5 September 2015); 121: 56-72.

[124] Lee, S.M. (1989). Surface analysis of polymer composites. In Reference Book for Composite Technology 2 (S.M. Lee ed.), Technomic, Lancaster, P.A. USA, pp. 81-103.

[125] Castle, J.E. and Watts, J.F. (1988). The study of interfaces in composite materials by surface analytical techniques. In Interfaces in Polymer, Ceramic and Metal Matrix Composites (Proc. ICCIII) (H. Ishida ed.), Elsevier Science, New York, pp. 57-71. 
[126] Ishida, H. (1994). Characterization of Composite Materials, Butterworth-Heinemann, Boston.

[127] Guigon M., «Phénomènes interfaciaux dans un composite carbone/époxy- Etude par microscopie électronique par transmission», Compte-rendus des Sixièmes Journées Nationales sur les Composites (JNCô), Paris, AMAC, Publ. J.-P. Favre \&0. Valentin (11- 13 oct. 1988) pp. 131145.

[128] Jeannetaud P., Krawczak P., Beouignat r., Pabiot J., Lemascon A., Bord C., Vancon M., Bard M., Atlas de fractographie de composites, Colloque "La Construction Navale en Composites", Actes de Colloque n¹5, IFREMER, Paris (7-9 déc. 1992) communication n³5, pp 365-374.

[129] Wang, Q., Chiang, F.P. Experimental characterization of interphase mechanical properties of composites. Compos. Part B Eng., 1996; 27 (2): 123-128.

[130] Mai, K., Mäder, E., and Mühle, M., „Interphase characterization in composites with new nondestructive methods“, Composites Part A 1998; Vol. 29A: pp. 1111- 1119.

[131] Joliff Y, Belec L, Chailan JF. Modified water diffusion kinetics in an unidirectional glass/fibre composite due to the interphase area: experimental, analytical and numerical approach. Composite Structures 2013; 97: 296-303.

[132] Joliff Y. , W. Rekik, L. Belec, J.F. Chailan, Study of the moisture/stress effects on glass fibre/epoxy composite and the impact of the interphase area. Composite Structures 2014; 108: 876-885.

[133] Caldwell D.L, Babbington D.A., Johnson C.F., «lnterfacial bond strength determination in manufactured composites, Proceedings of lnterfacial Phenomena in Composite Materials, edited by F.R. Jones, 44-52, 1989.

[134] Kerans r. J. , Hav R. S. , Pagano N. J. \& Parthasarathy T. A.(1989). The role of the fiber-matrix interface in ceramic composites. Am. Ceram. Soc. Bull.,1989; vol.68, n 2: p. 429-42.

[135] Detassis M, Frydman E, Vrieling D, Zhou XF, Wagner HD, Nairn JA. Interface toughness in fibre composites by the fragmentation test. Compos A: Appl Sci Manuf 1996; 27(9):769-73.

[136] Lacroix T, Tilmans B, Keunings R, Desaeger M, Verpoest I. Modeling of critical fiber length and interfacial debonding in the fragmentation testing of polymer composites. Compos Sci Technol 1992; 43(4):379-87.

[137] Zhao FM, Takeda N. Effect of interfacial adhesion and statistical fiber strength on tensile strength of unidirectional glass fiber/epoxy composites. Part I: experiment results. Composite Part A: Appl Sci Manuf 2000; 31(11):1203-14.

[138] Fraser W.A., Ancker F.H., Di Benedetto A.T., 30th Annual Technical Conference, Reinforced Plastics/Composites Instituts, The Society of the Plastics Industry (SPI) (1975) Session 22-A.

[139] Fraser W.A., Ancker F.H., Di Benedetto A.T., Elbirli b., Evaluation of surface treatment for fibers in composite materials, Polymer Composites (oct.1983); Vol.4, $\mathrm{N}^{\circ} 4:$ pp 238-248.

[140] Favre J.-P., «Review of test methods and testing for assessment of fibre/matrix adhesion», Proceedings of Interfacial Phenomena in Composite: Materials (IPCM'89), Ed. F.R. Jones, Butterworth Publ., Sheffield UK (sept. 1989) pp 7-12.

[141] Feillard P., Desarmot G., Dallies E., «Analyse critique du test de fragmentation appliqué •aux systèmes verre/époxy», Compte-Rendus des Sèmes Journées Nationales sur les Composites (JNC8), Palaiseau, 16-18 nov. 1992, AMAC, Paris (1992) pp 339-351.

[142] Piggott M.R., Chua P.S., Andison D., «The interface beween glass and carbon fibres thermosetting polymers», Polymer Composites, Vol.6, $\mathrm{N}^{\circ} 4$ (oct.1985) pp 242-248.

[143] Miller B., Muri P., Rebenfeld L., "A microbond method for determination of the shear strength of a fiber/resin interface», Composite Science and Technology 1987, 28: pp 17-32. 
[144] Mooney R.D., Mc GARRY F.J., 14th Annual Technical Conference Reinforced Plastics Div., The Society of the Plastics Industry (SPI) (1959) Session 12-E.

[145] Broutman L.J., « Measurement of the fiber-polymer matrix interfacial strength, in Interfaces in composites», ASTM STP 452, ASTM, American society for Testing and Materials, (USA). Philadelphia (1969) pp 27-41.

[146] S.J. Park, M.K. Seo, Modeling of Fiber-Matrix Interface in Composite Materials, Interfaces Science and Technology 2011; Vol. 18: p. 739-776.

[147] Brandon, D.G. \& Fuller, E.R.Jr., New Technique for Measuring Debond Strength and Interfacial Shear Resistance in Fiber-Reinforced Ceramic Matrix Composites (Abstract), Ceram. Eng. Sci. Proc., 1989; Vol. 10, N7-8: p. 871.

[148] S. Zhandarov, E. Mader, Composites Science and Technology 65 (2005) 149-160.

[149] C. DiFrancia, T.C. Ward, R.O. Claus, Composites Part A: Applied Science and Manufacturing 27 (1996) 597-612.

[150] V.M.C.F. Cunha, J.A.O. Barros, J.M. Sena-Cruz, Journal of Materials in Civil Engineering 22 (2010) 1-9.

[151] A.J.G. Jurewicz, R.J. Kerans, J. Wright, Ceramic Engineering and Science Proceedings 10 (1989) 925-937.

[152] E.P. Butler, E.R. Fuller, H.M. Chan, Materials Research Society Symposium Proceedings 170 (1990) 17-24.

[153] V. Bheemreddy and al, Modeling of fiber pull-out in continuous fiber reinforced ceramic composites using finite element method and artificial neural networks, Computational Materials Science 79 (2013) 663-673.

[154] C.-H. Hsueh, Materials Science and Engineering A123 (1990) 1-11.

[155] H. Stang, S.P. Shah, Journal of Material Science 21 (1986) 953-957.

[156] Y.C. Gao, Y.-W. Mai, B. Cotterell, Journal of Applied Mathematics and Physics 39 (1988) 550572.

[157] J.W. Hutchinson, H.M. Jensen, Mechanics of Materials 9 (1990) 139-163.

[158] R.J. Kerans, T.A. Parthasarathy, Journal of American Ceramic Society 74 (1991) 1585-1596.

[159] Hsueh, C.H., 1991. Interfacial debonding and fiber pull-out stresses of fiber-reinforced composites III: with residual radial and axial stresses. Mater. Sci. Eng. A 145 (2), 135-142.

[160] Hsueh, C.H., 1991. Interfacial debonding and fiber pull-out stresses of fiber-reinforced composites IV: sliding due to residual stresses. Mater. Sci. Eng. A 145 (2), 143-150.

[161] Hsueh, C.H., 1991. Interfacial debonding and fiber pull-out stresses of fiber-reinforced composites Part V. With a viscous interface. Mater. Sci. Eng. A 149 (1), 1-9.

[162] Hsueh, C.H., 1992. Interfacial debonding and fiber pull-out stresses of fiber-reinforced composites VII: improved analyses for bonded interfaces. Mater. Sci. Eng. A 154 (2), 125-132.

[163] Nairn, J.A., 1997. On the use of shear-lag methods for analysis of stress transfer in unidirectional composites. Mech. Mater. 26 (2), 63-80.

[164] Nairn, J.A., 1992. A variational mechanics analysis of the stresses around breaks in embedded fibers. Mech. Mater. 13 (2), 131-154.

[165] Christensen, R., Lo, K., 1979. Solutions for effective shear properties in three phase sphere and cylinder models. J. Mech. Phys. Solids 27 (4), 315-330.

[166] Hashin, Z., 1990. Thermoelastic properties of fiber composites with imperfect interface. Mech. Mater. 8 (4), 333-348.

[167] Hayes, S., Lane, R., Jones, F., 2001. Fibre/matrix stress transfer through a discrete interphase. Part 1: single-fibre model composites. Compos.Part A Appl. Sci. Manuf. 32 (3), 379389. 
[168] Qiu, Y., Weng, G., 1991. Elastic moduli of thickly coated particle and fiber reinforced composites. J. Appl. Mech. 58 (2), 388-398.

[169] Rjafiallah, S., Guessasma, S., Bizot, H., 2010. Effect of surface etching on interphase and elastic properties of a biocomposite reinforced using glass-silica particles. Compos. Sci. Technol. $70(8), 1272-1279$.

[170] Jiang, Y., Guo, W., Yang, H., 2008. Numerical studies on the effective shear modulus of particle reinforced composites with an inhomogeneous inter-phase. Comput. Mater. Sci. 43 (4), 724-731.

[171] Wang, J., Crouch, S.L., Mogilevskaya, S.G., 2006. Numerical modeling of the elastic behavior of fiber-reinforced composites with inhomogeneous interphases. Compos. Sci. Technol. 66 (1), 118.

[172] Shen, L., Li, J., 2005. Homogenization of a fibre/sphere with an inhomogeneous interphase for the effective elastic moduli of composites. Proc. R. Soc. A Math. Phys. Eng. Sci. 461 (2057), $1475-1504$.

[173] Jayaraman, K., Reifsnider, K.L., 1992. Residual stresses in a composite with continuously varying Young's modulus in the fiber/matrix interphase. J. Compos. Mater. 26 (6), 770-791.

[174] Jayaraman, K., Reifsnider, K.L., 1993. The interphase in unidirectional fiber-reinforced epoxies: effect on residual thermal stresses. Compos. Sci. Technol. 47 (2), 119-129.

[175]Huang, Y., Young, R.J., 1996. Interfacial micromechanics in thermoplastic and thermosetting matrix carbon fibre composites. Compos. Part A Appl. Sci. Manuf. 27 (10), 973-980.

[176] Kiritsi, C., Anifantis, N., 2001. Load carrying characteristics of short fiber composites containing a heterogeneous interphase region. Comput. Mater. Sci. 20 (1), 86-97.

[177] Shen, L., Li, J., 2003. Effective elastic moduli of composites reinforced by particle or fiber with an inhomogeneous interphase. Int. J. Solids Struct. 40 (6), 1393-1409.

[178] Romanowicz, M., 2010. Progressive failure analysis of unidirectional fiber-reinforced polymers with inhomogeneous interphase and randomly distributed fibers under transverse tensile loading. Compos. Part A Appl. Sci. Manuf. 41 (12), 1829-1838.

[179] Kovalev, S.P., Miranzo, P., Osendi, M.I., 1998. Finite element simulation of thermal residual stresses in joining ceramics with thin metal interlayers. J. Am. Ceram. Soc. 81 (9), 2342-2348.

[180] Qing, H., 2013. A new theoretical model of the quasistatic single-fiber pullout problem: analysis of stress field. Mech. Mater. 60 (0), 66-79.

[181] Dong S, Gauvin R. Application of dynamic mechanical analysis for the study of the interfacial region in carbon fiber/epoxy composite materials. Polym Compos 1993; 14(5): 414-420.

[182] L. Tong, A.P. Mouritz and M.K. Bannister, 3D Fibre Reinforced Polymer Composites1 ed. , Elsevier Science Ltd. 2002, Kidlington, Oxford OX5 IGB, UK.

[183] A. Mlyniec, J. Korta , R. Kudelski , T. Uhl, The influence of the laminate thickness, stacking sequence and thermal aging on the static and dynamic behavior of carbon/epoxy composites, Composite Structures 2014; 118: 208-216.

[184] Kessler, A. and Bledzki, A., «Correlation between Interphase-Relevant Tests and the ImpactDamage Resistance of Glass/Epoxy Laminates with Different Fibre Surface Treatments», Composites Science and Technology 2000; 60: 125-130.

[185] Christophe Baley, Yves Grohens, Frédéric Busnel and Peter Davies, «Application of Interlaminar Tests to Marine Composites. Relation between Glass Fibre/Polymer Interfaces and Interlaminar Properties of Marine Composites» Applied Composite Materials 2004; 11: 77-98.

[186] Kelly, A., Strong Soilids, 2nd Ed., Oxford University Press, 1973, Chap. 5.

[187] Shiriajeva G.V., Andreevskaya G.D. Sov. Plastics, (1962), 4:40. 
[188] Favre J.P., Perrin J., « Carbon fibre adhesion to organic matrices » J. of Mat. Science (1972); 7: 1113-1118.

[189] HAMPE A. Amts und Mitteilungsblatt der BAM, (1988); 18:3-3.

[190] HAMPE A., BORO I., SCHUMACHER K. Composites, France, (1989) ;29:3.

[191] X.B. Zhang, H. Aljewifi, J. Li « Failure mechanism investigation of continuous fibre reinforced cementitions composites by pull-out behavior analysis» Procedia Materials Science 2014; 3: 1377-1382.

[192] Piggott M.R. «Load bearing fibre composites» Pergamon Press 1980, pp. 83-87.

[193] Piggott M.R., Sanadi A., Chua P.S., Andison D. «Mechanical interactions in the interphasial region of fibre reinforced thermosets » Composite interfaces, H. Ishida and J. L. Koenig, Editors, Elsevier Science Publishing Co., Inc., 1986, pp. 109-121.

[194] Takaku A., Arridge R.G.C. «The effect of interfacial radial and shear stress on fibre pull-out in composites materials» J. Phys. D: Appl. Phys. 1973; vol. 6.

[195] Stang H., Shah S.P. «Characterization of Interfacial Bond in FRC Materials» Toughening Mechanisms in Quasi-Brittle Materials, 507-527. Kluwer Academic Publishers 1991.

[196] Piggott M.R. «Interphase failure and friction: measurement and implications» Proceeding of the American Society for Composites, $4^{\text {th }}$ technical conference, 3-5 October 1989, Blackbursg, Virginia, thechnomic publishing co., Inc., pp. 505-512.

[197] Penn L.S., Chou C.T. «Identification of factors affecting single filament pull-out test resultats», Journal of composites Technology and Research, JCTRER, vol.12, No.3, Fall 1990, pp. 49-59.

[198] Palley I., Stevans D. «A fracture mechanics approach to the single fibre pull-out problem as applied to the evaluation of the adhesion strength between the fibre and the matrix», J. Adh. Sci. techn, (1989); Vol.3 (2): pp. 141-153.

[199] Pikethly M.J., Doble J.B. «characterizing the fibre/matrix interface of carbon reinforced composites using a single fibre pull-out test » composites volume 21 number 5 September 1990 pp. 389-395.

[200] Desarmot G., Sanchez M. «Mesure de fortes contraintes de décohésion à l'interface fibre de carbon-résine : évaluation de l'efficacité d'un traitement de surface », Comptes rendus des JNC'4, Paris,11-13 Septembre 1984, pp. 449-460.

[201] Gaur U., Miller B. «Effects of environmental exposure on fibre/epoxy interfacail shear strength», Polymer Composites, August 1990, Vol. 11(4).

[202] Scheer J., Nairn J.A., «Varaitional mechanics analysis of the stresses in microdrop debond specimens», Proceeding of ICCM8, S. W. Tsai and G. S. Springer, Stanford University, 1991.

[203] Marotzke C. «The elastic stress field arising in the single fiber pull-out test » Composites Science and Technology 1994; 50: 393-405.

[204] Galiotis C. "Interfacail studies on model composites by laser Raman spectroscopy» Composites Science and Technology 1991; 42: pp. 125-150.

[205] M. S. Amer, M. J. Koczak, C. Galiotis, L. S. Schadler, «Environmental Degradation Studies of the Interface in Single-Filament Graphite/ Epoxy Composites Using Laser Raman Spectroscopy», Advanced Composites Letters, (1994), 3/1 17-20.

[206] M.C. Andrews, R.J. Day, A.K. Patrikis and R.J. Young, «Deformation micromechanics in aramid/epoxy composites» Composites (1994); vol. 25 (7): 745-751.

[207] I. YE, A.K. Kaw, «Determination of mechanical properties of fiber-matrix interface from pushout test » Mechanical Engineering, University of south Florida (1999).

[208] Rouby, D. \& Reynaud, P., Fatigue Behaviour Related to Interface Modification During Load Cycling in Ceramic-Matrix Fibre Composites, Comp. Sci. Tech., 1993, Vol. 48, p. 109-118. 
[209] Caldwell D.L., Jarvie D.A. " Determination of the interfacial strength of advanced composites» 33 ${ }^{\text {rd }}$ International SAMPE Symposium, Anaheim CA, March 7-10 1988.

[210] Mandell, Grande D.H., Tsiang T.H. and McGarry F. J. « Modified microdebonding test for direct in situ Fibre/Matrix Bond Strength determination in fiber Composite» composite materials: Testing and Design (7th conference) ASTM STP 893, 1986, pp. 87-108.

[211] Netravali A.N., Stone D., Ruoff S., Topoleski L.T.T. «Continuous microindenter pushthrougth technique for measuring shear strength of fibre composites» Composites Science and Technology 1989; 34: 289-303.

[212] Chen E.J.H, Young J.C. «The microdebonding testing system: a method of quantifying adhesion in real composites » Composites Science and Technology 1991; 42: 189-206.

[213] B. Large-Toumi, M. Salvia, L. Carpentier, O. Veauville, P. Kapsa, L. Vincent «Microindentation technique for characterizing fibre/matrix interface of fiber reinforced polymers» EACM $6^{\text {th }}$ European conference on composite materials, September 20-24, 1993, pp. 145-148, BordeauxFrance . Editors: A.R. Bunsell, A. Kelly, A. Massiah.

[214] L. Riaño, L. Belec, Y. Joliff. «Validation of a Representative Volume Element for unidirectional fiber-reinforced composites: Case of a monotonic traction in its cross section» Composite Structures 2016; 154: 11-16.

[215] Y. Joliff, L. Belec, M.B. Heman, J.F. Chailan. «Experimental, analytical and numerical study of water diffusion in unidirectional composite materials - Interphase impact» Computational Materials Science 2012; 64: 141-145.

[216] Y. Joliff, L. Belec, J.F. Chailan. «Impact of the interphases on the durability of a composite in humid environment - a short review», 20th International Conference on Composite Structures, 47 September 2017, CNAM, Paris, Structural and Computational Mechanics Book Series., p. 149.

[217] Y. Joliff, L. Belec, J.F. Chailan. « Influence of the interphases on the mechanical properties of the composite», 20th International Conference on Composite Structures, 4-7 September 2017, CNAM, Paris, Structural and Comput 